Universidad de Lima

Facultad de Administración

Carrera de Negocios Internacionales

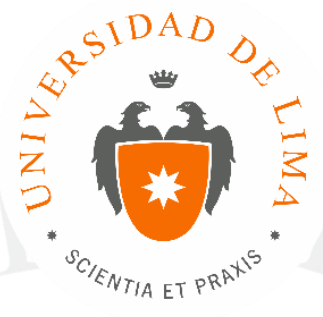

\title{
EXPORTACIÓN DE BARRAS ENERGÉTICAS A BASE DE QUINUA A CANADÁ
}

Trabajo de Investigación para optar el título profesional de Licenciado en Negocios Internacionales

Natalia Arcaya del Águila

Código 20082056

Asesor

Norma Maribel Espinoza Muñante

$$
\text { Lima - Perú }
$$

Diciembre de 2015 


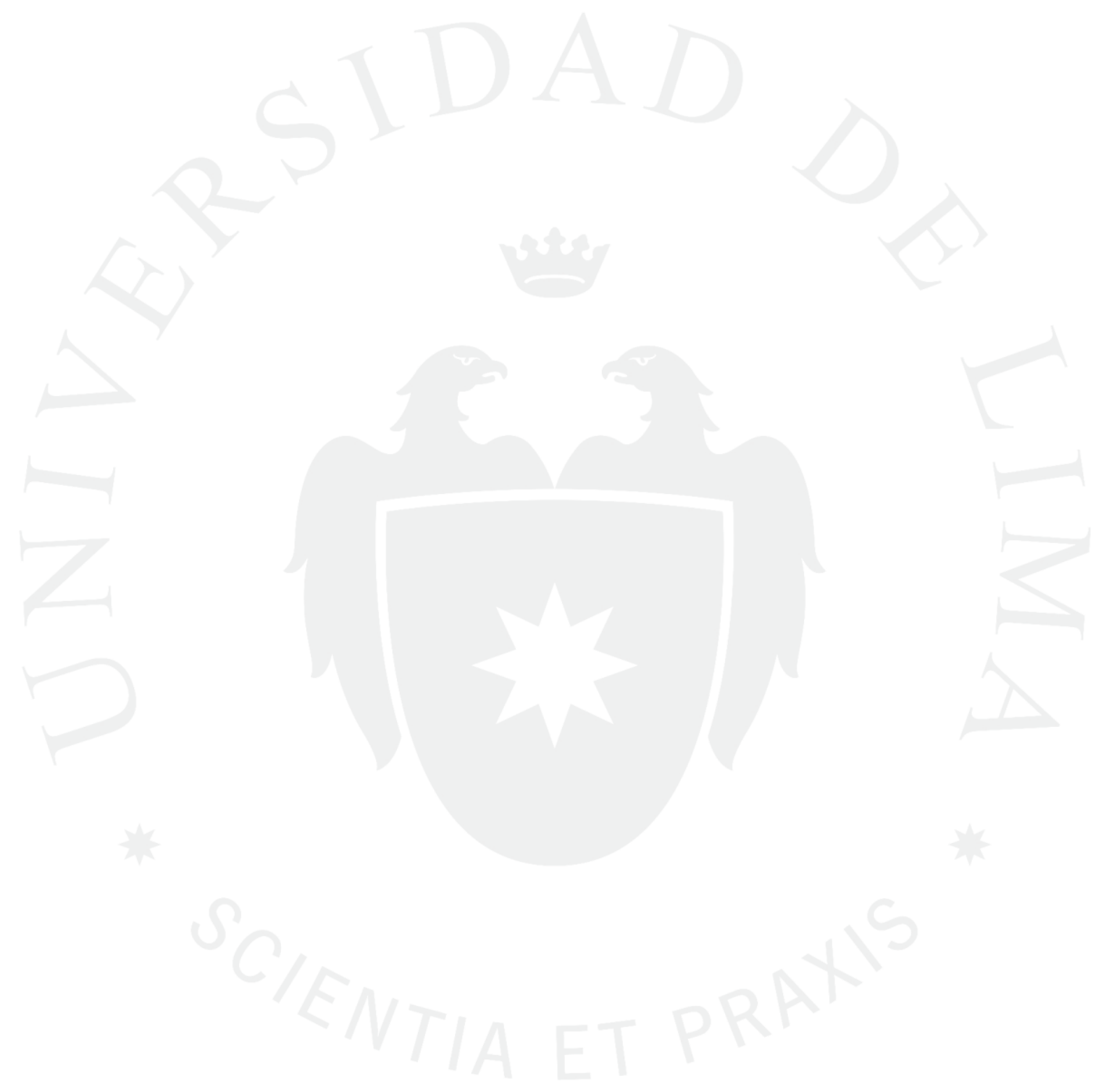




\section{EXPORTACIÓN DE BARRAS ENERGÉTICAS A BASE DE QUINUA A CANADÁ}


ÍNDICE

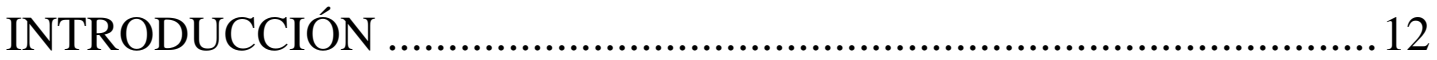

CAPÍTULO I: PLANTEAMIENTO DEL PROBLEMA …...................... 14

1.1. Planteamiento del problema..............................14

1.2. Justificación..................................................16

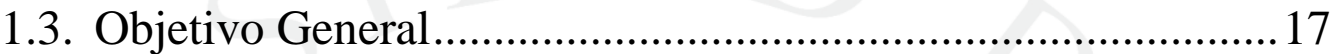

1.3.1. Objetivos Específicos ..................................................... 18

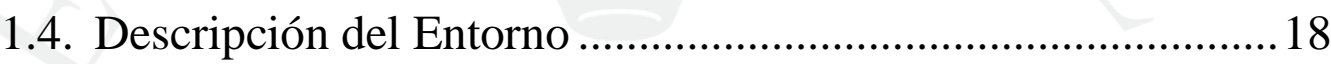

1.4.1. Análisis PESTEC del Perú y Sector ................................. 18

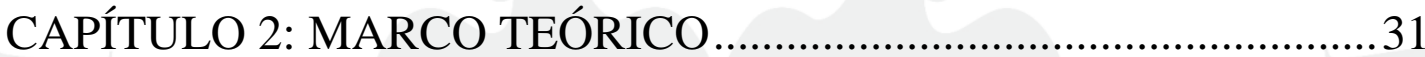

2.1. Análisis PESTEC del País de destino y sector .........................31

2.1.1. Político (The World Factbook, 2015) ................................31

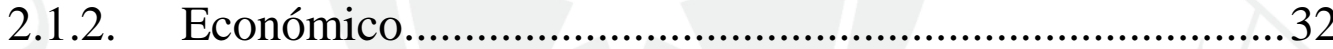

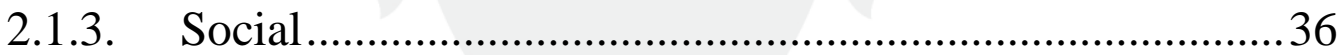

2.1.4. Tecnológico (Industry Canada y The Canadian Internet) 42

2.2. Diamante Competitivo de Porter..........................47

2.2.1. Amenaza de entrada de nuevos competidores ...............48

2.2.2. La rivalidad entre los competidores...................49

2.2.3. Poder de negociación de los proveedores ......................49

2.2.4. Poder de negociación de los compradores..............50

2.2.5. Amenaza de ingreso de productos sustitutos.............50 
2.3. Hipótesis General........................................51

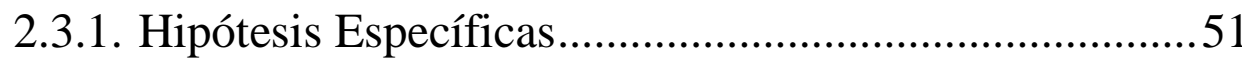

CAPÍTULO 3: PLAN DE NEGOCIO ...................................................52

3.1. Información General del Proyecto.............................................52

3.1.1. Datos generales de la empresa .......................................52

3.1.2. Identificación de la oportunidad de negocio .......................53

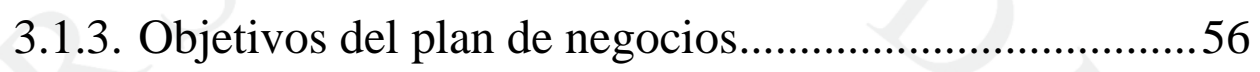

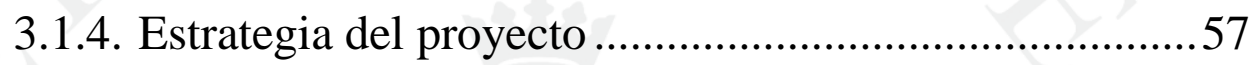

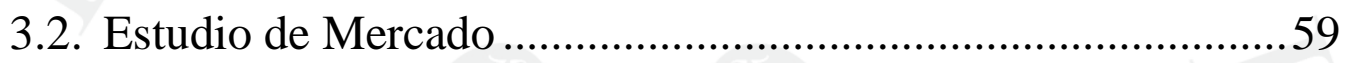

3.2.1. Análisis de la demanda ..................................................59

3.2.2. Demanda histórica y presente ……………….................66

3.2.3. Variables que afectan la demanda .................................69

3.2.4. Demanda futura ………………………......................... 71

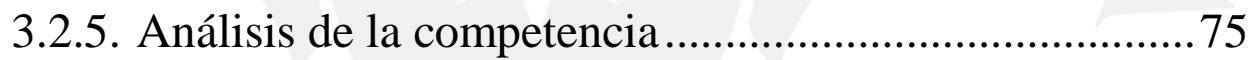

3.2.6. Análisis FODA de la competencia .................................. 79

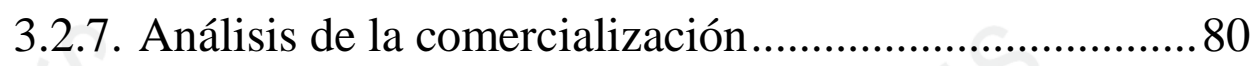

3.2.7.1. Decisiones sobre el producto...................................... 80

3.2.8. Decisiones sobre el precio .............................................. 84

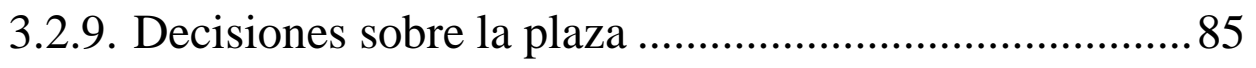

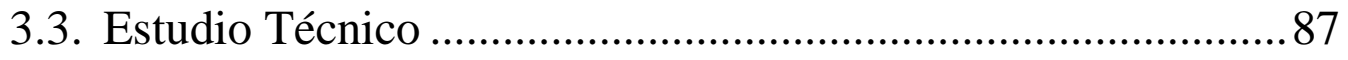

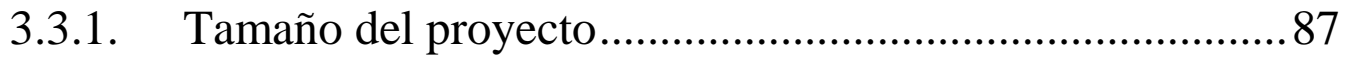

3.3.2. Factores determinantes del tamaño ................................. 87 
3.3.3. Proceso y tecnología.......................................................... 89

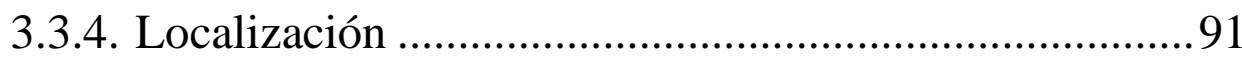

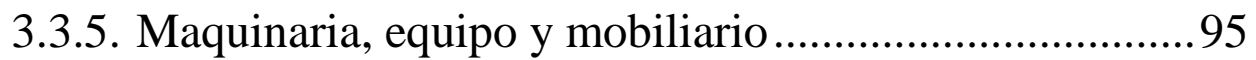

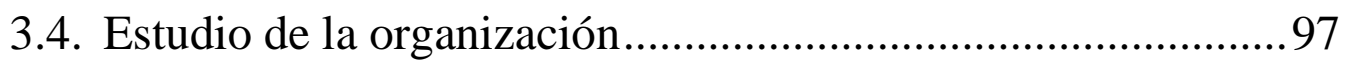

3.4.1. Estructura organizativa....................................................

3.4.2. Visión, misión y valores ..................................................98

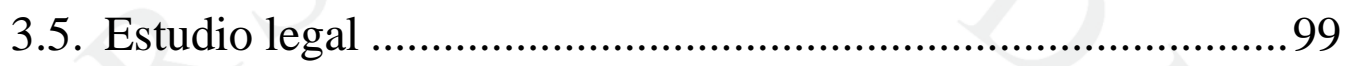

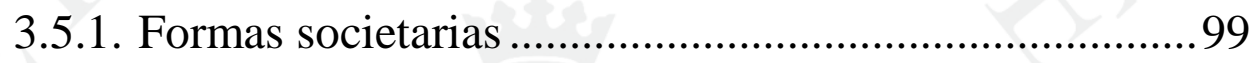

3.5.2. Flujograma de creación de la empresa ..........................100

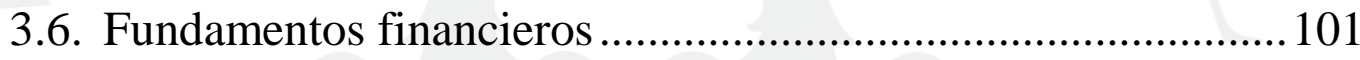

3.6.1. Estructura de costos fijos y variables .............................101

3.6.2. Margen y determinación del precio de venta .................. 103

3.6.3. Proyección de ventas ....................................................... 104

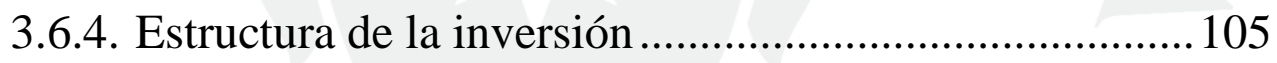

3.6.5. Financiamiento de la inversión .....................................107

3.6.6. Flujo de caja económico (COK, TIR y VAN) ...............107

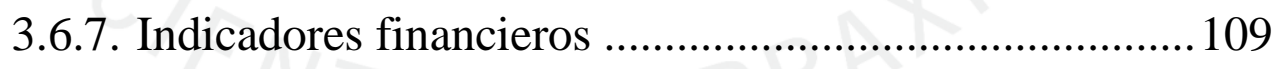

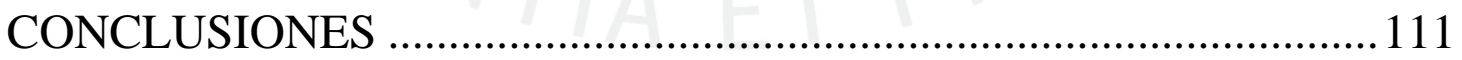

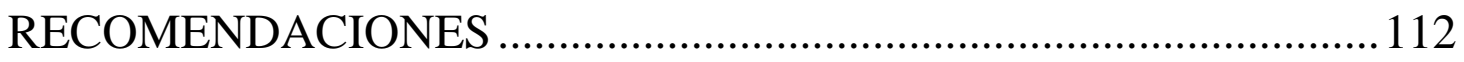

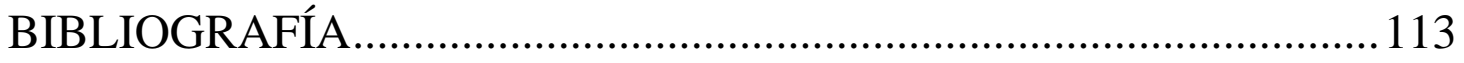

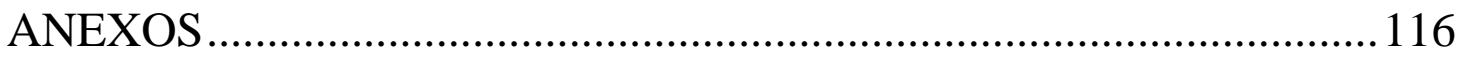




\section{ÍNDICE DE IMAGENES}

Imagen $\mathrm{N}^{\mathrm{o}}$ 1.1: Evolución del sobre peso en países de la OCDE ......................................... 14 Imagen $\mathrm{N}^{\mathrm{o}}$ 1.2: Etapas de desarrollo de Perú en comparación a América Latina y el Caribe 29

Imagen $\mathrm{N}^{\mathrm{o}}$ 2.1: Población según sexo y edad ........................................................................... 41

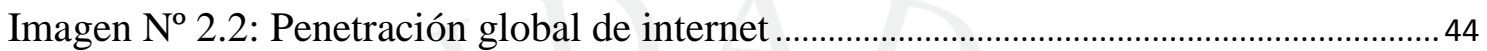

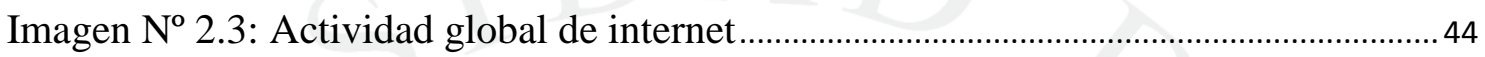

Imagen $\mathrm{N}^{\mathrm{o}}$ 3.1: Canales de distribución y comercialización para la quinua .........................53

Imagen $N^{o}$ 3.2: Producción de quinua en el Perú ................................................................... 65

Imagen $\mathrm{N}^{\mathrm{o}}$ 3.3: Caja de 6 unidades de barras energéticas...................................................... 81

Imagen $\mathrm{N}^{\mathrm{o}}$ 3.4: Ejemplo de etiquetado nutricional del producto de la empresa Eco

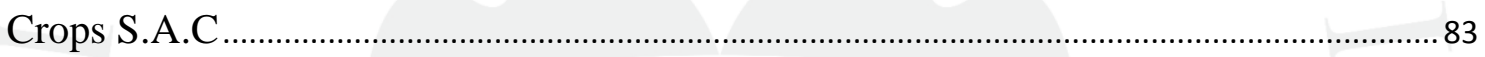

Imagen $N^{\circ}$ 3.5: Canales de Distribución y Comercialización para Quinua ..........................85

Imagen $\mathrm{N}^{\mathrm{o}}$ 3.6: Plano del local en la situación del proyecto ..................................................95 


\section{ÍNDICE DE TABLAS}

Tabla $N^{\circ} 1.1$ Volumen de ventas entre 2009 - 2014 ('000 toneladas) ......................... 17

Tabla $N^{\circ} 1.2$ : Uso de internet Perú (casa 100 habitantes), en porcentaje .....................25

Tabla No 2.1: Comercio Canadá con el mundo 2014.................................................... 34

Tabla $N^{o}$ 3.1: Principales destino de exportación (millones de dólares). .......................55

Tabla N 3.2: Composición de una barra energética Eco Crops S.A.C ...........................60

Tabla No 3.3: Composición química y valor nutricional (contenido en 100gr.).............6 61

Tabla 3.4: Contenido de aminoácidos en la quinua y otros granos (mg/100gr de

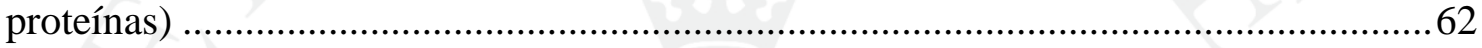

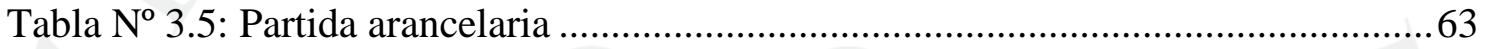

Tabla N 3.6: Demanda histórica y presente de Canadá en Peso Neto (Kg) y Valor FOB de la Partida Arancelaria 1904100000: Productos a base de Cereales, obtenido por inflado o tostado .66

Tabla No 3.7: Valor FOB unitario de la Partida Arancelaria1904100000 Productos a base de Cereales, obtenido por inflado o tostado (USD/kg). .69

Tabla N $N^{\text {3.8: }}$ Demanda anual proyectada de Canadá de barras snack por categoría. ('000 toneladas) .71

Tabla No 3.9: Demanda proyectada de barras nutritivas y energéticas .72

Tabla N $\mathrm{N}^{\mathrm{O}}$ 3.10: Proyección de la participación de mercado en Canadá con barras nutritivas y energéticas.

Tabla No 3.11: Demanda anual objetivo (toneladas). .74

Tabla No 3.12: Arancel aplicado por Canadá a la Partida Arancelaria 1904100000:

Productos a base de Cereales, obtenido por inflado o tostado .79

Tabla $N^{\circ}$ 3.13: Ficha técnica del producto barras energéticas a base de quinua. .80

Tabla No 3.14: Costo de Fletes Promedio hacia Canadá .86 
Tabla No 3.15: Estacionalidad de Quinua en el Perú .88

Tabla $\mathrm{N}^{\circ}$ 3. 16: Escala de valores 91

Tabla $\mathrm{N}^{\mathrm{o}}$ 3.17: Evaluación de los distritos según el método “cualitativo por puntos”...91

Tabla N ${ }^{\mathrm{o}}$ 3.18: Características del local en la situación actual ......................................92

Tabla 3.19: Distribución del local en la situación del proyecto.....................................94

Tabla No 3.20: Requerimiento de maquinaria y equipo............................................. 95

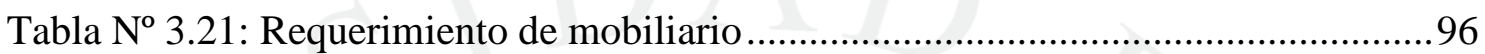

Tabla $\mathrm{N}^{\circ}$ 3.22: Tabla $\mathrm{N}^{\circ} 3.23$ : Estructura de costos fijos mensuales ............................ 101

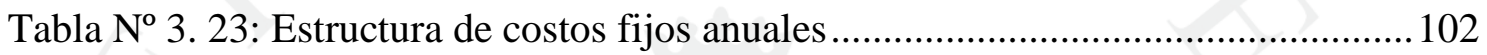

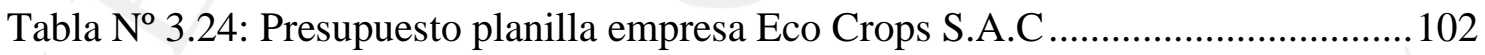

Tabla N ${ }^{\circ}$ 3.25: Estructura de costos variables mensuales.......................................... 103

Tabla $\mathrm{N}^{\mathrm{o}}$ 3. 26: Determinación del margen de ganancia y precio para el primer y

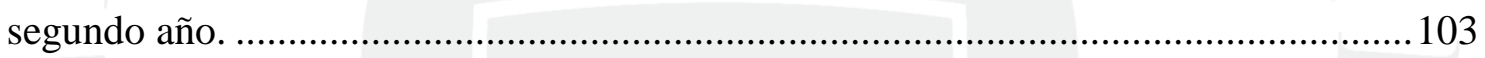

Tabla No 3.27: Determinación del punto de equilibrio............................................. 104

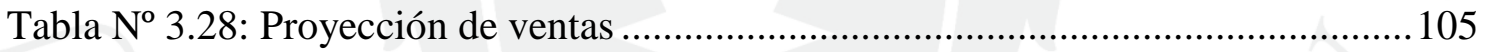

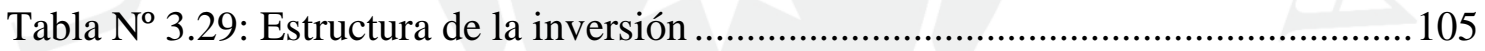

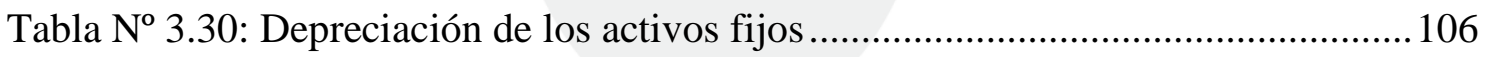

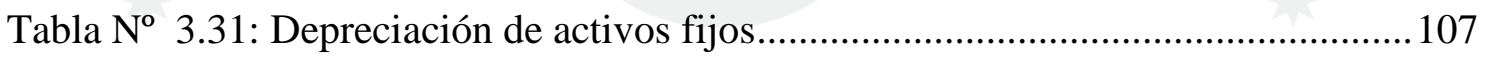

Tabla No 3.32: Flujo de caja económico de la empresa Eco Crops S.A.C .................... 107

Tabla No 3.33: COK, VAN, TIR de la empresa Eco Crops S.A.C ............................... 108

Tabla N ${ }^{\circ}$ 3. 34: Estado de Ganancias y Pérdidas de la empresa Eco Crops S.A.C ...... 109

Tabla No 3.35: Balance General de la empresa Eco Crops S.A.C ....................110 


\section{ÍNDICE DE GRAFICOS}

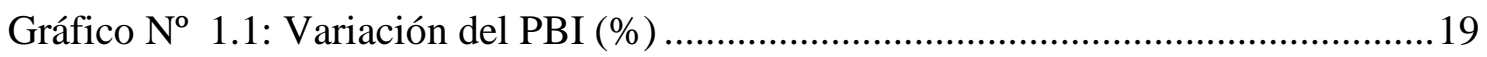

Gráfico No 1.2: Acuerdos Comerciales Vigentes de Perú ...........................................2 21

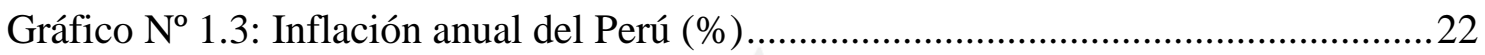

Gráfico $\mathrm{N}^{\mathrm{0}}$ 1.4: Tipo de cambio del Perú (PEN por USD) ..........................................23

Gráfico No 1.5: Población peruana proyectada (2008-2017);Error! Marcador no definido.

Gráfico No 1.6: Evolución de la pobreza en el Perú .....................................................24

Gráfico $\mathrm{N}^{\circ}$ 1.7: Población de 6 y más años que hace uso de internet en Perú, según

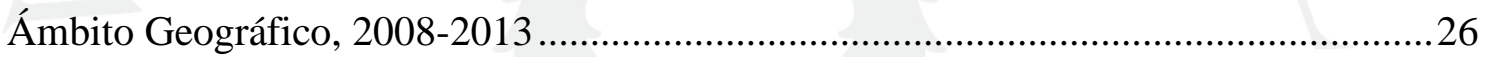

Gráfico $N^{\circ}$ 1.8: Posición en el índice de Competitividad Global 2014-2015 a nivel

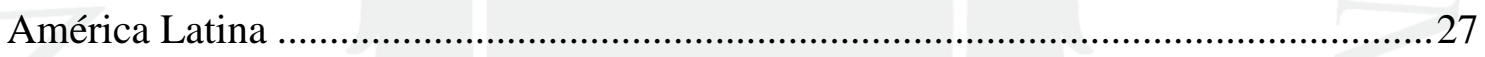

Gráfico No 2.1: Evolución Tasa de crecimiento PBI ...................................................... 32

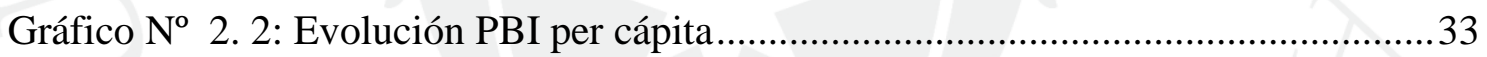

Gráfico No 2.3: Mercaderías exportadas de Canadá hacia el mundo por regiones (2014)

Gráfico No 2. 4: Mercaderías importadas por Canadá del mundo por regiones (2014).. 36

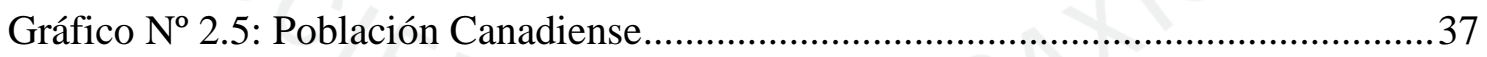

Gráfico 2.6: Grafico N².8: Evolución de la natalidad en Canadá..................................38

Gráfico No 2.7: Esperanza de vida de la población Canadiense. ....................................39

Gráfico $\mathrm{N}^{\mathrm{o}}$ 2.8: Estructura de edades de la población de Canadá .................................. 40

Gráfico $\mathrm{N}^{\mathrm{0}} 2.9$ : Factores más problemáticos para “doing business" ......................... 47

Gráfico No 2.10: Diamante Competitivo de Porter...............................48

Gráfico № 3.1: Producción nacional de quinua (miles de toneladas) .............................54 
Gráfico $\mathrm{N}^{\mathrm{o}} 3.2$ : Exportaciones de Quinua (miles de toneladas) .55

Gráfico $\mathrm{N}^{\mathrm{0}}$ 3.3: Producción nacional y exportación (miles de toneladas) .64

Gráfico No 3.4: Producción de quinua en el Perú

Gráfico No 3.5: Demanda Histórica Anual de la Partida Arancelaria 1904100000:

Productos a base de Cereales, obtenido por inflado o tostado 67

Gráfico 3.6: Exportaciones de Quinua Peruana a Canadá..... .68

Gráfico No 3. 7: Valor FOB unitario de la Partida Arancelaria1904100000 Productos a base de Cereales, obtenido por inflado o tostado (USD/kg)

Gráfico $\mathrm{N}^{\circ}$ 3.8: Proyección de la demanda de Canadá de barras nutritivas y energéticas (toneladas) 72

Gráfico 3.9: Demanda anual objetivo (toneladas) .74

Gráfico $\mathrm{N}^{\mathrm{o}}$ 3.10: Distribución de los principales mercados de exportación de la partida arancelaria 1904100000: Productos a base de Cereales, obtenido por inflado o tostado, en el año 2014. .75

Gráfico $\mathrm{N}^{\mathrm{o}}$ 3.11: Principales empresas exportadoras de la sub-partida sistema armonizado 140910: Productos a base de Cereales, obtenido por inflado o tostado......77

Gráfico $\mathrm{N}^{\mathrm{o}}$ 3.12: Proceso productivo de barras energéticas a base de quinua .90

Gráfico No 3.13: Organigrama de la empresa Eco Crops S.A.C .97

Gráfico No 3.14: Flujograma de creación de la empresa Eco Crops S.A.C. 100 


\section{INTRODUCCIÓN}

En la últimas dos décadas ha incrementado una concientización por el medio ambiente. "Dicha conciencia ha tenido un profundo efecto en el comportamiento del consumidor y su consecuencia es que el producto orgánico está expandiéndose en los mercados a un ritmo notable. Además, es interesante saber que la mayoría de los consumidores en los países desarrollados está pagando un precio premium por este tipo de producto diferenciado" (Beltrán Morales, Salgado Beltrán, \& Subiran Lobera, 2009). El consumidor percibe estos productos como más sanos, de mayor calidad y amigables con el medio ambiente. Siendo lo expuesto una de las principales razones por la que la empresa Eco Crops S.A.C. opta desarrollar en este proyecto la producción de una barra energética a base de quinua para ser exportado a Toronto, Canadá pues es un mercado con una mayor consciencia sobre el cuidado personal de la salud y la importancia de mejorar los hábitos alimenticios a través de alimentos más sanos y nutritivos.

El presente documento tiene por objetivo desarrollar un plan de negocios para implementar una empresa productora y comercializadora de Barras Energéticas a base de quinua al mercado Canadiense La partida arancelaria 1904100000, cuya descripción es Productos a base de Cereales, obtenidos por inflado o tostado". Es importante mencionar que la partida arancelaria a la que pertenece nuestro producto es muy general, es decir, existe una gran cantidad de productos que pertenecen a la misma partida.

A través de este plan de negocios se busca ofrecerle al mercado canadiense un producto con valor agregado teniendo como base un insumo $100 \%$ peruano y amigable con el medio ambiente.

Tras los estudios financieros realizados, el proyecto requerirá de una inversión total de USD 21,586.80, teniendo una proyección de ventas para el primer y segundo año de 480 y 576 cajas de producto respectivamente, aumentando en el tercer año a 672 y en el cuarto a 768 cajas, finalmente en el quinto año se estiman unas ventas de 864 cajas en el quinto año; considerándose como unidad exportadora 1 caja. Así mismo, la cantidad a exportar por caja es $12.24 \mathrm{~kg}$, lo cual hace referencia a 82 caja inner de producto por caja máster. Cabe mencionar que cada caja inner del producto tiene un peso de 150 gramos. 
Por otro lado, obtendrá ganancias desde el segundo año, obteniendo en los cinco primeros años un resultado acumulado de USD 20,367.14, obtendrá ganancias desde el primer año, recuperando en este año el capital de trabajo invertido (USD 12,195.77). Además, se demostrará que el proyecto es viable al contar con un Valor Actual Neto mayor a cero y una Tasa Interna de Retorno mayor al Costo de Oportunidad de Capital. 


\section{CAPÍTULO I: PLANTEAMIENTO DEL PROBLEMA}

\subsection{Planteamiento del problema}

Las barras energéticas son consideradas un suplemento alimenticio pues incrementan la energía, asimismo aporta nutrientes a nuestra dieta y cubren necesidades puntuales como por ejemplo aumentar la densidad calórica en momentos de mayor desgasto de energía y la dieta regular no es capaz de aportarla.

Adicionalmente cabe mencionar que en la actualidad existe un mayor número de personas con exceso de peso que desnutridas. "El 30\% de la población mundial (2.100 millones de personas) sufren de sobrepeso, de los cuales 670 millones padecen de obesidad", según un informe de la consultora McKinsey augura que el número se elevará a la mitad de los habitantes del planeta en 2030. "La obesidad está en ascenso en los países desarrollados y, ahora, está también presente en las economías emergentes" (McKinsey Global Institute).

A continuación se muestra una imagen donde se puede observar a evolución del sobrepeso en principales economías del mundo.

\section{Imagen $N^{o}$ 1.1: Evolución del sobre peso en países de la OCDE}

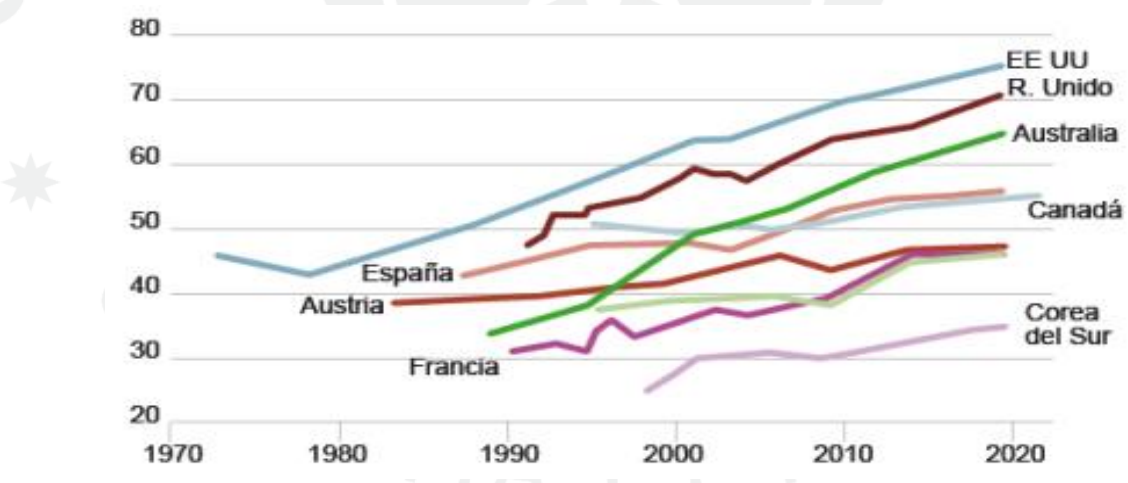

Fuente: McKinsey Global Institute

Actualmente como consecuencia de la creciente tasa de obesidad en el mundo, existe una tendencia a nivel mundial con respecto al cuidado del consumo de productos naturales y orgánicos, que tengan un gran aporte nutricional y no generen perjuicios a la salud. Esto ha contribuido a un incremento considerable en la demanda de productos saludables, sobre todo en 
países desarrollados donde los estándares de vida son elevados y las personas cuentan con un mayor poder de adquisición.

En muchos casos la obesidad es una consecuencia de los malos hábitos alimenticios; sin embargo también tiene una gran responsabilidad el sedentarismo. La mayoría de personas obesas son adultos y niños, por lo que la edad es un indicador que se debe considerar en la determinación del nicho de mercado. Otro factor importante que se debe de considerar sobre nuestro mercado de destino es que en Canadá, la población continuará envejeciendo en las próximas dos décadas lo cual tendrá como consecuencia que haya una mayor proporción de personas mayores a los 65 años debido al envejecimiento de los baby boomers (personas nacidas entre los años 1946-1965). Es así como en el año 2030 los baby boomers más jóvenes alcanzará los 65 años, y “cerca de una de cada cuatro personas en Canadá serían de 65 años o más representando un $22.2 \%$ de la población en comparación con el $15.7 \%$ en el año 2014". (Statistics Canada, Population projections: Canada, the provinces and territories, 2013 to 2063). Siendo nuestro nicho mercado personas de 45 años en adelante.

El enfoque de este proyecto está basado en barras energizantes de quinua a Canadá; por tradición la quinua; que es el insumo de este producto; desde la época de los Incas, es considerada un grano con una gran concentración de cantidad de nutrientes lo cual la convierten en el uno de los alimentos de procedencia vegetal con un gran nivel más proteico. Asimismo la quinua se destaca por poseer una mayor cantidad de hierro, calcio y fósforo en comparación con el huevo y la carne de res sólo que con la excepción que no contiene grasa, colesterol y gluten además de tener elevados contenidos de omega (omega 3, omega 6 y omega 9). Este grano ancestral en la actualidad ha experimentado una creciente demanda en el mercado canadiense debido a sus valores nutritivos asociados a los mercados de comida saludable, donde sin duda se encuentra su mercado principal de desarrollo. Adicionalmente este grano andino, resulta un alimento muy importante a incluir en las dietas pues ayuda a prevenir la aparición de osteoporosis, disminuye los efectos de la menopausia, ayuda a cicatrizar heridas, es regeneradora de la flora intestinal, desinfecta las 
vías urinarias, refuerza el sistema inmunológico, etc. Es por eso que la quinua es el ingrediente base ideal para nuestra barras energéticas pues proporciona altos beneficios para la salud del consumidor.

En la actualidad, Canadá el segundo país importador de quinua blanca oriunda del Perú significando un $8 \%$ de participación de la misma. En el mercado canadiense, el nivel de cultura saludable es cada vez mayor, razón por la cual es importante ofrecerle al cliente productos naturales que no hayan sido expuestos a alteraciones como lo son los agroquímicos; siendo pieza clave para el ingreso al mercado. También se debe considerar el interés por productos de consumo rápido que no cuenten con elevadas calorías, con el fin de mantener niveles adecuados de salud pues el consumidor canadiense usualmente está interesado en este tipo de productos.

Por lo tanto existe una necesidad de buscar alternativas saludables para los "snack" pues deben de tener un efecto positivo en nuestro organismo, brindando los nutrientes y calorías necesarias para continuar con nuestras actividades sin perjudicar la salud. En este contexto, aparece la pregunta ¿si existe la viabilidad de exportar barras energéticas a base de quinua al mercado Canadiense con énfasis en Toronto? Otro aspecto a considerar es la tendencia de la demanda sobre el producto del proyecto, también se desea saber cuáles son los requisitos de ingreso al mercado canadienses, cuáles son las características del consumidor del producto en Canadá y por último, cuál es la estrategia de distribución que el proyecto debe usar.

1.2. Justificación (EUROMONITOR INTERNATIONAL, Snack Bars in Canadá, 2014)

Existe en Canadá una creciente tendencia en el consumo de productos saludables que tengan un gran porcentaje de fibra y proteína como ingredientes principales. En el año 2014 las diferentes presentaciones de barras energéticas tuvieron un crecimiento de $3 \%$ en su valor y un $1 \%$ en el volumen. 
Las barras son uno de los "snacks" favoritos para el consumidor canadiense ya que consideran que tiene un producto para llevar que es saludable y aporta la energía, fibra y proteína que necesitan para continuar realizando diferentes actividades.

El pronóstico que se tiene para este tipo de productos es muy positivo ya que se espera que tanto el valor de venta como el volumen sigan creciendo de manera conjunta. El principal motor de crecimiento en esta categoría es la demanda de "snacks" saludables; sin embargo la ventaja de los mismo estará liderada por aquellos posicionados a base de insumos naturales u orgánicos ya que el consumidor espera le proporcione un mejor desempeño a la vez que le da un valor extra al producto.

Existe una gran oportunidad para las empresas que se dediquen a mejor el perfil del producto y este aporte ingredientes que sean buenos para la salud. Dada la tendencia clave de consumo de "snack bars" se recomienda agregar ingredientes funcionales para diferenciar el producto y tener una mejor demanda.

A continuación se muestra el volumen de ventas expresado en toneladas en el periodo entre 2009 y 2014 que han obtenido las categorías de barras en el mercado canadiense.

Tabla $N^{o} 1.1$ Volumen de ventas entre 2009 - 2014 ('000 toneladas)

\begin{tabular}{|l|r|r|r|r|r|r|}
\cline { 2 - 7 } \multicolumn{1}{l|}{} & \multicolumn{1}{c|}{$\mathbf{2 0 0 9}$} & \multicolumn{1}{c|}{$\mathbf{2 0 1 0}$} & \multicolumn{1}{c|}{$\mathbf{2 0 1 1}$} & \multicolumn{1}{c|}{$\mathbf{2 0 1 2}$} & \multicolumn{1}{c|}{$\mathbf{2 0 1 3}$} & \multicolumn{1}{c|}{$\mathbf{2 0 1 4}$} \\
\hline Barras de desayuno & 13.30 & 13.30 & 13.10 & 13.20 & 13.30 & 13.30 \\
\hline $\begin{array}{l}\text { Barras nutritivas y } \\
\text { energéticas }\end{array}$ & 5.10 & 5.10 & 5.20 & 5.30 & 5.40 & 5.40 \\
\hline Barras de fruta & 5.50 & 5.50 & 5.40 & 5.40 & 5.40 & 5.40 \\
\hline Barras de granola/muesli & 22.40 & 23.50 & 24.30 & 251.00 & 25.70 & 26.10 \\
\hline Otras barras & 1.60 & 1.70 & 1.80 & 1.80 & 1.80 & 1.80 \\
\hline Total & $\mathbf{4 7 . 9 0}$ & $\mathbf{4 9 . 1 0}$ & $\mathbf{4 9 . 8 0}$ & $\mathbf{2 7 6 . 7 0}$ & $\mathbf{5 1 . 6 0}$ & $\mathbf{5 2 . 0 0}$ \\
\hline
\end{tabular}

Fuente: Euromonitor International, año 2014

\subsection{Objetivo General}


Desarrollar un Plan de Negocio para la exportación de barras energéticas a base de quinua para el mercado de Toronto, Canadá.

\subsubsection{Objetivos Específicos}

a) Analizar las exigencias del mercado con relación a las características que debe tener el producto para ingresar a Toronto.

b) Definir la estrategia de distribución comercial en Canadá para el producto.

c) Analizar el incremento de la demanda de barras energéticas en Canadá en los últimos años.

d) Definir la ruta logística más adecuada para la exportación el producto al mercado de Toronto.

\subsection{Descripción del Entorno}

\subsubsection{Análisis PESTEC del Perú y Sector}

\subsubsection{Político}

La política actual del Perú está basada en la Constitución Política la cual se toma coma base del sistema jurídico del país, la misma que tienen como pilares la justicia, el derecho y las normas del país. Está controla, regula y defiende los derechos y libertades de los peruanos; organiza los poderes e instituciones políticas. Con relación a la organización del Estado, éste es una República, contando con un Gobierno unitario, representativo y descentralizado.

Según el Portal del Estado Peruano, "existen tres poderes independientes: Poder Ejecutivo, Poder Legislativo y el Poder Judicial". Donde el "Poder Ejecutivo está constituido por el Presidente, quien desarrolla las funciones de Jefe de Estado. Él simboliza y representa los intereses del país, siendo elegido a través de un sufragio popular". "El Poder Legislativo, reside en el 
Congreso de la República contando con un Parlamento Unicameral con 120 miembros elegidos por sufragio directo". Y finalmente el Poder Judicial está encabezado por la Corte Suprema de la República con competencia en todo el territorio peruano; siendo el órgano encargado de administrar la justicia del país. El segundo nivel jerárquico son las Cortes Supremas con competencia en un Distrito Judicial. El tercer nivel está compuesto por los Juzgados de Primera Instancia cuya competencia es básicamente provincial. En el último nivel se encuentran los Juzgados de Paz con competencia a nivel distrital.

\subsubsection{Económico}

El primer factor que se debe poner bajo análisis es la variación del Producto Bruto Interno (PBI), debido a que es una medida macroeconómica que indica el valor monetario de la producción de bienes y servicios de un país durante un periodo determinado. A continuación se observa la variación del PBI del Perú de manera porcentual del año 2006 al 2014.

\section{Gráfico $N^{o}$ 1.1: Variación del PBI (\%)}

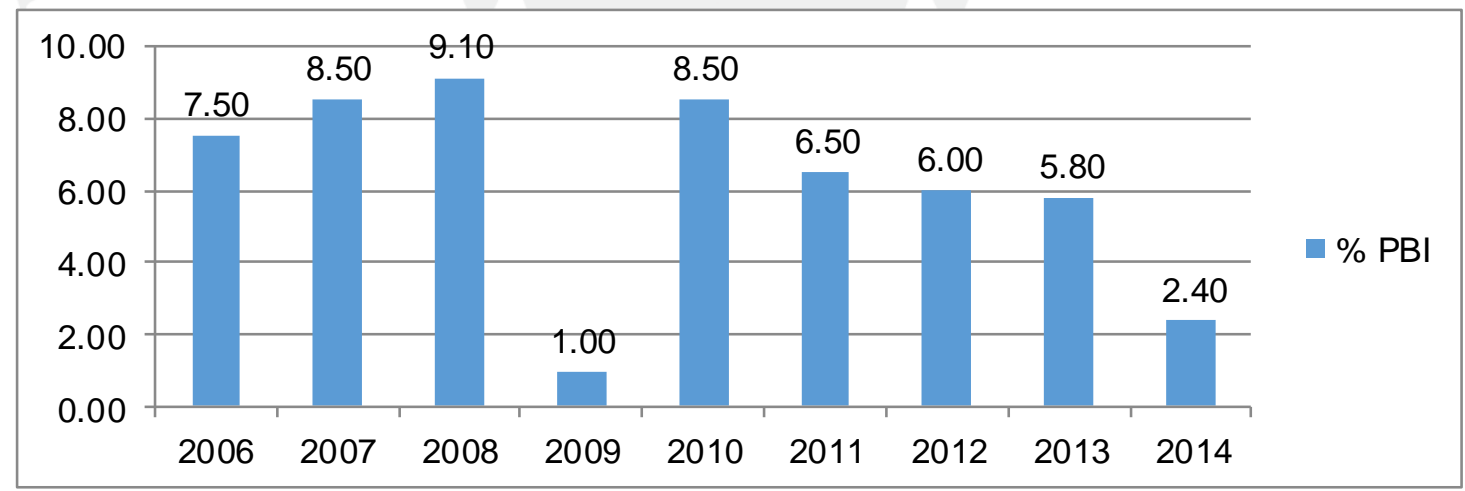

Fuente: Instituto Nacional de Estadística e Informática y Ministerios de Agricultura y Riego, Energía y Minas y de la Producción.

Se puede observar en el gráfico $n^{\circ} 1.1$ que el año con el mayor PBI entre el periodo 2006-2014 es el 2008 con una tasa de 9.10\%, le siguen los años 2007 y 2010 ambos con una tasa de $8.50 \%$. También se puede apreciar que el año con menor variación del PBI es el 2009 
con $1.00 \%$, lo cual se debe a contracción de la economía global debido a la crisis económica que sufrió Estados Unidos en ese año. Sin embargo desde el año 2011 el PBI viene contrayéndose en lugar de crecer y según proyecciones macroeconómicas la tendencia es a que continúe bajando. Finalmente, el año 2014 se cerró con un PBI de $2.40 \%$ en donde los sectores que mayor aporte brindaron a la economía peruana fueron electricidad y agua junto con servicios con $4.90 \%$ cada uno de ellos.

Cabe mencionar que si bien el PBI está compuesto por varios sectores económicos este posee cuatro pilares, lo cuales son el consumo interno, ellos han venido bajando en los últimos cuatro años, siendo esta una de las principales razones de la contracción del PBI del país.

Otro aspecto importante es la progresiva integración económica comercial del Perú con los países con los que mantiene los mayores intercambios comerciales.

"Los tratados de libre comercio traen consigo beneficios que están relacionados no sólo con aspectos de tipo comercial, sino que son positivos para la economía en su conjunto: permiten reducir y en muchos casos eliminar las barreras arancelarias y no arancelarias al comercio; contribuyen a mejorar la competitividad de las empresas (dado que es posible disponer de materia prima y maquinaria a menores costos); facilitan el incremento del flujo de inversión extranjera, al otorgar certidumbre y estabilidad en el tiempo a los inversionistas...asimismo, la apertura comercial genera una mayor integración del país a la economía mundial, lo que hace posible reducir la volatilidad de su crecimiento, el nivel de riesgo-país y el costo de financiamiento de la actividad privada en general. 
(Ministerio de Comercio Exterior y Turismo, Ventajas y Desventajas de los Acuerdos Comerciales, 2014)

A continuación se muestra una gráfica con la evolución de los acuerdos comerciales que actualmente Perú tiene con diferentes países.

\section{Gráfico $N^{o}$ 1.2: Acuerdos Comerciales Vigentes de Perú}

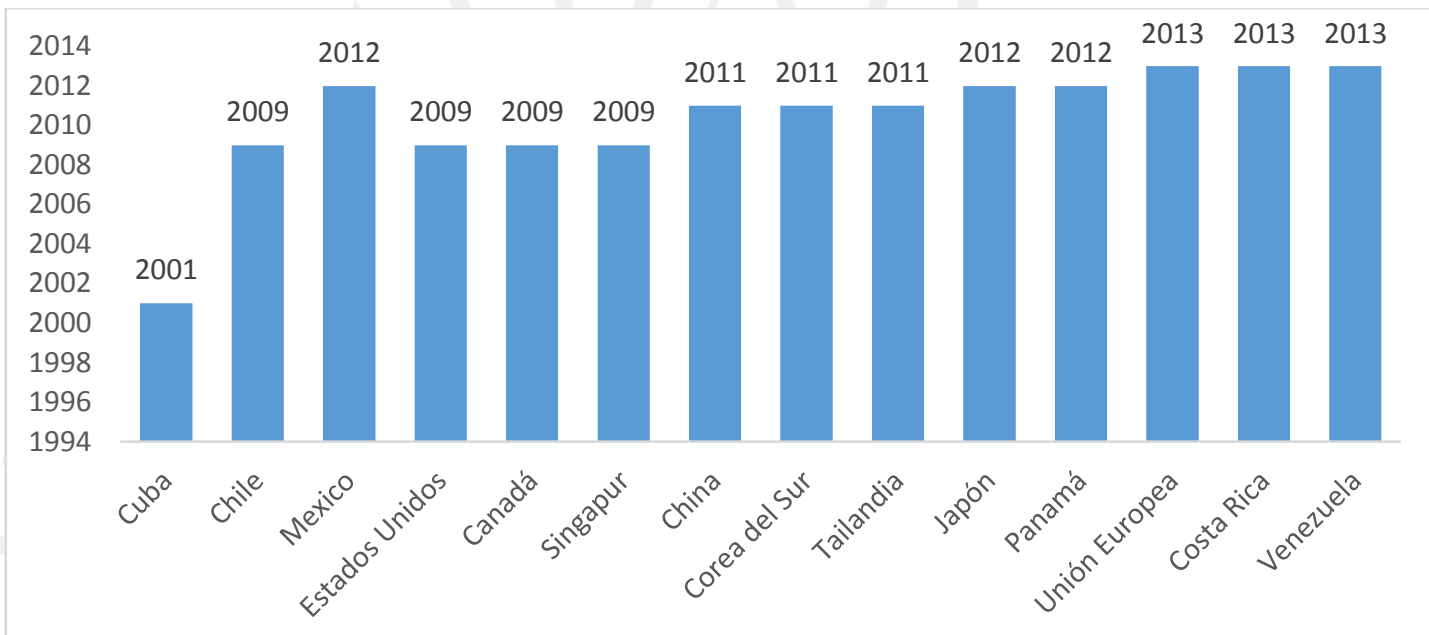

Fuente: Ministerio de Comercio Exterior y Turismo.

Se puede observar que a partir del año 2009 la mayoría de los acuerdos comerciales negociados empiezan a entrar en vigencia para beneficio de ambas partes en el intercambio de bienes.

A pesar de contar con ellos, se ha presentado una situación de virtual estancamiento financiero. Se evidencia mucha exigencia de calidad en la presentación de productos destinados a los países industrializados. Esto origina que las constantes fusiones de las corporaciones transnacionales agudicen el acelerado proceso de absorción empresarial en cuanto a los bancos, compañías de comunicaciones, alimentos, informática, audiovisuales, línea blanca, línea aérea, etc. Asimismo, como consecuencia a la disminución de las tasas de interés internacionales las tasas de interés de diversas instituciones peruanas se redujeron, lo cual contribuyo de manera positiva a la economía del país. 
Otro factor importante que se debe analizar en el entorno económico es la inflación, pues esta nos permite saber el aumento de los precios de bienes y servicios en un país.

Gráfico $N^{o}$ 1.3: Inflación anual del Perú (\%)

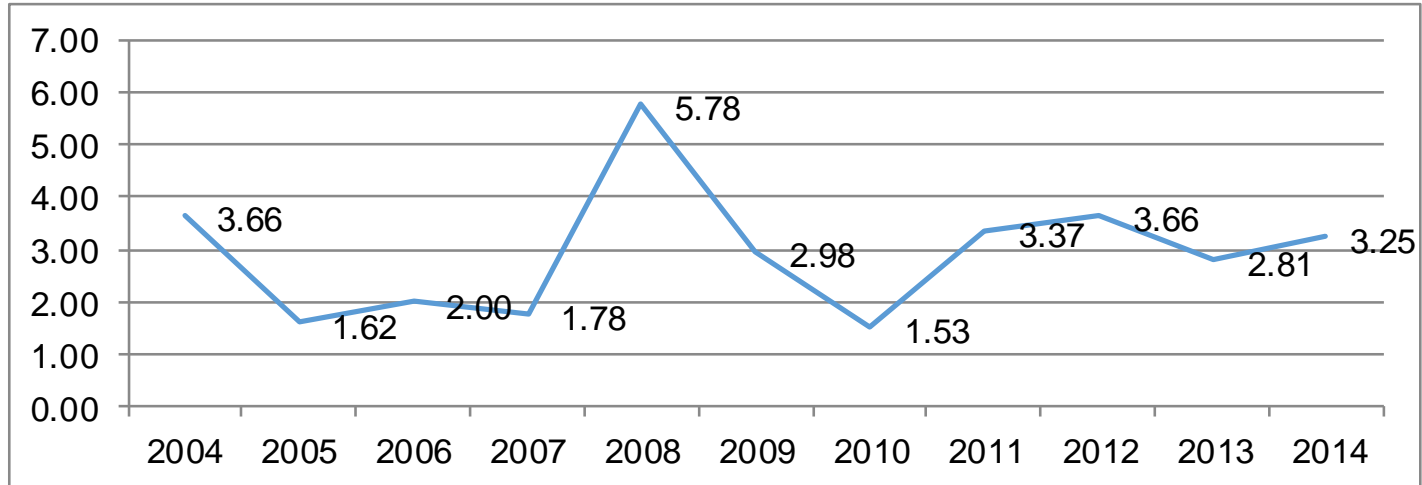

Fuente: Banco Central de Reserva del Perú.

En el gráfico $\mathrm{N}^{\circ} 1.3$ se observa que el comportamiento que ha tenido la inflación en nuestro país. El año con mayor inflación entre el periodo de 2004 hasta 2014 es el año 2008 con una tasa de inflación de $5.78 \%$ la cual se obtuvo como consecuencia del mayor precio de los alimentos, los cuales aumentaron en $10.45 \%$, el sector de alquiler de vivienda, combustible y electricidad en su conjunto significaron un aumento de $5.28 \%$ y el sector de transportes y comunicaciones creció $4.51 \%$.

Por último, se debe analizar el factor tipo de cambio. Según estadísticas históricas en el periodo entre los años 2004 hasta el 2014, en esos diez años el pico más alto que tuvo el tipo de cambio fue de 3.4130 en el año 2004 y en el año 2012, Perú obtuvo el menor tipo de cambio de nuevos soles (PEN) frente a dólares americanos (USD) con 2.6378, seguido por un aumento al 2013 a 2.7023 y finalizando el año 2014 con un tipo de cambio tipo de cambio de 2.8389 de nuevos soles por dólares americano. La proyección del tipo de cambio para el 2015 es que el dólar continúe apreciándose frente a nuestra moneda nacional el nuevo sol y finalice con 3.25. A 
continuación, en el siguiente gráfico se muestra la fluctuación del tipo de cambio:

Gráfico $N^{o}$ 1.4: Tipo de cambio del Perú (PEN por USD)

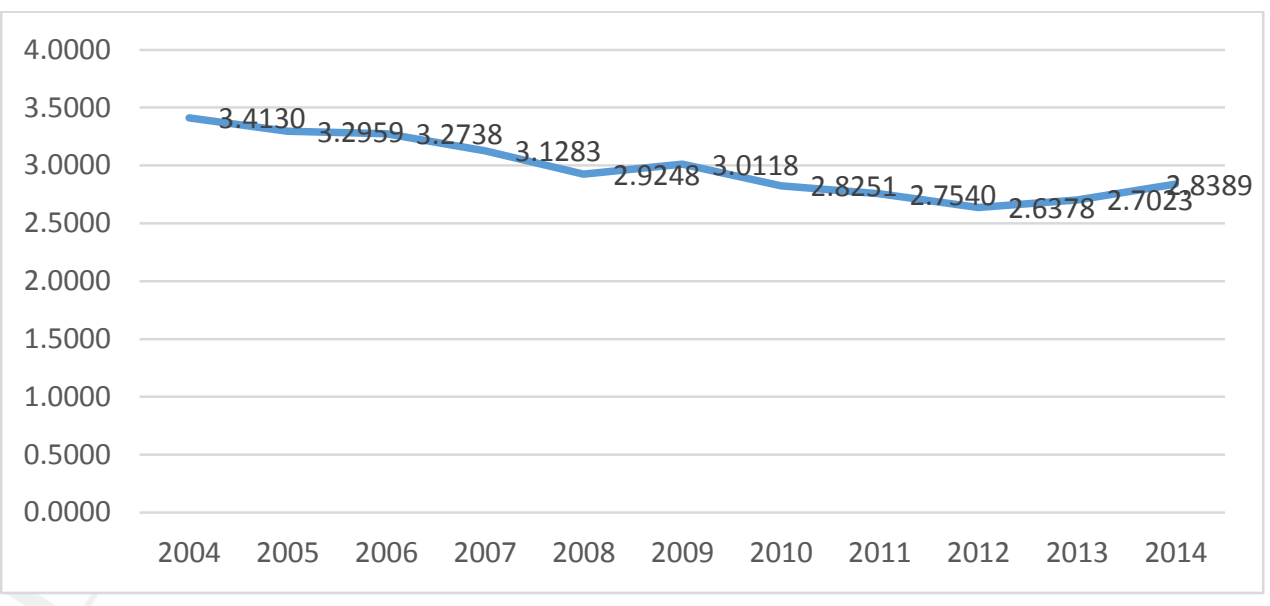

Fuente: Banco Central de Reserva del Perú

\subsubsection{Social}

La población del Perú al año 2014 es de 30’ 814,175 habitantes, de los cuales 15 ' 438, 887 son hombres y 15’375,288 son mujeres, representan el $50.10 \%$ y $49.89 \%$ de la población respectivamente. Se estima que la población tenga un crecimiento en el siguiente año de 339 mil personas aproximadamente.

A continuación se muestra la evolución demográfica de nuestro país y una posible proyección de la misma.

Gráfico No 1.5: Población peruana proyectada (2008-2017)

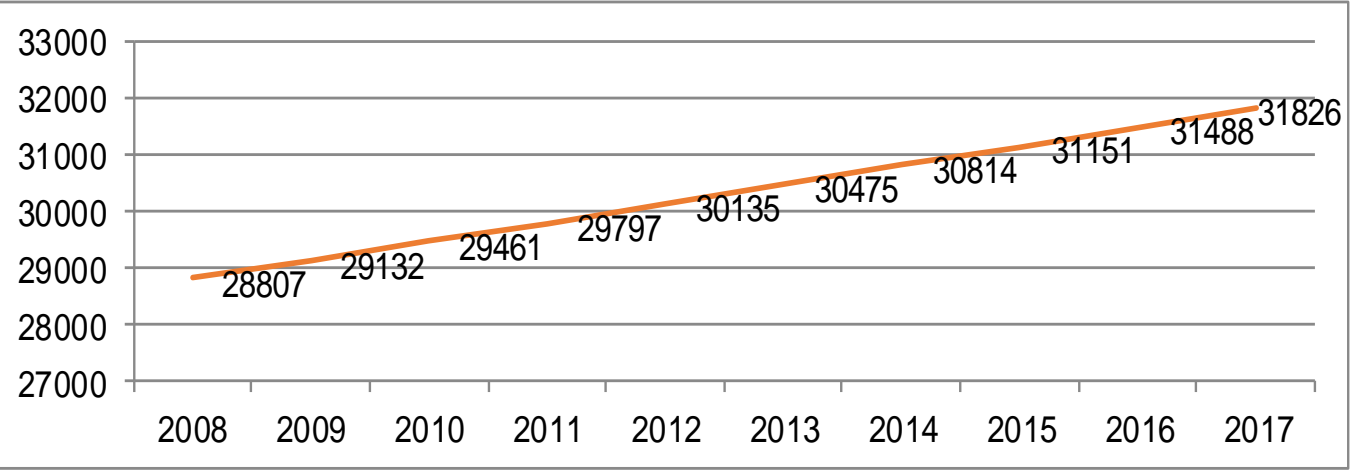

Fuente: Instituto Nacional de Estadística e Información 
Según el Instituto Nacional de Estadísticas e Información (INEI) “en lo que respecta a la demografía por departamentos, once de ellos cuentan con una población mayor a un millón de habitantes de los cuales seis de ellos están ubicados en la Sierra del Perú y son Cajamarca, Puno, Junín, Cusco, Arequipa y Áncash, cuatro en la Costa (Lima, La Libertad, Piura y Lambayeque) y uno a la Selva que es Loreto". Asimismo con relación a la pirámide de población correspondiente al año 2014 se sabe que "la base (0 a 5 años de edad) es mayor en aproximadamente $0,5 \%$ con respecto a la pirámide proyectada del 2021", con lo que se puede concluir que cada año nacen niños y niñas, además que hay un incremento de población a partir de los 30 años lo que significaría un envejecimiento de la población peruana.

A continuación se muestra un gráfico con la evolución de la pobreza en el Perú entre los años 2004 y 2014.

\section{Gráfico $N^{o}$ 1.6: Evolución de la pobreza en el Perú}

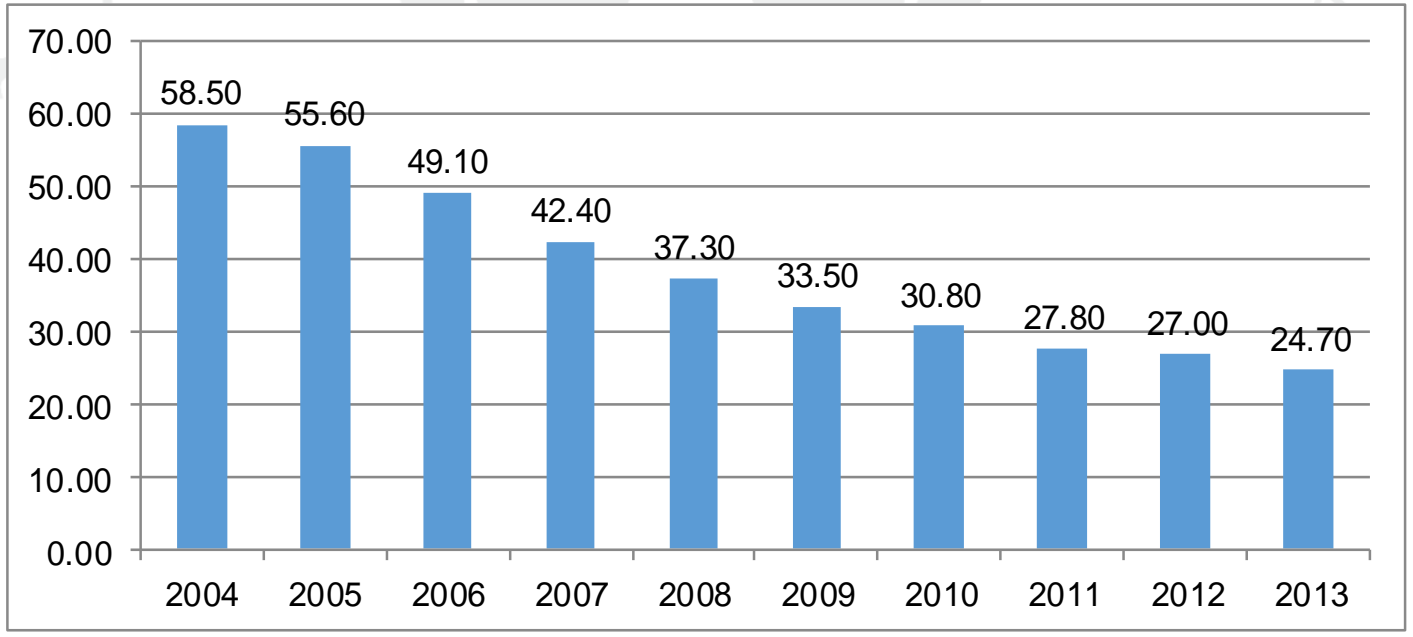

Fuente: Instituto Nacional de Estadísticas e Información

\subsubsection{Tecnológico}

El aspecto tecnológico de un país es importante pues va de la mano con la competitividad que tiene frente a otras economías. En el Perú 
con la apertura a los mercados que se da en los años noventa, el país empieza a experimentar cambios que han revolucionado el mundo con una serie de innovaciones. A través de la masificación del Internet, la información está al alcance de todos siendo transparente y accesible, todo esto gracias a la proliferación de la fibra óptica.

En este contexto, resultan eventos cotidianos el acceso a Internet, el envío de correos electrónicos, el diseño de páginas web, la creación de dominios personalizados, así como el diseño, la implementación, la configuración y la instalación de Intranets corporativos.

Por otro lado, las organizaciones se tornan horizontales y se reemplaza el enfoque funcional por el de procesos. Las demandas o expectativas del usuario se convierten en aspectos principales. Asimismo, la modernización de los servicios informáticos garantiza la flexibilidad de sus aplicaciones y la integración de los sistemas, y propone una plataforma estable que conduce a la reducción de los costos operativos. Además, las fuerzas tecnológicas afectan la administración en el área del diseño de oficinas.

Según el ranking de Competitividad del World Economic Forum 2014-2015 basado en 143 economías, Perú se encuentra ubicado en el puesto 65, bajando cuatro puntos con relación al año anterior, en cuanto a preparación tecnológica posicionándose como el sexto país de la región.

En el Perú, el uso de internet ha aumentado notablemente, a continuación se puede apreciar esta significante variación entre el 2010-2013.

Tabla $N^{o} 1.2$ : Uso de internet Perú (casa 100 habitantes), en porcentaje

\begin{tabular}{|c|c|c|c|c|}
\hline País & $\mathbf{2 0 1 0}$ & $\mathbf{2 0 1 1}$ & $\mathbf{2 0 1 2}$ & $\mathbf{2 0 1 3}$ \\
\hline Perú & 34.77 & 36.00 & 38.20 & 39.20 \\
\hline
\end{tabular}


Cuando se analiza el consumo de internet según el área geográfica en Perú, es evidente la diferencia en el consumo entre Lima Metropolitana y el resto del país.

Gráfico $N^{o}$ 1.7: Población de 6 y más años que hace uso de internet en Perú, según Ámbito Geográfico, 2008-2013

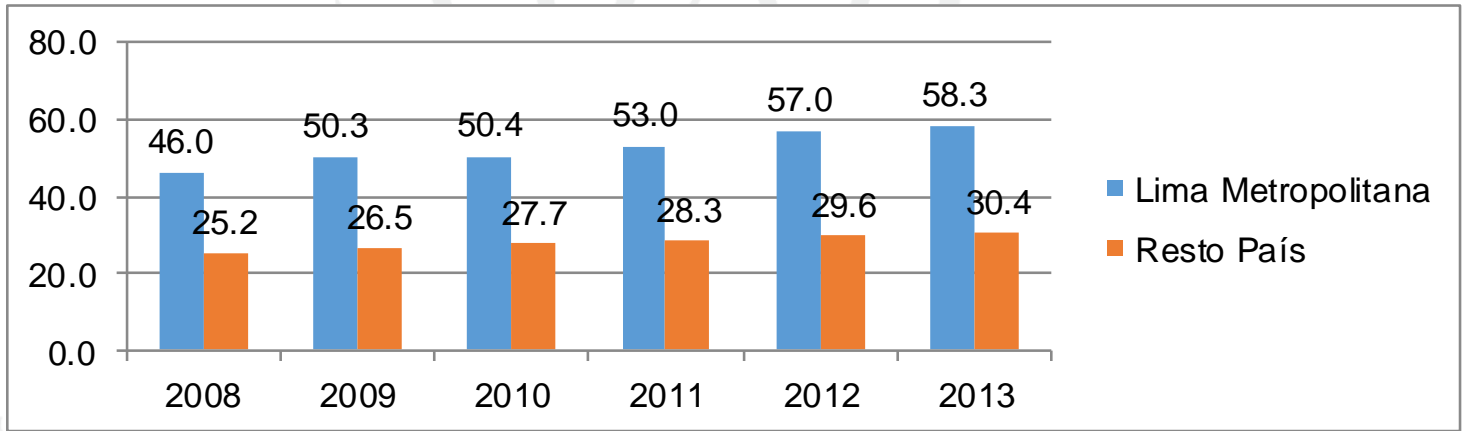

Fuente INEI. Tecnologías de la Información y Comunicación, 2014

En lo que respecta el consumo de internet, en Lima Metropolitana se observa un aumento $12.67 \%$ en el año 2013 respecto al 2008 mientras que en el resto del país el aumento ha sido de $6 \%$ en el año 2013 respecto al 2008. Debido a esta fuerte centralización de tecnología el Gobierno Peruano se encuentra fomentando el desarrollo de acceso a esta fuente de información a través de diversos programas de implementación de equipos en colegios estatales.

Actualmente nuestro país se encuentra posicionado en el puesto 90 en lo que respecta a un desarrollo en la tecnología. "El desarrollo del Perú se ve limitado por barreras tales como el sistema educativo de baja calidad (Puesto 133), baja calidad de la educación en matemáticas y ciencias (Puesto 138) que dificultan la preparación del país para hacer un buen uso de las Tecnologías de la información, así como la falta de eficacia de los órganos legislativos (Puesto 140), que retrasan el entorno regulatorio para las TIC" (World Economic Forum, Ranking Global de Tecnología, 2015). 
1.4.1.5. Competitivo (World Economic Forum, Ranking de Competitividad Global, 2014-2015)

Hoy en día el Perú se encuentra entre la mitad superior de las economías de América Latina, no obstante con relación al año 2014 nuestro país ha descendido cuatro puntos en la lista de Índice de Competitividad Global 2014-2015 ubicándose en el puesto 65 de 143 economías.

A continuación se muestra las posiciones de las economías de América Latina que fueron consideradas en el Reporte Global de Competitividad 2014-2015.

Gráfico $N^{o} 1.8$ : Posición en el índice de Competitividad Global 2014-2015 a nivel América Latina

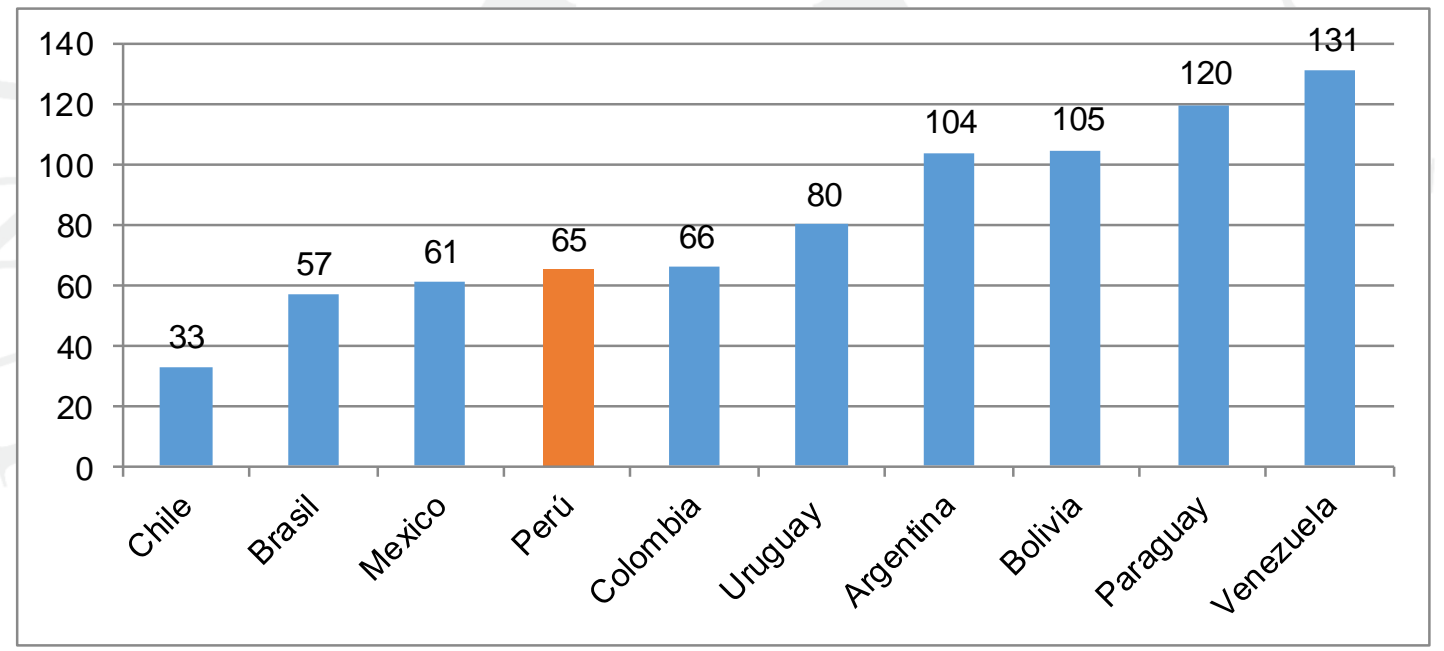

Fuente: The Global Competitiveness Report 2014-2015.

Cada vez los inversionistas extranjeros se muestran más interesados en realizar negocios con el Perú pues “destaca la fortaleza del desempeño macroeconómico así como los altos niveles de eficiencia en el mercado de bienes, financiero y de trabajo, a pesar de la rigidez en las prácticas de contratación y despido". Sin embargo todavía existen factores que se deben de reforzar tales como la ineficiencia burocrática, la corrupción y las restrictivas 
regulaciones laborales han sido los aspectos más problemáticos para hacer negocios en el país.

En lo que respecta al marcador de la competitividad, se ha observado un retroceso pues las calificaciones de desempeño de la economía, las políticas gubernamentales que fomenten competitividad, eficiencia en los negocios y la infraestructura se han visto contraídas pues el gobierno actual no ha dado las facilidades para continuar el desarrollo de las inversiones sino por el contrario se han encontrado trabas sociales y políticas que llegan a un consenso, lo que ha resultado como un estancamiento de los grandes proyectos de inversión del país. Adicionalmente el país ha caído 14 posiciones en el rubro de desempeño económico como consecuencia a la desaceleración económica y a la caída de las exportaciones lo cual provocan un déficit en la balanza comercial del país.

Según el Índice de Desempeño Logístico elaborado por el Banco Mundial, el Perú ha descendido 38 puntos ubicándose actualmente en el puesto 96 debido al bajo desempeño de aduanas y el despacho en las fronteras, y 20 puntos en competencia y la calidad de servicios logístico, estando ahora ubicado en el puesto 76 . Las principales causas de estas caídas son los problemas de subvaluación y contrabando, los cuales continúan deteriorando la eficiencia en el control de las aduanas. 


\section{Imagen $N^{o}$ 1.2: Etapas de desarrollo de Perú en comparación a}

\section{América Latina y el Caribe}

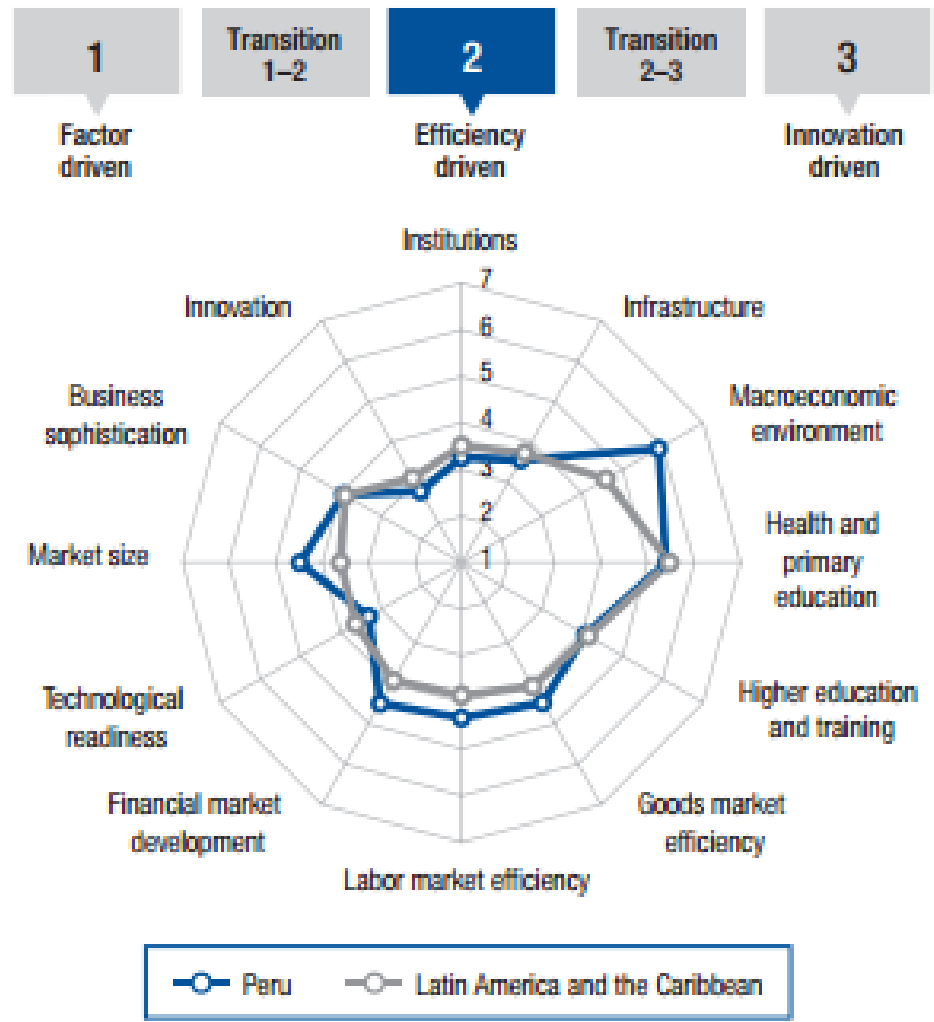

Fuente: The Global Competitiveness Report 2014-2015.

Según la imagen se puede concluir que una de las principales acciones que debe de tomar el Perú para ser más atractivo a la inversión extranjera y mejorar la facilidad de hacer negocios es mejora la institucionalidad del sector público y privado, con la finalidad de mejorar el nivel de competitividad del país. Finalmente cabe mencionar, que se debe de trabajar en la invocación, la tecnología y la educación pues estos son pilares claves para un crecimiento en la competitividad de los países. 


\subsubsection{Matriz de Compatibilidad Metodológica}

\begin{tabular}{|c|c|c|c|}
\hline Problemas & bjetivos & Hipótesis & Metodología \\
\hline $\begin{array}{l}\text { Problema general } \\
\text { La tendencia del consumo natural y el } \\
\text { cuidado de la salud han llevado a un } \\
\text { incremento en la demanda de productos } \\
\text { saludables en el mercado Canadiense. Por } \\
\text { lo que surge la pregunta: } \\
\text { ¿Si existe la viabilidad de exportar barras } \\
\text { energéticas a base de quinua al mercado } \\
\text { Canadiense con énfasis en Toronto? } \\
\text { Problemas específicos } \\
\text { ¿Cuál es el incremento de la demanda de } \\
\text { barras energéticas en el mercado de } \\
\text { destino? } \\
\text { ¿Cuáles son los requisitos de ingreso al } \\
\text { mercado canadiense? } \\
\text { ¿Cuáles son las características del } \\
\text { consumidor? } \\
\text { ¿Cuál es la estrategia de distribución que el } \\
\text { proyecto debe usar? }\end{array}$ & $\begin{array}{l}\text { Objetivo general } \\
\text { Desarrollar un Plan de Negocio para la } \\
\text { exportación de barras energéticas a base de } \\
\text { quinua para el mercado de Toronto, } \\
\text { Canadá. } \\
\text { Objetivos Específicos } \\
\text { Analizar las exigencias del mercado con } \\
\text { relación a las características que debe tener } \\
\text { el producto para ingresar a Toronto. } \\
\text { Definir la estrategia de distribución } \\
\text { comercial en Canadá para el producto. } \\
\text { Analizar el incremento de la demanda de } \\
\text { barras energéticas en Canadá en los últimos } \\
\text { años. } \\
\text { Definir la ruta logística más adecuada para } \\
\text { la exportación el producto al mercado de } \\
\text { Toronto. }\end{array}$ & $\begin{array}{l}\text { Hipótesis General } \\
\text { La exportación de barras energéticas a base } \\
\text { de quinua en Toronto, Canadá resulta una } \\
\text { oportunidad de negocio para pequeñas } \\
\text { empresas exportadoras, ofreciendo un } \\
\text { producto con valor agregado y que cumple } \\
\text { con los requerimientos de los consumidores } \\
\text { canadienses con relación al consumo } \\
\text { productos naturales y orgánicos que } \\
\text { contribuyan con la salud. } \\
\text { Hipótesis Específicas } \\
\text { El cambio en la tendencia consumo hacia } \\
\text { alimentos saludables, genera una gran } \\
\text { oportunidad para las barras energéticas a } \\
\text { base de quinua. } \\
\text { La estrategia de distribución que el } \\
\text { proyecto debe utilizar es a través de tiendas } \\
\text { minoristas de productos naturales. }\end{array}$ & $\begin{array}{l}\text { Tipo de Investigación } \\
\text { Descriptivo Enfoque: } \\
\text { Cualitativo y cuantitativo. } \\
\text { Sujeto de estudio: El mercado de } \\
\text { importaciones de barras energéticas a base } \\
\text { de quinua en Canadá con énfasis en } \\
\text { Toronto. } \\
\text { Instrumentos: } \\
\text {-Análisis de datos históricos tales como } \\
\text { Trademap, Euromonitor, etc. } \\
\text { - Análisis de datos numéricos y cualitativos } \\
\text { SIICEX y Trademap para el producto. }\end{array}$ \\
\hline
\end{tabular}




\section{CAPÍTULO 2: MARCO TEÓRICO}

\subsection{Análisis PESTEC del País de destino y sector}

2.1.1. Político (The World Factbook, 2015)

Canadá es un país que por tradición cuenta con monarquía la cual es hereditaria y es representada por el Gobernador General. Este cargo es dado por la monarquía pues es la persona que los va a presentar en temas políticos, actualmente quien ocupa este cargo es David Lloyd Johnston. Desde febrero del 2006 se encuentra gobernado por el primer ministro Stephen Joseph Harper quien cuenta con un Gabinete Ministerial Federal el mismo que es escogido por el primer ministro y usualmente son miembros de su propio partid.

El Poder Legislativo está compuesto por un "parlamento bicameral que consiste en el Senado (105 asientos; miembros nombrados por el Gobernador General con el asesoramiento del primer ministro y pueden servir en este cargo políticos no mayores a los 75 años) y la Cámara de los Comunes (308 asientos; miembros elegidos directamente en circunscripciones de un solo escaño por mayoría simple de votos de servir a un máximo de un período de 4 años)”. (The World Factbook, 2015).

Con respecto al Poder Judicial, existe la Corte Suprema de Canadá que está formada por el Presidente del Tribunal Supremo y 8 jueces. Es interesante mencionar que en el año 1949, Canadá abolió finalmente todas las apelaciones más allá de su Tribunal Supremo ante el Comité Judicial del Consejo Privado (en Londres). El presidente del Tribunal Supremo y su equipo de jueces son nombrados por el primer ministro; todos los jueces designados por la vida con la jubilación obligatoria a los 75 años. Además a un nivel federal existen: El Tribunal Federal de Apelación; la Corte Federal; el Tribunal Fiscal; tribunales administrativos federales; los consejos de guerra; apelaciones provinciales superior, primera instancia y tribunales especializados; provinciales / territoriales. En 1999, la Corte 
Nunavut - un tribunal de circuito con el poder de un tribunal superior y los tribunales territoriales - fue establecido para servir asentamientos aislados.

\subsubsection{Económico}

En el año 2014 el producto bruto interno (PBI) de Canadá ha crecido en $0.5 \%$ con respecto al 2013 y esto significa una tasa de 5 décimas mayor que la del año anterior que fue $2.0 \%$. La cifra del PBI fue de 1'788,717 millones de dólares americanos, lo cual posiciona a Canadá como la décimo primera economía en el ranking de 183 países que publican su PBI. Asimismo cabe mencionar que el PBI per cápita de Canadá para el año 2013 es de 52,393\$ teniendo una variación negativo en $0.8 \%$ con respecto al año anterior que fue de $52,818 \$$.

A continuación se muestra la variación anual del PBI en el periodo de 2004-2014, donde se observa que en el año 2009 que hubo la crisis económica mundial esta se contrajo a $2.70 \%$, recuperándose al siguiente año a 3.40\% que ha significado en este período la variación más alta.

\section{Gráfico $N^{o}$ 2.1: Evolución Tasa de crecimiento PBI}

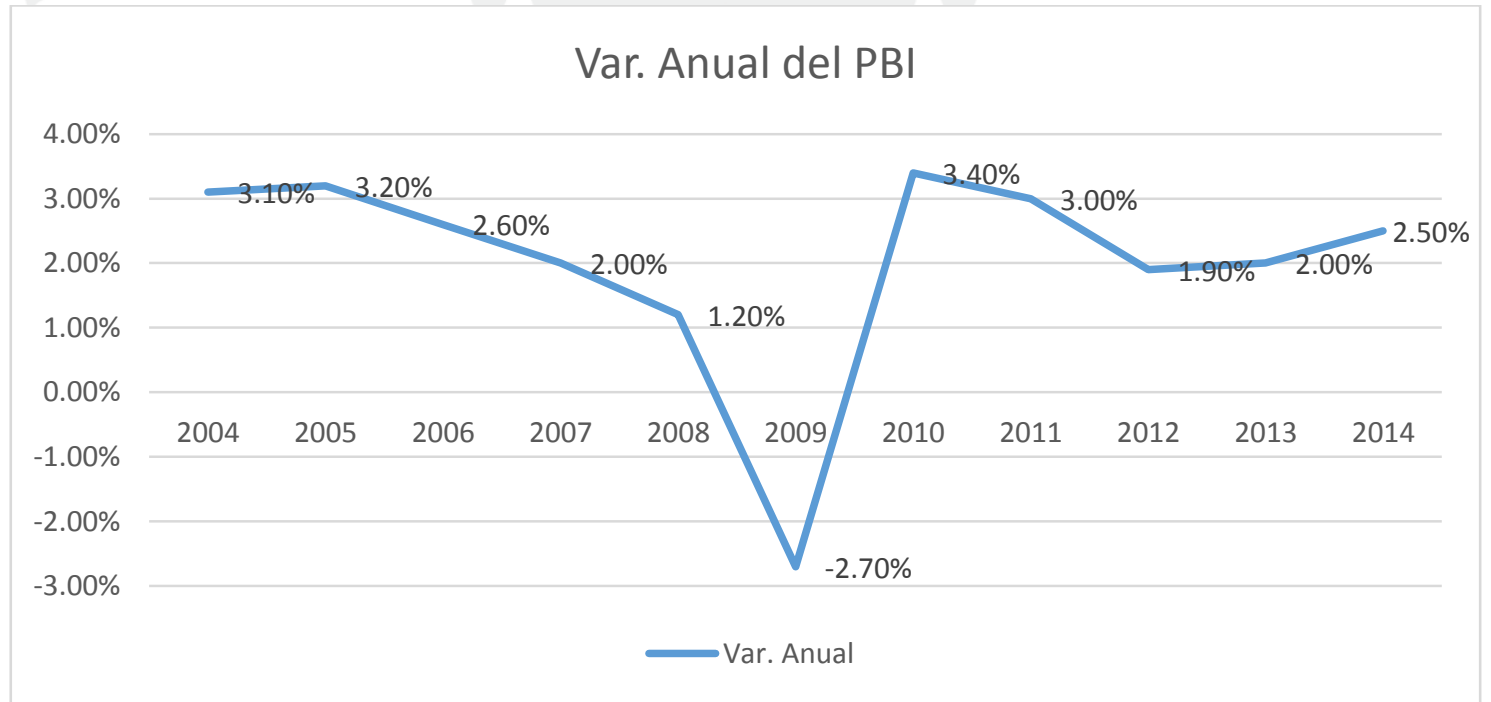

Fuente: Datos Macro, 2014. 
Gráfico No 2. 2: Evolución PBI per cápita

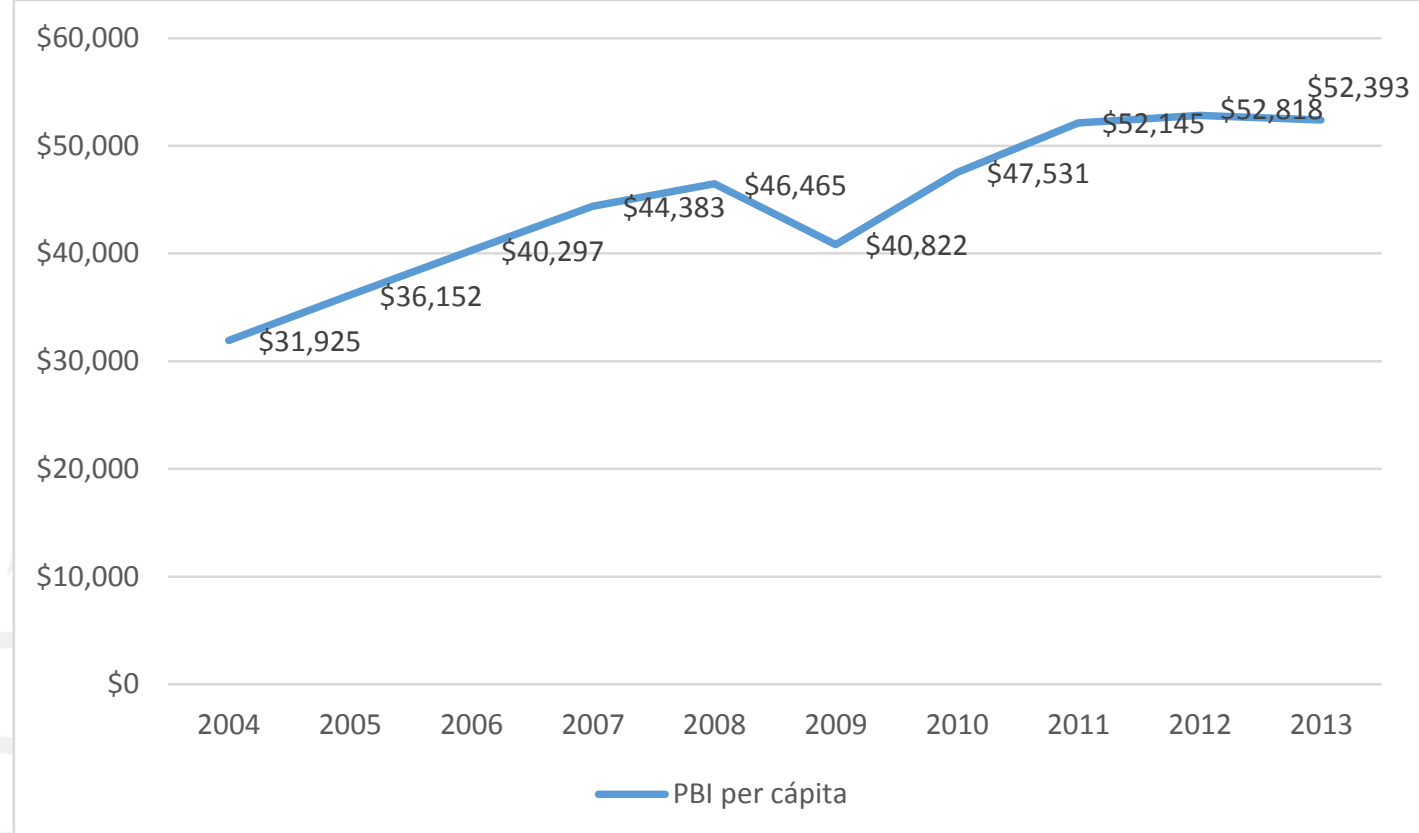

Fuente: Datos Macro, 2014

En el gráfico $\mathrm{N}^{\circ} 2.4$ se observa que el crecimiento del PBI per cápita del año 2013 con respecto al año 2004 es de $64.11 \%$, además se puede observar que en el año 2009 debido a la crisis económica mundial que empezó en Agosto del 2007, el PBI tuvo una contracción en 12.14\%, recuperándose en los siguientes años.

Con respecto a las exportaciones de Canadá, en el año 2014 estas fueron de USD\$ 465.1 billones teniendo un crecimiento de $3.52 \%$ con relación al año anterior, estas representan el $26.53 \%$ del PBI del país. El sector automotriz junto con el sector energía (petrolero y gas), representan el grueso de las importaciones y exportaciones de Canadá. La gran mayoría de las exportaciones de automóviles de Canadá se destinan a los Estados Unidos. Asimismo las exportaciones de petróleo crudo representaron aproximadamente el $20 \%$ de las exportaciones canadienses al mundo en el año 2014. 
A continuación se detalla una tabla comparativa de los diez principales productos de exportación e importación que tuvo la economía canadiense en el año 2014.

Tabla Nº 2.1: Comercio Canadá con el mundo 2014

\begin{tabular}{|l|r|l|r|}
\hline \multicolumn{2}{|c|}{ Importaciones Canadienses del Mundo } & \multicolumn{2}{c|}{ Exportaciones Canadienses al Mundo } \\
\hline Mercaderías & $\%$ & \multicolumn{1}{c|}{ Mercaderías } & 28.93 \\
\hline Vehículos, tráiler, bicicletas, & 15.26 & Combustible, minerales & 13.19 \\
\hline Piezas mecánicas & 14.60 & Vehículos, tráiler, bicicletas, & 6.27 \\
\hline Combustible & 10.23 & Piezas mecánicas & 4.67 \\
\hline Maquinaria y equipos & 9.55 & Perlas, piedras y metales preciosos & 2.88 \\
\hline Plástico/Artículos de plástico & 3.48 & Plástico/Artículos de plástico & 2.84 \\
\hline Instrumentos médicos & 2.77 & Artículos de madera, carbón & 2.68 \\
\hline Perlas, piedras y metales preciosos & 2.77 & Aviones & 2.33 \\
\hline Productos farmacéuticos & 2.70 & Maquinaria y equipos & 1.97 \\
\hline Artículos de acero & 2.54 & Artículos de aluminio & 1.96 \\
\hline Muebles & 2.00 & Cereales & \\
\hline
\end{tabular}

Fuente: Trade Data Online. Industry Canada. February 28, 2015, http://www.ic.gc.ca/eic/site/tdo-dcd.nsf/eng/Home

Como se mencionó anteriormente, Estados Unidos sigue siendo el destino principal de las exportaciones de mercancías canadienses. Sin embargo, en parte debido a la crisis financiera mundial, el valor absoluto de las exportaciones estadounidenses se ha mantenido relativamente sin cambios: Desde el 2000 al 2014 las exportaciones de Canadá a Estados Unidos crecieron un $13 \%$. En contraste, las exportaciones canadienses a Asia han crecido un $137 \%$, de $\$ 21,6$ mil millones en 2000 (5,6\% del total de las exportaciones) a \$51,2 mil millones en 2014 (11,6\%). Asia representa actualmente el segundo mayor destino de las exportaciones de productos canadienses. 


\section{Gráfico $N^{o}$ 2.3: Mercaderías exportadas de Canadá hacia el}

\section{mundo por regiones (2014)}

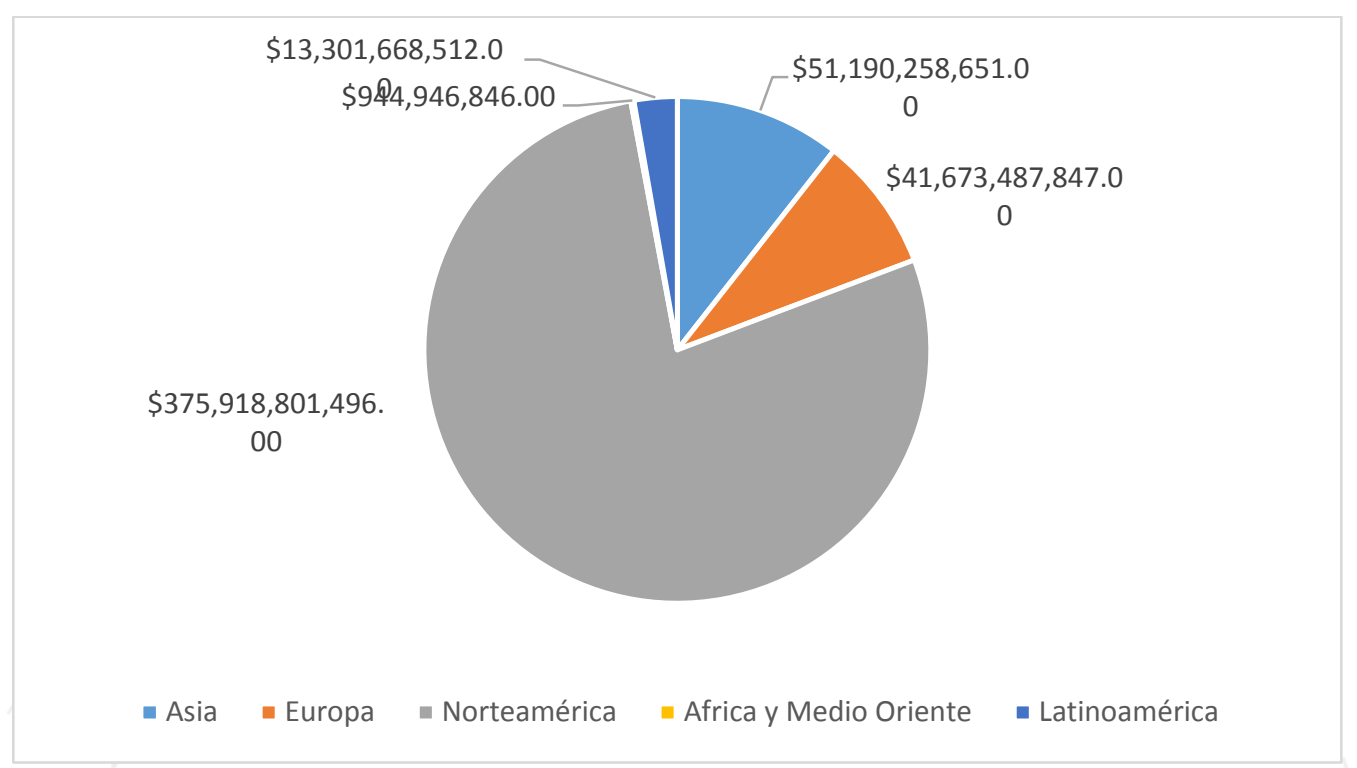

Fuente: The Asia Factor. http://theasiafactor.ca/ca\#e $=0 \& \mathrm{e} 0=0 \&$ scrollTo=e

Adicionalmente se debe mencionar que Canadá recibe más de la mitad de sus bienes importados desde América del Norte, y en 2014 las importaciones de América del Norte ascendieron a \$ 277 mil millones (o $54,7 \%$ de todos los bienes importados). Sin embargo, las importaciones procedentes de Asia han aumentado de manera constante en el tiempo, y Canadá ahora importa el 20,5\% de sus bienes (por valor de \$ 104 mil millones en 2014) de la región. 
Gráfico $N^{\circ}$ 2. 4: Mercaderías importadas por Canadá del mundo por regiones (2014)

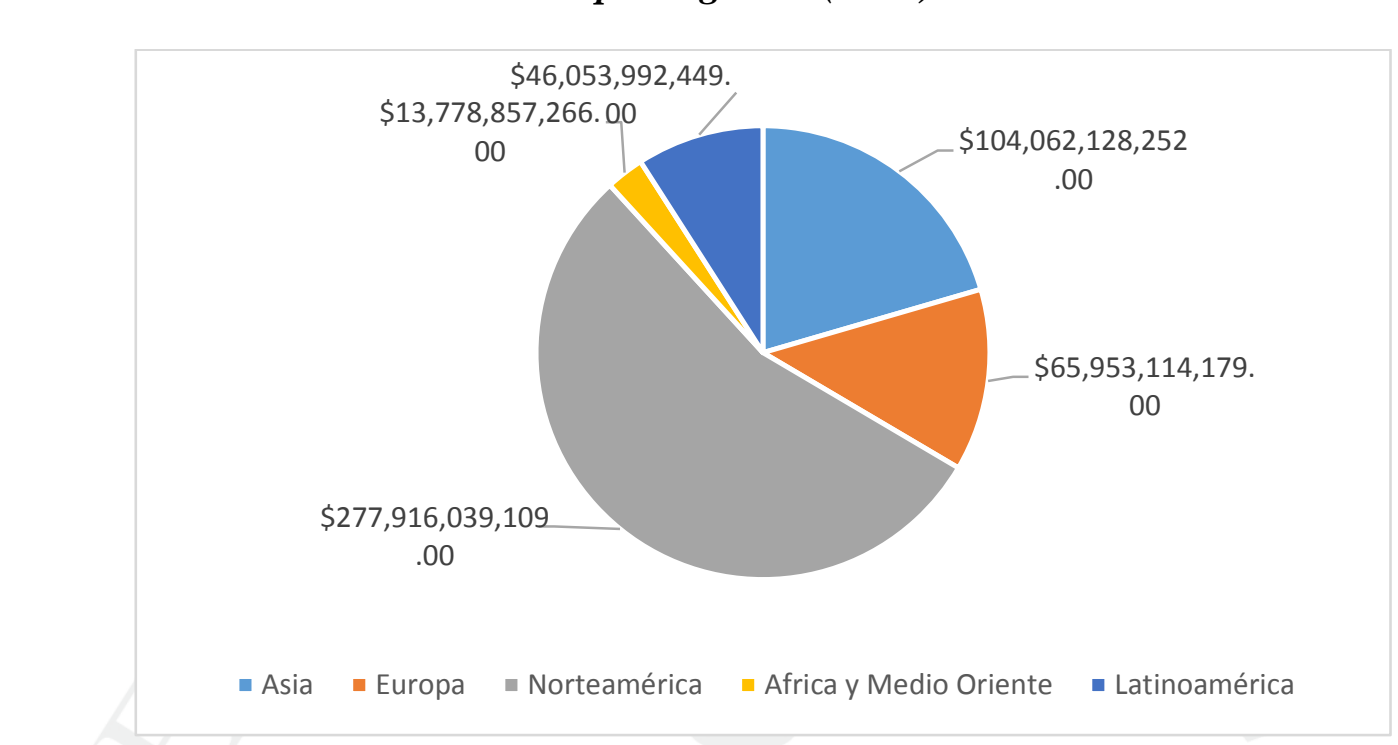

Fuente: The Asia Factor. http://theasiafactor.ca/ca\#e=0\&e0=0\&scrollTo=e

\subsubsection{Social}

Canadá cerró el 2014 con una población de 35,540, 400 habitantes lo que significa un aumento de 386,100 habitantes con respecto al año anterior, las provincias con mayor porcentaje de población son: Ontario (38,78\%), Québec $(23,11 \%)$, la Columbia británica $(13,26 \%)$ y Alberta $(11,01 \%)$.

Como la mayoría de los países desarrollados, uno de los principales factores que inciden en el consumo es el progresivo envejecimiento de la población. Según la fuente Datos Macro, “el 15,9\% de la población canadiense tiene más de 64 años y se espera que la cifra llegue al $21 \%$ en los próximos 20 años".

En el siguiente gráfico se puede visualizar la composición de la población Canadienses por género. 
Gráfico $N^{o}$ 2.5: Población Canadiense

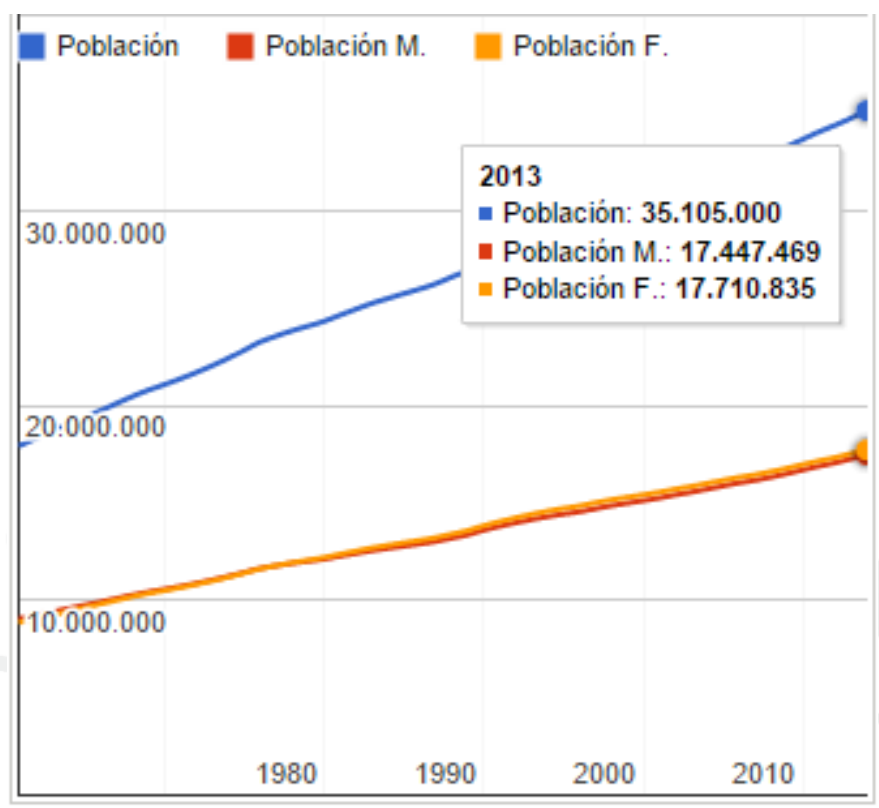

Fuente: Datos Macro, 2014

En el año 2014 se ha registrado el nacimiento de 385.937 niños, siendo el $51.29 \%$ varones y el $48.70 \%$ mujeres. Sin embargo Canadá tiene una tasa de natalidad muy baja sólo del 11\%, siendo en el 2012 el país número 151 en Tasa de Natalidad y el 149 en Índice de Fecundidad de 182 países.

Con relación al índice de fecundidad tiene un promedio de 1.61 hijos por mujer, por lo tanto en su mayoría las familias canadienses están constituidas por 3 integrantes.

A continuación se muestra la evolución de la tasa de natalidad en los últimos 10 años. 
Gráfico 2.6: Grafico $N^{\circ}$ 2.8: Evolución de la natalidad en Canadá.

\begin{tabular}{|c|c|c|c|c|c|}
\hline \multicolumn{6}{|c|}{ Canadá - Natalidad } \\
\hline Fecha & Nacidos & Nacidos Hombres & Nacidos Mujeres & Tasa Natalidad & Índice de Fecund. \\
\hline 2014 & 385.937 & 197.948 & 187.989 & & \\
\hline 2013 & 383.103 & 196.496 & 186.607 & & \\
\hline 2012 & 377.920 & 193.837 & 184.083 & $11,00 \%$ & 1,61 \\
\hline 2011 & 376.951 & 193.170 & 183.781 & $11,00 \%$ & 1,61 \\
\hline 2010 & 379.373 & 194.674 & 184.699 & $11,10 \%$ & 1,63 \\
\hline 2009 & 379.290 & 194.746 & 184.544 & $11,30 \%$ & 1,67 \\
\hline 2008 & 373.695 & 191.202 & 182.493 & $11,30 \%$ & 1,68 \\
\hline 2007 & 360.916 & 185.176 & 175.740 & $11,20 \%$ & 1,66 \\
\hline 2006 & 346.082 & 177.623 & 168.459 & $10,90 \%$ & 1,59 \\
\hline 2005 & 339.270 & 174.138 & 165.132 & $10,65 \%$ & 1,54 \\
\hline 2004 & 337.762 & 173.476 & 164.286 & $10,65 \%$ & 1,53 \\
\hline 2003 & 330.523 & 169.469 & 161.054 & $10,50 \%$ & 1,53 \\
\hline 2002 & 328.155 & 168.191 & 159.964 & $10,70 \%$ & 1,52 \\
\hline 2001 & 327.107 & 168.050 & 159.057 & $10,60 \%$ & 1,51 \\
\hline 2000 & 336.912 & 172.823 & 164.089 & $10,90 \%$ & 1,49 \\
\hline 1999 & 338.295 & 173.349 & 164.946 & $11,20 \%$ & 1,51 \\
\hline 1998 & 345.123 & 176.597 & 168.526 & $11,40 \%$ & 1,53 \\
\hline 1997 & 357.313 & 184.259 & 173.054 & $11,60 \%$ & 1,55 \\
\hline 1996 & 372.453 & 190.697 & 181.756 & $12,00 \%$ & 1,59 \\
\hline 1995 & 381.998 & 196.326 & 185.672 & $12,60 \%$ & 1,64 \\
\hline 1994 & 386.159 & 198.399 & 187.760 & $13,10 \%$ & 1,67 \\
\hline
\end{tabular}

Fuente: Datos Macro, 2014

Como medida a la baja tasa de natalidad, fecundidad y el envejecimiento progresivo de la población, el Gobierno canadiense ha propuesto un nuevo plan de migración con el que se espera la llegada en los próximos 5 años entre 240.000 y 265.000 inmigrantes, en su mayoría de países asiáticos.

Con respecto a la esperanza de vida en Canadá, está subió a un promedio de 81.24 años en el 2012. No obstante, se ha demostrado que las mujeres son más longevas que los hombres pues la esperanza de es de 83.44 años y 79.14 respectivamente. 
Gráfico $N^{\circ}$ 2.7: Esperanza de vida de la población Canadiense.

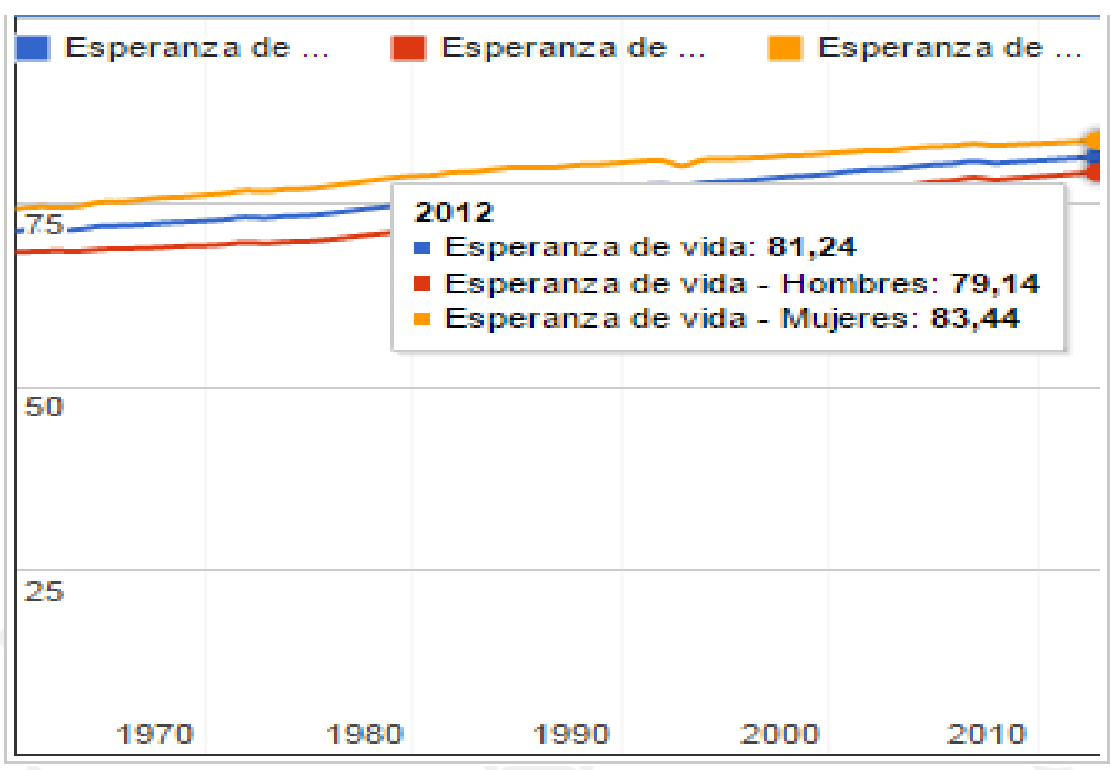

Fuente: Datos Macro, 2014

Asimismo, para el año 2061 (último dato disponible) se espera que Canadá alcance los 43,0 millones de habitantes en un escenario de bajo crecimiento y 63,8 millones en un escenario de alto crecimiento. Dichas estimaciones tienen implícitas CAGR de $0,4 \%$ y $1,2 \%$ sobre la población del año 2012, respectivamente. 
Gráfico $N^{o}$ 2.8: Estructura de edades de la población de Canadá

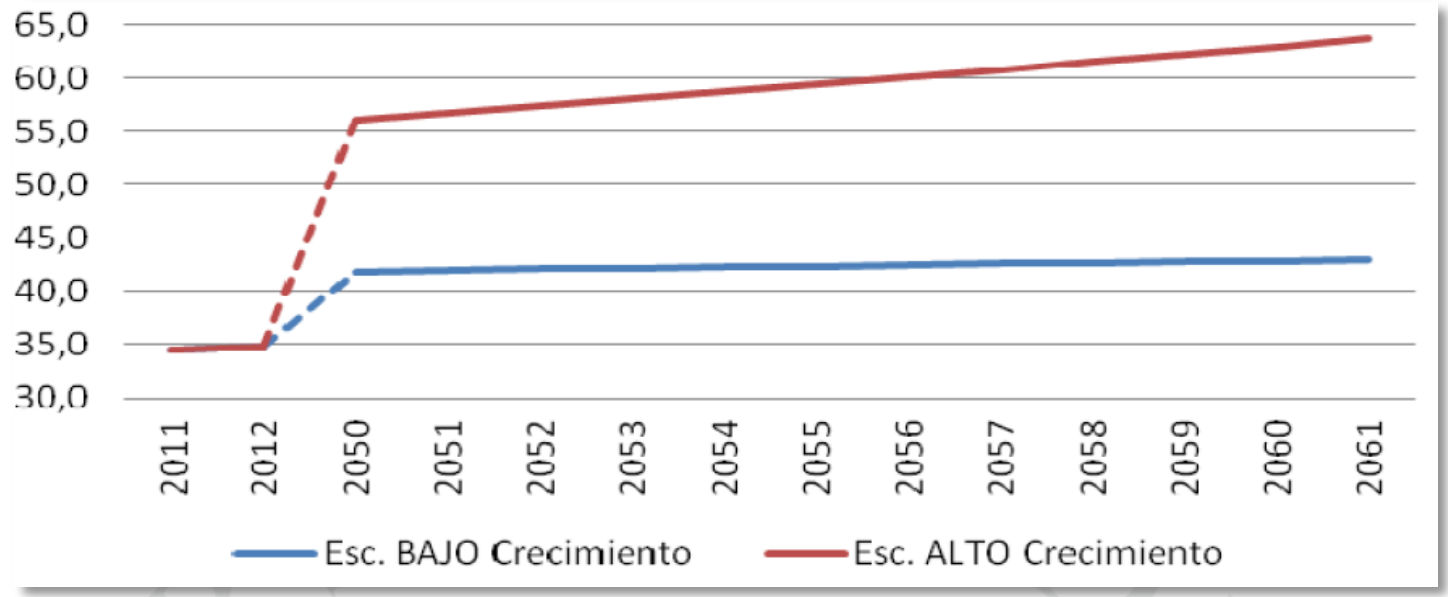

Fuente: Statistics Canada, 2013

En el siguiente gráfico se muestra la población de Canadá según rango de edades y sexo. Los datos evidencian una distribución bastante equitativa entre ambos sexos, donde el $49,6 \%$ del total corresponde a hombres y el 50,4\% a mujeres. A la vez, los rangos de edad entre 45- 49 y 50- 54 años son los que concentran la mayor cantidad de habitantes, donde además se observa que las mujeres tienen una mayor expectativa de vida. 
Imagen $N^{o}$ 2.1: Población según sexo y edad

\begin{tabular}{|c|c|c|c|c|c|c|}
\hline Cifras Año 2012 & Canadá & Hombres & Mujeres & Canadá & Hombres & Mujeres \\
\hline Grupo de edades & \multicolumn{3}{|c|}{ Nümero de personas } & \multicolumn{3}{|c|}{ \% del total en cada grupo } \\
\hline Población total & 34.880 .491 & 17.309 .143 & 17.571 .348 & 100,0 & 100,0 & 100,0 \\
\hline Menos de 5 añ்s & 1.928 .762 & 988.702 & 940.060 & 5,5 & 5,7 & 5,3 \\
\hline 5 a 9 años & 1.857 .086 & 955.026 & 902.060 & 5,3 & 5,5 & 5,1 \\
\hline 10 a 14 aก̃os & 1.877 .315 & 964.740 & 912.575 & 5,4 & 5,6 & 5,2 \\
\hline 15 a 19 айоos & 2.162 .960 & 1.108 .238 & 1.054 .722 & 6,2 & 6,4 & 6,0 \\
\hline 20 a 24 аก̆оos & 2.441 .086 & 1.254 .222 & 1.186 .864 & 7,0 & 7,2 & 6,8 \\
\hline 25 a 29 aก̃os & 2.452 .285 & 1.246 .818 & 1.205 .467 & 7,0 & 7,2 & 6,9 \\
\hline 350 a 34 aก̃os & 2.406 .319 & 1.203 .520 & 1.202 .799 & 6,9 & 7,0 & 6,8 \\
\hline 35 a 39 aกึos & 2.307 .219 & 1.155 .226 & 1.151 .993 & 6,6 & 6,7 & 6,6 \\
\hline 40 a 44 aก̃os & 2.384 .574 & 1.199 .401 & 1.185 .173 & 6,8 & 6,9 & $6, \pi$ \\
\hline 45 a 49 años & 2.681 .337 & 1.350 .108 & 1.331 .229 & 7,7 & 7,8 & 7,6 \\
\hline 50 a 54 años & 2.703 .198 & 1.352 .288 & 1.350 .910 & 7,7 & 7,8 & $7, \pi$ \\
\hline 55 a 59 años & $2,428.528$ & 1.199 .013 & 1.229 .515 & 7,0 & 6,9 & 7,0 \\
\hline 60 a 64 años & 2.063 .000 & 1.010 .196 & 1.052 .804 & 5,9 & 5,8 & 6,0 \\
\hline 65 a 69 años & 1.645 .143 & 797.942 & 847.201 & 4,7 & 4,6 & 4,8 \\
\hline 70 a 74 afios & 1.190 .654 & 563.820 & 626.834 & 3,4 & 3,3 & 3,6 \\
\hline 75 a 79 años & 924.085 & 418.918 & 505.167 & 2,6 & 2,4 & 2,9 \\
\hline 80 a 84 años & 718.825 & 303.603 & 415.222 & 2,1 & 1,8 & 2,4 \\
\hline 85 a 89 aก๊os & 450.986 & 164.114 & 286.872 & 1,3 & 0,9 & 1,6 \\
\hline 90 años y más & 257.129 & 73.248 & 183.881 & 0,7 & 0,4 & 1,0 \\
\hline
\end{tabular}

Fuente: Statistics Canada, 2013

Actualmente, en Canadá existe una preocupación por los niveles de obesidad infantil y adulta. Según datos de la Organización Mundial de la Salud en Canadá "en promedio entre 2000-2006 el 15,9\% de los hombres y $13,9 \%$ de las mujeres mayores de 15 años, eran obesos. La concienciación de los efectos de la dieta sobre el estado de salud, particularmente entre los sectores jóvenes canadienses, establece una tendencia hacia productos cada vez menos manipulados industrialmente y cuyos valores nutritivos no solo sean mesurables en cuanto a valores nutricionales, sino evidentes al tacto, vista y sabor". 
Los canadienses han logrado que la legislación de etiquetado contenga el mayor detalle posible de los factores nutricionales del producto con la finalidad de tener un completo conocimiento de los ingredientes que conforman los productos que van a consumir. Adicionalmente a ello, buscan aún que los alimentos que consumen estén en su totalidad libres de residuos tóxicos.

En conclusión, la preocupación social por la salud está incrementando cada vez más en este país por lo que el consumidor canadiense busca alimentos sanos y nutritivos, libres de grasas que puedan repercutir en contra de su salud y los lleven a engordar. En la actualidad se ha iniciado una ola de consumo de productos orgánicos los cuales han experimentado un gran crecimiento.

La Organización Mundial de la Salud (OMS), indica que "los canadienses consumen más del doble de la Cantidad Diaria Recomendada (CDR) por este organismo".

\subsubsection{Tecnológico (Industry Canada y The Canadian Internet)}

La economía de Canadá se ha mantenido fuerte, en parte por la inversión estratégica en áreas claves tales como ciencia, tecnología e innovación. Adicionalmente es reconocido a nivel internacional por la alta investigación que realiza en diferentes temas científicos, económicos, regionales, entre otros.

En el 2007, el Gobierno propone un plan estratégico para poder alcanzar una mejor economía. Actualmente, Canadá continúa con esta estrategia, sin embargo para posicionarse como un país con un nivel mundial de liderazgo en ciencia y tecnología, para lo cual ha implementado 3 pilares y cada uno de ellos cuenta con un rol indispensable. 
1. Pilar Personas: El Gobierno se encargara de desarrollar, atraer y retener personas con alta calificación y habilidades individuales con el fin de promover la investigación de temas de toda índole favorables para Canadá.

2. Pilar Conocimiento: El Gobierno brindará apoyo para fortalecer los proyectos de investigación e infraestructura.

3. Pilar Innovación: El Gobierno ayudará dando nuevas ideas y conocimiento del mercado, estimulando de esta manera el incremento de la demanda por innovación para poder atraer inversión directa extranjera.

Canadá es uno de los países más "conectado" del mundo, pues cerca del $87 \%$ de sus habitantes tiene internet en casa. En el 2013 se encontraba en el puesto 16 de los países con mayor penetración en términos de uso de internet.

Adicionalmente lo canadienses tienen un promedio de $3.7 \mathrm{~kb}$ mensuales de páginas web siendo el más alto a nivel mundial, en comparación al promedio global de visitas de páginas web que es $2.3 \mathrm{~kb}$. 


\section{Imagen $N^{o}$ 2.2: Penetración global de internet}

\begin{tabular}{|c|c|c|c|c|c|}
\hline & Country/Area & Internet Users & Rank & Penetration & Rank \\
\hline m & Falkland Islands & 2,842 & 208 & $96.9 \%$ & 1 \\
\hline 믐듬 & Iceland & 300,656 & 139 & $96.0 \%$ & 2 \\
\hline 들 & Norway & $4,471,907$ & 65 & $95.0 \%$ & 3 \\
\hline 믐 & Sweden & $8,557,561$ & 44 & $94.0 \%$ & 4 \\
\hline$E$ & Netherlands & $15,559,488$ & 32 & $93.0 \%$ & 5 \\
\hline 므 & Denmark & $5,155,411$ & 58 & $93.0 \%$ & 5 \\
\hline$=$ & Luxembourg & 468,348 & 132 & $92.0 \%$ & 7 \\
\hline 팜 & Bermuda & 63,070 & 178 & $91.3 \%$ & 8 \\
\hline+ & Finland & $4,789,266$ & 61 & $91.0 \%$ & 9 \\
\hline w & New Zealand & $3,873,982$ & 73 & $89.5 \%$ & 10 \\
\hline E & Liechtenstein & 32,824 & 195 & $89.4 \%$ & 11 \\
\hline 口 & Qatar & $1,719,437$ & 98 & $88.1 \%$ & 12 \\
\hline & Bahrain & $1,098,546$ & 117 & $88.0 \%$ & 13 \\
\hline 隶操 & United Kingdom & $54,861,245$ & 9 & $87.0 \%$ & 14 \\
\hline - & Monaco & 26,544 & 198 & $87.0 \%$ & 15 \\
\hline 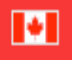 & Canada & $29,760,764$ & 20 & $86.8 \%$ & 16 \\
\hline II & Andorra & 73,540 & 175 & $86.4 \%$ & 17 \\
\hline$t$ & Faroe Islands & 42,226 & 186 & $85.3 \%$ & 18 \\
\hline$\$$ & Switzerland & $6,752,540$ & 49 & $85.2 \%$ & 19 \\
\hline E & United Arab Emirates & $4,517,169$ & 64 & $85.0 \%$ & 20 \\
\hline
\end{tabular}

Fuente: The Canadian Internet

\section{Imagen $N^{o}$ 2.3: Actividad global de internet}

\begin{tabular}{|c|c|c|c|c|}
\hline & Geography & $\begin{array}{l}\text { Average monthly } \\
\text { pages per visitor }\end{array}$ & $\begin{array}{l}\text { Average monthly } \\
\text { hours per visitor }\end{array}$ & $\begin{array}{l}\text { Average monthly } \\
\text { unique visitors (OOO) }\end{array}$ \\
\hline$+\div$ & Canada & 3,731 & 41.3 & 25,497 \\
\hline 鍳 & United States & 3,709 & 43.0 & 188,743 \\
\hline 武高 & United Kingdom & 3,432 & 38.9 & 39,318 \\
\hline & Russian Federation & 2,835 & 25.0 & 60,922 \\
\hline & France & 2,681 & 27.9 & 43,176 \\
\hline & Germany & 2,681 & 24.7 & 52,373 \\
\hline$\theta$ & Brazil & 2,345 & 27.9 & 45,762 \\
\hline & Worldwide & 2,278 & 24.6 & $1,519,489$ \\
\hline
\end{tabular}


Los canadienses tienden a utilizar diferentes dispositivos para conectarse a internet dependiendo de la actividad que estén realizando, estos pueden ser laptop, desktop, tablet y celular. Entre el 2012 y 2013, se obtiene que la principal actividad que se realiza utilizando internet es la recepción y envío de correos electrónicos (89\%), seguido por el uso de banca móvil (69\%) y en un tercer lugar el entretenimiento personal (64\%).

Sin embargo lo que llama la atención es que a pesar de tener un gran acceso a internet, el comercio electrónico en Canadá se viene desarrollando de manera lenta pues sólo el $45.5 \%$ de las empresas cuentan con una página web. En el 2012 un estudio reveló que el 3.4\% del gasto de la población es facturado a través del comercio electrónico, se pronostica que para el 2016 esta cifra ascenderá a 5.3\%. Las compras en líneas más frecuentes que realizan los canadienses son pasajes aéreos $(58 \%)$, entradas para eventos de entretenimiento (52\%), ropa, joyas y accesorios (42\%), libros, revistas y periódicos (52\%) y música (35\%).

Finalmente el uso de teléfonos móviles ha estado muy presente entre los usuarios canadienses debido a la gran infraestructura de telecomunicaciones que el país posee. Sin embargo en el año 2013 es cuando se hace notorio un incremento en el uso de teléfonos inteligentes teniendo como resultado que 6 de cada 10 canadienses cuenta con acceso a internet vía móvil, asimismo las subscripciones a celulares ascendió en un $10 \%$ en el último año y el $57 \%$ de los habitantes es dueño de un teléfono inteligente.

\subsubsection{Competitivo (The Global Competitiveness Report 2014-2015)}

De acuerdo índice de competitividad, Canadá está ubicado en el puesto 15 de 144 países. Cabe resaltar que el PBI de Canadá es aproximadamente el $2 \%$ del PBI mundial. 


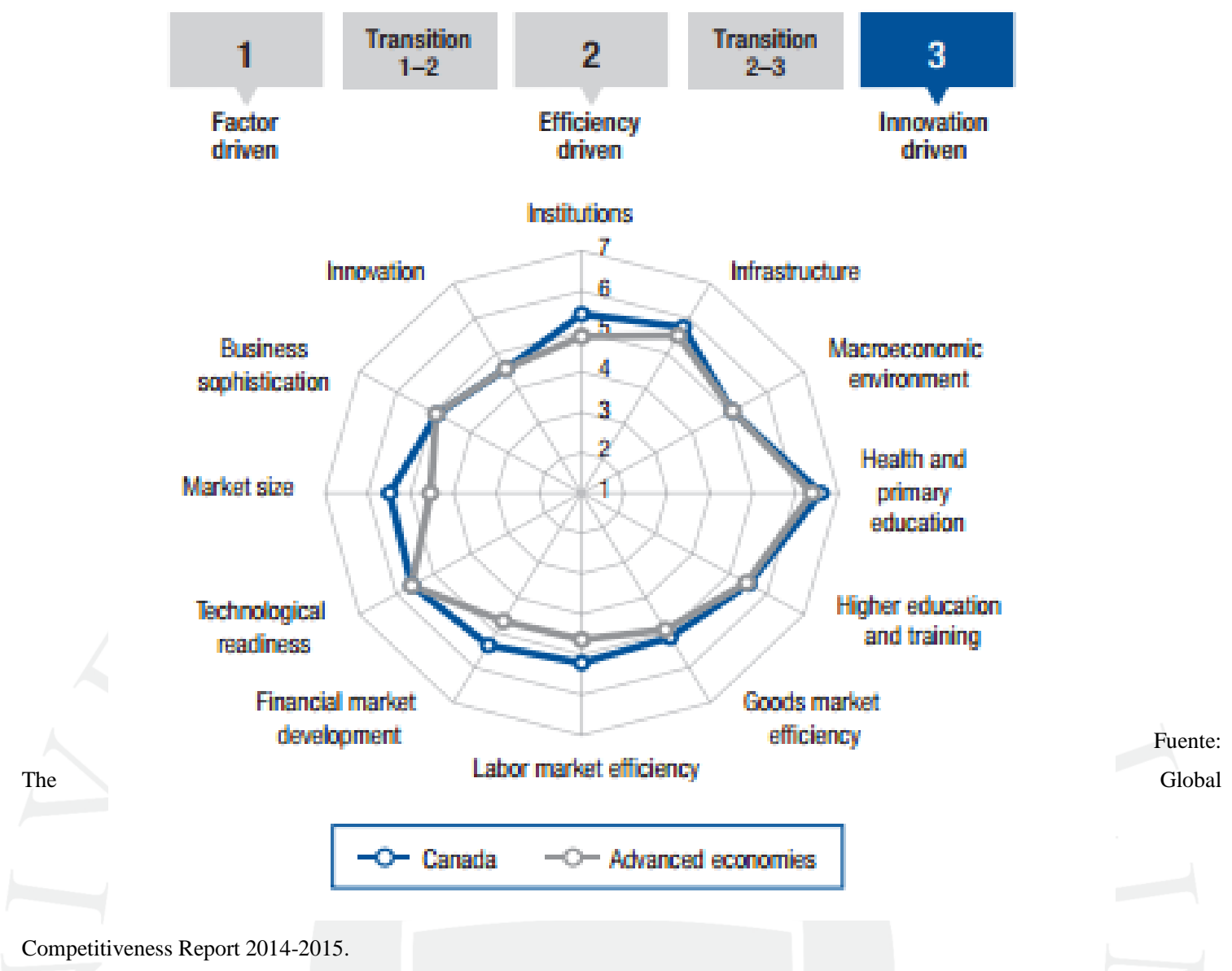

Como se observa en el gráfico 2.10, Canadá tiene un buen desempeño en los doce factores de competitividad que se evalúan. Sin embargo existen algunos de ellos en los que tienen un grado de evaluación mayor que de las economías avanzadas, entre ellos están:

- El tamaño de mercado, debido al poder adquisitivo que tiene el país. Además cabe mencionar que aproximadamente el $80 \%$ de su territorio es inhabitable debido a las bajas temperaturas por lo que su población esta concentrados en los estados limítrofes con Estados Unidos.

- Instituciones que permiten regular las leyes y normas establecidas, adicionalmente permite el desarrollo del comercio pues no genera cuellos de botella en tiempo de trámites, exportaciones, importaciones, etc.

- Eficiencia en el mercado de trabajo, esto se debe gracias a que el mercado laboral canadiense ha mantenido una tasa de participación de fuerza laboral más alta (la parte de la población en edad de trabajar que están trabajando bien o buscando trabajo activamente) que la de los Estados Unidos. Lo que 
indica que hay relativamente menos buscadores de empleo desalentados en Canadá, ya más de los desempleados están buscando trabajo y encontrarlo. (Jobs Report The State of the Canadian Labour Market, 2014)

- Adicionalmente vale la pena mostrar los factores más problemáticos para “doing business" en Canadá, los cuales se ha recomendado al Gobierno que dé prioridad y trabaje en ellos para mejorar la atracción de inversión privada al país.

Gráfico $N^{\circ} 2.9$ : Factores más problemáticos para "doing business”

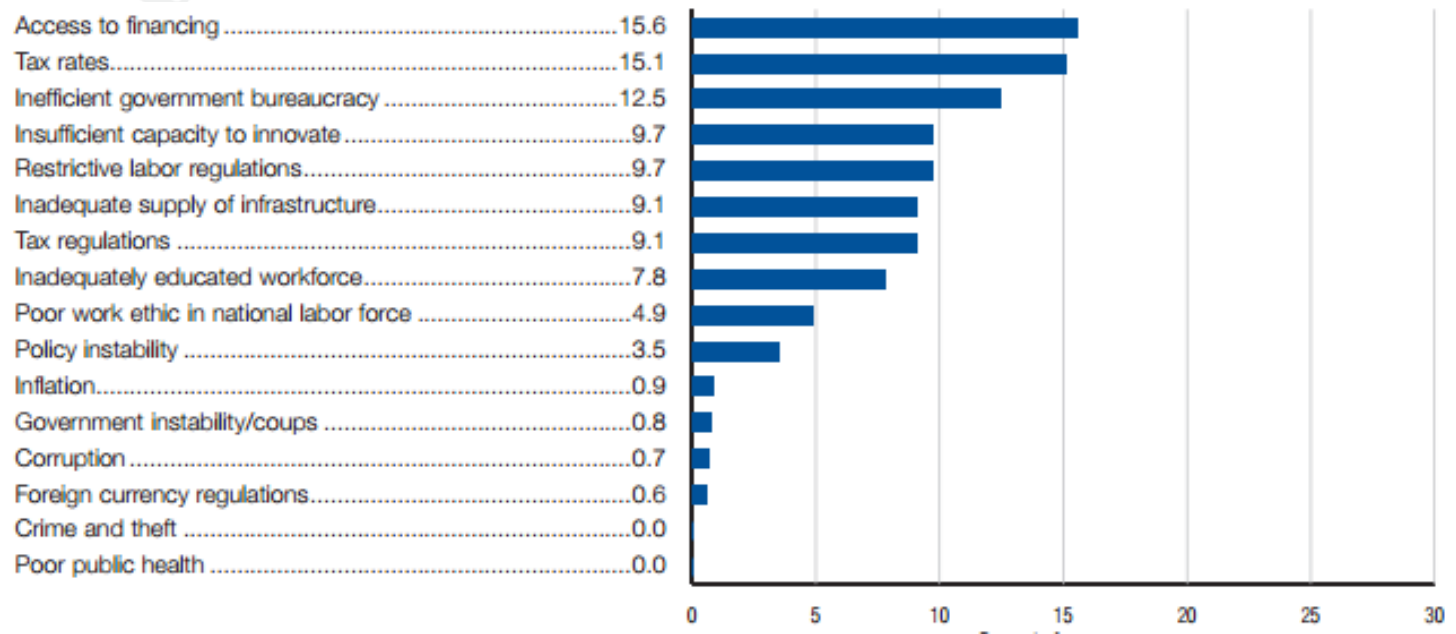

Fuente: The Global Competitiveness Report 2014-2015.

\subsection{Diamante Competitivo de Porter}




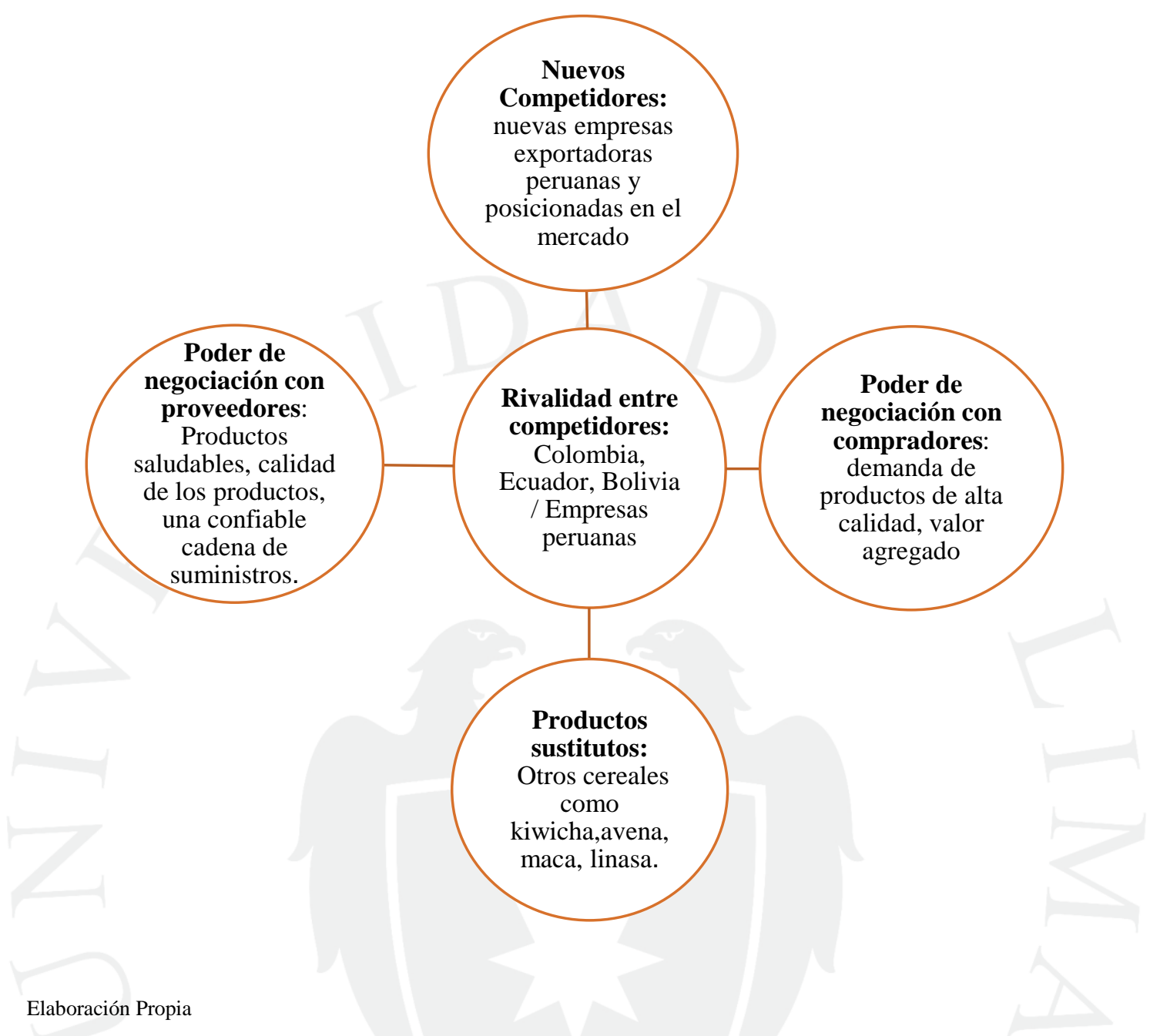

2.2.1. Amenaza de entrada de nuevos competidores

Las empresas exportadoras han empezado a diversificar e innovar sus productos de acuerdo a las necesidades y demanda de los consumidores, siendo esta la principal razón por la que ha incrementado el número de empresas que está produciendo y comercializando barra energéticas de nuevos cereales tales como quinua, maca entre otras; ofreciendo un producto novedoso, de calidad y saludable. Adicionalmente, cabe mencionar que Canadá cuenta con barreras de entrada para nuevas empresas.

En lo que respecta a competencia, los principales países exportadores de la partida arancelaria 190410 son países industrializados. 
Sin embargo en lo que respecta a países que sean economías en vías de desarrollo como la nuestra, Colombia se está desarrollando de manera rápida $\mathrm{y}$ firme en lo que respecta a productos innovadores $\mathrm{e}$ industrializados, además de tener la misma ventaja de nosotros frente a Canadá puesto que tienen una liberación de arancel.

\subsubsection{La rivalidad entre los competidores}

Las principales importaciones de barras energéticas a base de cereales (partida arancelaria 190410) al mercado canadiense provienen de Alemania, Estados y Reino Unido 14\%, $12.9 \%$ y $11.9 \%$ respectivamente. La ventaja de estos países en relación a Perú es que son economías desarrolladas, tienen una industrialización consolidada y se encuentran más cercanos a Canadá, por lo que sus costos de transporte disminuyen.

No obstante, lo expuesto arriba no es impedimento para nuestro país pues existen empresas peruanas como Global Alimentos S.A.C, Inka Crops S.A con $63 \%$ y $28 \%$ de participación en las exportaciones peruanas de la partida arancelaria 1904100000.

Como empresa nueva es importante reforzar nuestro posicionamiento a través de productos innovadores, valores agregados, satisfacción de necesidades del mercado, buen diseño y calidad.

\subsubsection{Poder de negociación de los proveedores}

En el año 2014 el aumento de la producción de quinua con respecto al año 2013 fue de más del 100\% colocando a Perú como el principal país productor de quinua teniendo una participación de $52 \%$ de la producción mundial aproximadamente esto ha sido consecuencia que el año 2013 fue muy importante para la quinua ya que se recibió un gran apoyo por parte del gobierno. 
Asimismo el incremento de la demanda de quinua provocará que muchos empresarios ingresen al cultivo y comercialización de la misma, lo cual provocará que exista una mayor oferta, por lo tanto habrá mayor competencia y los cultivos deberán ser más competitivos por lo que se infiere que la calidad del insumo mejorará. Esto nos permitirá crear una negociación a futuro con nuestro proveedor pues sentirá la seguridad de tener un ingreso constante por parte de su cliente, además es importante crear una alianza estratégica con nuestro proveedor para no encontrarnos desabastecidos de quinua.

\subsubsection{Poder de negociación de los compradores}

El segmento de mercado al que se dirige este plan de negocio posee un nivel de ingreso medio para arriba, por lo que están dispuestos a pagar un precio mayor por productos saludables y que aporten un gran valor nutricional.

Adicionalmente se debe tener en consideración que el consumidor canadienses es muy exigente con respecto al producto que van a comprar por lo que es necesario dar importancia a que en el etiquetado se encuentre toda la información nutricional necesaria, especificar la cantidad neta del producto y el los ingrediente. Asimismo "en lo que se refiere al empaque, los consumidores canadienses prefieren envolturas y etiquetas llamativas, que proporcionen información y que sean modernas con textos en inglés y, si es posible, en francés así como gramajes que van desde un empaque familiar (alrededor de 300 - 350 gramos) hasta presentaciones personales." (PROEXPORT, Preferencias de los compradores y consumidores Canadienses, 2013)

\subsubsection{Amenaza de ingreso de productos sustitutos}

El mercado canadiense tiene diversos proveedores de "snack bars" las cuales están subdividas en barra de desayuno, barras energéticas, barras de fruta, barras de granola, avena y otros cereales. Estas son a su vez productos sustitutos entre sí debido a que si el cliente 
no cuenta con un producto igual puede sustituir el cereal principal en que se encuentra basada la barra e inclinarse por otras: consumir una barra energética a base de granola.

\subsection{Hipótesis General}

La exportación de barras energéticas a base de quinua en Toronto, Canadá resulta una oportunidad de negocio para pequeñas empresas exportadoras, ofreciendo un producto con valor agregado y que cumple con los requerimientos de los consumidores canadienses con relación al consumo productos naturales y orgánicos que contribuyan con la salud.

Gracias al Tratado de Libre Comercio entre Perú y Canadá el cual está vigente desde el $1^{\circ}$ de Agosto del 2009, el producto ingresa al país con 0\% de arancel. Adicionalmente se puede aprovechar el gran aporte de valor nutricional que tiene el producto al contar con un insumo como la quinua (proteína, calcio, hierro, magnesio, etc.) y que además solo algunos países en el mundo cuentan con cultivos de la misma.

Por lo tanto, aprovechando estas oportunidades del entorno se debe implementar una empresa exportadora de barras energéticas a base de quinua.

\subsubsection{Hipótesis Específicas}

a) El cambio en la tendencia de consumo hacia alimentos saludables y orgánicos, genera una gran oportunidad para las barras energéticas a base de quinua.

b) La estrategia de distribución que el proyecto debe utilizar es a través de supermercados y tiendas minoristas de productos naturales. 


\section{CAPÍTULO 3: PLAN DE NEGOCIO}

\subsection{Información General del Proyecto}

\subsubsection{Datos generales de la empresa}

\subsubsection{Nombre}

La empresa Eco Crops S.A.C. se encarga de la producción y comercialización de barras energéticas a base de quinua.

\subsubsection{Ubicación}

La empresa Eco Crops S.A.C. cuenta con oficinas ubicadas en el departamento de Lima, teniendo a la empresa Agrícola Anahui S.A.C como primordial proveedor de quinua, también con sede en Lima.

\subsubsection{Proceso productivo}

El proceso productivo de las barras energéticas a base de quinua inicia con la recepción de la quinua blanca dada por la empresa Agrícola Anahui S.A.C. Luego se procede con la selección de los granos de quinua y revisión de su certificación, junta con los demás ingredientes: almendras, granola, pasas y azúcar rubia para la elaboración del producto. Una vez seleccionada la quinua a utilizar, se mezcla la misma con los demás ingredientes, mencionados anteriormente. Se introduce la mezcla al horno industrial y posteriormente se moldea lo que se ha horneado con la máquina moldeadora universal. Esta moldeadora estruje la masa para darle forma y hacer diseños. Finalmente lo que se ha desmoldado pasa a ser empaquetado y embalado para su exportación.

\subsubsection{Comercialización}

El producto, barras energéticas a base de quinua, será comercializado a través de un bróker que será quien introducirá nuestro producto en tiendas minoristas y supermercados de productos naturales, en donde el cliente conoce los beneficios de consumir este tipo de productos y por los cuales tiene una preferencia. Por ende, se cuenta con 
un cliente dispuesto a pagar un mayor precio por un producto nutritivo y saludable.

Promperu, Perfil Producto - Mercado, Quinua Canadá señala: “Dado que gran porcentaje de la quinua consumida en Canadá posee alguna certificación, la distribución y comercialización de este producto sigue la siguiente dinámica"

\section{Imagen $N^{o}$ 3.1: Canales de distribución y comercialización para la quinua}

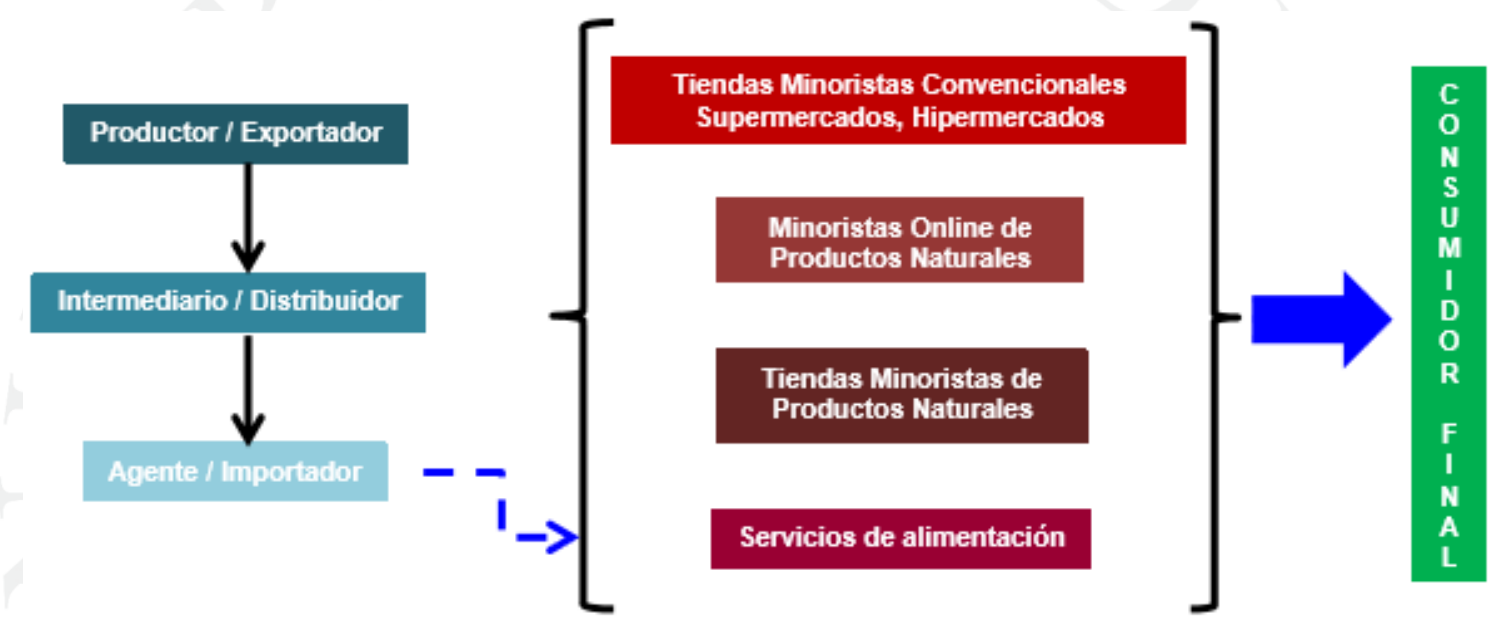

Fuente: Promperu, Perfil Producto - Mercado, Quinua - Canadá 2014

"De acuerdo a un informe de la Asociación Canadiense de Comercio Orgánico el canal con mayor participación lo conforman las tiendas minoristas convencionales (45\% del total). Estas tiendas están representadas por cadenas como Loblaw, Metro, Sobeys, Safeway, entro otros”. (PROMPERU, 2014, Perfil Producto-Mercado, Quinua-Canadá pág. 5)

\subsubsection{Identificación de la oportunidad de negocio}

La oportunidad de negocio radica en la gran producción de quinua que Perú tiene. Nuestro país por tradición ha cultivado este grano focalizándose la mayor parte de la producción principalmente en la zona alto andina con aproximadamente unos 4,100 msnm en los departamentos de Ayacucho, Junín y Puno. Los principales países productores en el 
mundo de la misma son Bolivia, Perú y Ecuador, los cuales gracias a sus condiciones climatológicas y geográficas permiten que este cultivo sea productivo en la zona.

En los últimos años la producción de quinua en el Perú ha ido incrementando ligeramente sin embargo, en el año 2014 el aumento de la producción con respecto al año 2013 fue de más del 100\% colocando a Perú como el primer país productor de quinua.

A continuación, en el gráfico $\mathrm{N}^{\circ} 3.1$ se muestra el crecimiento en la producción nacional de quinua en los últimos 6 años.

\section{Gráfico $N^{o}$ 3.1: Producción nacional de quinua (miles de toneladas)}

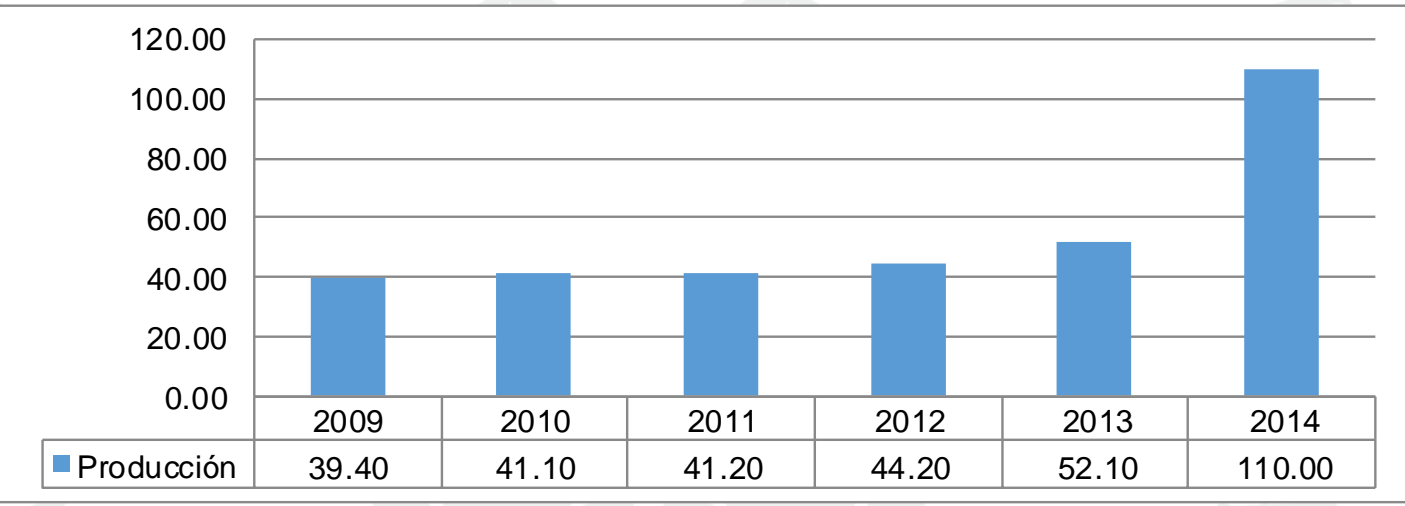

Fuente: Minagri

Por otro lado, el crecimiento de las exportaciones de quinua y sus principales destinos nos brinda una guía que nos permita conocer la demanda a nivel mundial del insumo base de nuestro producto final.

A continuación en el gráfico $\mathrm{N}^{\circ} 3.2$ se muestra la evolución de las exportaciones en los últimos 5 años, donde se puede observar que un aproximado del $33.58 \%$ de la producción es destinada al consumo en otros países y esta curva se encuentra en crecimiento.

En el año 2014, el Perú ha exportado 36’339,823 toneladas las cuales han representado en nuestra balanza comercial 196' 627, 941 dólares. (ADEX, 2015, Ranking de partidas arancelarias exportadas). 
Gráfico $N^{o}$ 3.2: Exportaciones de Quinua (miles de toneladas)

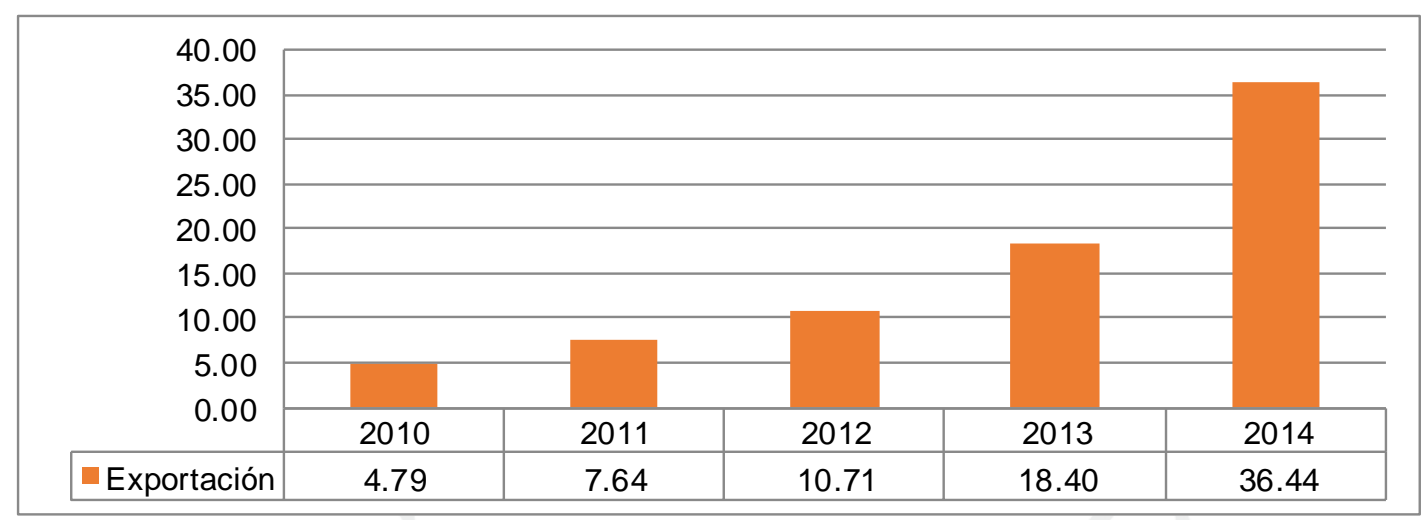

Fuente: Minagri

Adicionalmente, es necesario evaluar las exportaciones de quinua a nuestro país de destino y su evolución en los últimos cinco años. En la siguiente tabla se observa que Canadá es el segundo país importador de quinua procedente de Perú teniendo un aumento en el último año de $31.69 \%$ pasando de UD\$ 6’512,718 a USD\$20’547,997.

Tabla $N^{o}$ 3.1: Principales destino de exportación (millones de dólares).

\begin{tabular}{|l|r|r|r|r|r|}
\hline \multicolumn{1}{|c|}{ País } & \multicolumn{1}{c|}{$\mathbf{2 0 1 0}$} & \multicolumn{1}{c|}{$\mathbf{2 0 1 1}$} & \multicolumn{1}{c|}{$\mathbf{2 0 1 2}$} & \multicolumn{1}{c|}{$\mathbf{2 0 1 3}$} & \multicolumn{1}{c|}{$\mathbf{2 0 1 4}$} \\
\hline Estados Unidos & $8,420.91$ & $14,315.38$ & $20,538.32$ & $42,518.29$ & $100,073.56$ \\
\hline Canadá & 558.41 & $1,235.16$ & $1,563.94$ & $6,512.78$ & $20,547.99$ \\
\hline Holanda & 55.51 & 309.52 & 612.89 & $2,617.68$ & $12,774.05$ \\
\hline Australia & 390.57 & $1,155.50$ & $1,442.77$ & $5,927.09$ & $9,668.90$ \\
\hline Inglaterra & 6.05 & 52.61 & 506.10 & $4,516.66$ & $9,112.88$ \\
\hline Otros & $3,601.72$ & $6,845.49$ & $6,049.47$ & $15,109.07$ & $43,835.15$ \\
\hline Total & $\mathbf{1 3 , 0 3 3 . 1 7}$ & $\mathbf{2 3 , 9 1 3 . 6 6}$ & $\mathbf{3 0 , 7 1 3 . 4 9}$ & $\mathbf{7 7 , 0 6 6 . 1 7}$ & $\mathbf{1 9 5 , 5 2 3 . 4 1}$ \\
\hline
\end{tabular}

Minagri

La valorización por parte de los mercados internacionales hacia este grano nativo ha incrementado notablemente y esto se puede atribuir al alto valor proteico donde la calidad de sus proteínas y balance son 
evidentemente superiores. Asimismo cabe resaltar que el $37 \%$ de las proteínas que posee la quinua está formado por aminoácidos esenciales.

Finalmente, se sabe que los segmentos que tienen más crecimiento en Canadá en lo respecta al sector alimentos son el orgánico y étnico, "estos han formado un lazo común de interés entre los consumidores por alternativas saludables, naturales y de buen sabor. Así, desde que los canadienses consumen más alimentos orgánicos, muchos alimentos étnicos, especialmente los de origen hindú, latino y asiático, se están uniendo a la tendencia étnico convertido en orgánico". (PROMPERU, 2014, pág.3).

\subsubsection{Objetivos del plan de negocios}

Además de los objetivos mencionados y explicados en los incisos 1.3. Objetivo general y 1.3.1. Objetivos específicos, se cuenta con objetivos de marketing y de operaciones.

Los objetivos de marketing del proyecto son:

a) Utilizar la marca país con el fin de ser reconocido como producto peruano.

b) Contar con una página web que permita ser buscado y conocido por los clientes finales, brindándoles información sobre el producto que permita crear un lazo de confianza con el mismo.

c) Ingresar con una participación mínima, a un supermercado o tienda minorista canadiense en el primer año con el objetivo de incrementar las oportunidades de comercio.

d) Participar en ferias internacionales durante los primeros 5 años tales como "SIAL y CPMA" las cuales tienen lugar en Toronto; con el fin de conocer a mayor profundidad el mercado canadiense, tener acceso a posibles compradores y conocer la competencia mundial tanto directa como indirecta. 
e) Utilizar el método de costing para establecer los precios en base a los costos de elaboración del producto final, adicionándole un margen de utilidad por el uso de insumos orgánicos. También se debe tener en cuenta la franja de precios de los competidores en Canadá.

Adicionalmente, los objetivos de operaciones son:

a) Iniciar el negocio contando con un proveedor de quinua blanca.

b) Establecer parámetros que permitan obtener una quinua de óptima calidad y certificada.

c) Cumplir con las normas establecidas por Canadian Food Inspection Agency para cumplir con los requisitos de empaquetado y etiquetado del mercado canadiense.

\subsubsection{Estrategia del proyecto}

Para poder ingresar al mercado canadiense el exportador necesita contar con un producto de calidad que le permita diferenciarse frente a la competencia y tener una participación en el mercado de destino.

Por lo tanto, para poder lograrlo se debe recurrir a la marca país para de esta manera poder ser identificado como un producto de calidad y que utiliza insumos naturales. "La Marca País es una herramienta de promoción del Perú que tiene como objetivo impulsar los sectores turismo, exportaciones, inversiones y la imagen del país principalmente en los ámbitos de gastronomía, arte y cultura, deporte, educación y desarrollo de valores y autoestima nacional, a nivel nacional e internacional". (MINCETUR, Reglamento para el Uso de Marca País, 2012, pág. 2). Según el Reglamento para el Uso de Marca País, se establecen cuatro puntos para los cuales no se puede usar la Marca Perú y son los siguientes: políticos, religiosos, contrarios a la Constitución Política del Perú y perjudiciales para la imagen del país. Asimismo el único ente que puede otorgar esta licencia es PROMPERU, la misma que puede tener un plazo no mayor a dos años con la opción a renovación de 
la misma. La Marca Perú se puede otorgar para los siguientes usos: (Ver mayor detalle en el Anexo 2)

1. Uso Institucional: La empresa, nacional o extranjera, que adquiera la licencia y se convierta en embajador de la marca.

2. Uso productos: Es indispensable que las canastas de productos que se registren contengan un mínimo de $80 \%$ de productos exclusivamente peruanos.

3. Uso en eventos: Cuando un evento este promocionando la imagen del país.

4. Los productos de marca blanca también pueden contar con la licencia de Marca Perú, con la condición que estos sean producidos con la finalidad de ser exportados.

Además se debe considerar el interés por productos de consumo rápido que no cuenten con elevadas calorías, con el fin de mantener niveles adecuados de salud. Ello se debe a que el consumidor canadiense usualmente está interesado en productos de rápido consumo. Para esto el insumo principal de nuestras barras la quinua, es un producto que poco a poco se está haciendo más conocida, por lo que su consumo ha aumentado sobre todo por personas que están interesadas en mejorar su salud y sus hábitos alimenticios. La quinua es un alimento que ayuda a reducir el riesgo de osteoporosis, aminorar los efectos de la menopausia, ayuda con la cicatrización de heridas, regenera la flora intestinal, desinfecta las vías urinarias, refuerza el sistema inmunológico y demás

Asimismo es un alimento que es muy nutritivo pues posee más hierro, calcio y fósforo que el huevo o la carne con la excepción que no tiene grasas, colesterol ni gluten y aporta un alto contenido de omega 3, 6 y 9 , por que se recomienda su consumo en personas de todas las edades. 
Otra estrategia a considerar para el proyecto es la optimización de los costos a lo largo del tiempo con el fin de obtener mayores ganancias. Ello se logrará a través de las negociaciones con los proveedores de insumos, buscando beneficios económicos para ambas partes.

\subsection{Estudio de Mercado}

\subsubsection{Análisis de la demanda}

\subsubsection{Definición del producto}

El producto a exportar son barras energéticas a base de quinua $\mathrm{y}$ otros ingredientes como pasas, almendras, granola, entre otros de nombre Eco Crops S.A.C Siendo un suplemento alimenticio de gran fuente de carbohidratos y proteínas, el cual presenta un alto contenido de aminoácidos esenciales.

La quinua como se ha mencionado anteriormente es un alimento nutritivo que brinda muchos beneficios a la salud pues contribuye a fortalecer el sistema inmunológico, además que es un alimento bajo en grasas, alto en proteína y aminoácidos que puede ser consumido por todas las personas inclusive celiacos.

El producto del proyecto será comercializado en barras de $25 \mathrm{~g}$ con medidas aproximadas de $10 \mathrm{~cm}$ largo x $3 \mathrm{~cm}$ de ancho x $2 \mathrm{~cm}$ de alto.

\subsubsection{Características físicas}

Nuestro producto tiene una composición sólida, hecha a base de quinua proveído por la empresa Agrícola Anahui S.A.C A continuación se detalla los ingredientes y sus respectivos pesos para poder elaborar una barra energética de 25 gramos. 
Tabla $N^{o}$ 3.2: Composición de una barra energética Eco Crops S.A.C

\begin{tabular}{|l|r|}
\hline \multicolumn{1}{|c|}{ Ingrediente } & Cantidad \\
\hline Quinua Blanca & $10 \mathrm{gr}$ \\
\hline Almendras & $2 \mathrm{gr}$ \\
\hline Pasas & $2 \mathrm{gr}$ \\
\hline Granola & $8 \mathrm{gr}$ \\
\hline Azucar rubia & $3 \mathrm{gr}$ \\
\hline Agua & $15 \mathrm{ml}$ \\
\hline \multicolumn{2}{|c}{} \\
\multicolumn{2}{|c}{ Elaboración Propia }
\end{tabular}

\subsubsection{Propiedades del producto}

En nuestro país, "existen alrededor de tres mil tipos de quinua. El grano que más se produce es de color blanca, pero también destacan la amarilla, rosada, roja, gris y negra. Las diminutas semillas de esta última concentran gran cantidad de nutrientes y la convierten en el alimento más proteico”. (PROMPERU, Quinua, 2013, pág. 22)

Como se conoce el ingrediente principal en nuestras barras energéticas es la quinua blanca que es una planta herbácea oriunda de América Latina, teniendo ubicada la mayor parte de su producción en la zona del Titicaca entre Perú y Bolivia. Esta planta alcanza una tamaño entre $0.5 \mathrm{~cm}$ y 2 metros de altura, sus semillas o granos son donde se concentra la mayor cantidad del valor nutricional por lo mismo que son la parte que se comercializa de esta planta. Estos granos cuentan con un diámetro de entre 1.8 y $2.2 \mathrm{~mm}$ y dependiendo de la clase de quinua pueden ser de diferentes colore: blanco, café, amarillo, rosadas, rojas y negras

Adicionalmente la quinua cuenta con un aminoácido llamado lisina, el cual es esencial para "el desarrollo de las células del cerebro, por eso se relaciona con el desarrollo de la inteligencia, la rapidez de los reflejos y otras funciones cerebrales como la memoria y el aprendizaje". (La Quinua: Cultivo Promisorio del Siglo XXI, María Mercedes Abad, Grupo Comunicarte-Radios Comunitarias Colombia, Año 2012.) 
La quinua, es un producto que poco a poco se está haciendo más conocida, por lo que su consumo ha aumentado sobre todo por personas que están interesadas en mejorar su salud y sus hábitos alimenticios. La quinua es un alimento que ayuda a reducir el riesgo de osteoporosis, aminorar los efectos de la menopausia, ayuda con la cicatrización de heridas, regenera la flora intestinal, desinfecta las vías urinarias, refuerza el sistema inmunológico y demás.

Asimismo es un alimento que es muy nutritivo pues posee más hierro, calcio y fósforo que el huevo o la carne con la excepción que no tiene grasas, colesterol ni gluten y aporta un alto contenido de omega 3, 6 y 9, por que se recomienda su consumo en personas de todas las edades.

Según la Food and Agriculture Organization (FAO), "La Quinua es uno de los pocos alimentos de origen vegetal que es nutricionalmente completo, es decir, que presenta un adecuado balance de proteínas, carbohidratos y minerales, necesarios para la vida humana"

A continuación se muestra una tabla con la composición química y valor nutricional de la misma.

Tabla $N^{o}$ 3.3: Composición química y valor nutricional (contenido en 100gr.)

\begin{tabular}{|l|r|}
\hline \multicolumn{1}{|c|}{ Elemento } & \multicolumn{1}{c|}{ Valor } \\
\hline Agua & $11.20 \%$ \\
\hline Proteínas & $11.70 \%$ \\
\hline Grasas & $6.30 \%$ \\
\hline Carbohidratos & $68.00 \%$ \\
\hline Ceniza & $2.80 \%$ \\
\hline Fibra & $5.20 \%$ \\
\hline
\end{tabular}

Fuente: Quinua.pe

En la tabla 3.3 se puede observar que la quinua es un alimento que tiene poca humedad, lo cual es una ventaja para su conservación ya 
que no va a sufrir de oxidación y deterioro del grano permitiendo desarrollo por ejemplo de hongos.

También se observa que tiene un gran contenido de carbohidratos por lo que se considera un alimento completo y se recomienda incluirla en dietas de todas las personas y especialmente en deportistas, niños y adultos mayores.

La quinua es caracterizada por tener un elevado contenido de proteína siendo un alimento de procedencia vegetal, pues la calidad de la misma y el balance que esta tiene es superior a la de otros granos, fluctuando entre $10 \%$ a $12 \%$.

Como se menciona en el inciso 3.2.1.3, la quinua tiene un aminoácido en gran proporción que es la lisina sin embargo, no es el único que la compone pues cuenta con diez de ellos. A continuación se detalla una tabla comparativa de estos aminoácidos en relación a otros granos.

Tabla 3.4: Contenido de aminoácidos en la quinua y otros granos (mg/100gr de proteínas)

\begin{tabular}{|c|c|c|c|c|c|}
\hline & Trigo & Cebada & Avena & Maíz & Quinua \\
\hline Isoleucina & 32 & 32 & 24 & 32 & 68 \\
\hline Leucina & 60 & 63 & 68 & 103 & 104 \\
\hline Lisina & 15 & 24 & 35 & 27 & 79 \\
\hline Fenilamina & 34 & 37 & 35 & 27 & 79 \\
\hline Tirosina & 16 & 17 & 16 & 14 & 41 \\
\hline Cistina & 26 & 28 & 45 & 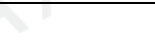 & 68 \\
\hline Metionina & 10 & 13 & 14 & 16 & 18 \\
\hline Treonina & 27 & 32 & 36 & 39 & 40 \\
\hline Triptofano & 6 & 11 & 10 & 5 & 16 \\
\hline Valina & 37 & 46 & 50 & 49 & 76 \\
\hline
\end{tabular}

Fuente: Quinua.pe 
Como se puede visualizar la quinua es el grano más completo con respecto a contenido de aminoácido y cada uno de ellos tiene una función particular en nuestra salud. Cabe mencionar algunas de ellas, la tirosina es un aminoácido que tiene un efecto anti estrés y es fundamental para evitar posibles depresiones y contrarrestar la ansiedad. Asimismo la lisina mejora la función del sistema inmunológico desarrollando anticuerpos, ayuda en la reparación celular y participa en el metabolismo de ácidos grasos. Con respecto a la isoleucina, leucina y valina colaboran en la producción de energía muscular, prevén daños hepáticos y mantienen los niveles de azúcar en la sangre.

\subsubsection{Sub partida nacional}

La barra energética a base de quinua para exportación tiene una subpartida nacional N¹904100000, lo cual se detalla a continuación.

\section{Tabla $N^{0}$ 3.5: Partida arancelaria}

\begin{tabular}{|l|c|l|}
\hline \multicolumn{2}{|l|}{ Partida Arancelaria } & Descripción \\
\hline $\begin{array}{l}\text { Sub-Partida del } \\
\text { Sistema Armonizado }\end{array}$ & 190410 & $\begin{array}{l}\text { Productos a base de Cereales, obtenidos por inflado o } \\
\text { tostado. }\end{array}$ \\
\hline Sub-Partida Nacional & 1904100000 & $\begin{array}{l}\text { Productos a base de Cereales, obtenidos por inflado o } \\
\text { tostado. }\end{array}$ \\
\hline
\end{tabular}

Fuente: SIICEX.

\subsubsection{Producción en el Perú}

Como se ha mencionado anteriormente en la investigación, el sector productivo de quinua en el Perú ha presentado una tendencia de crecimiento en los últimos dos años (ver gráfico $\mathrm{N}^{\circ} 3.1$ ). La cual se ha visto impulsada por una mayor demanda del producto debido a su excelente aporte nutritivo y gastronómico. 
Gráfico $N^{o}$ 3.3: Producción nacional y exportación (miles de toneladas)

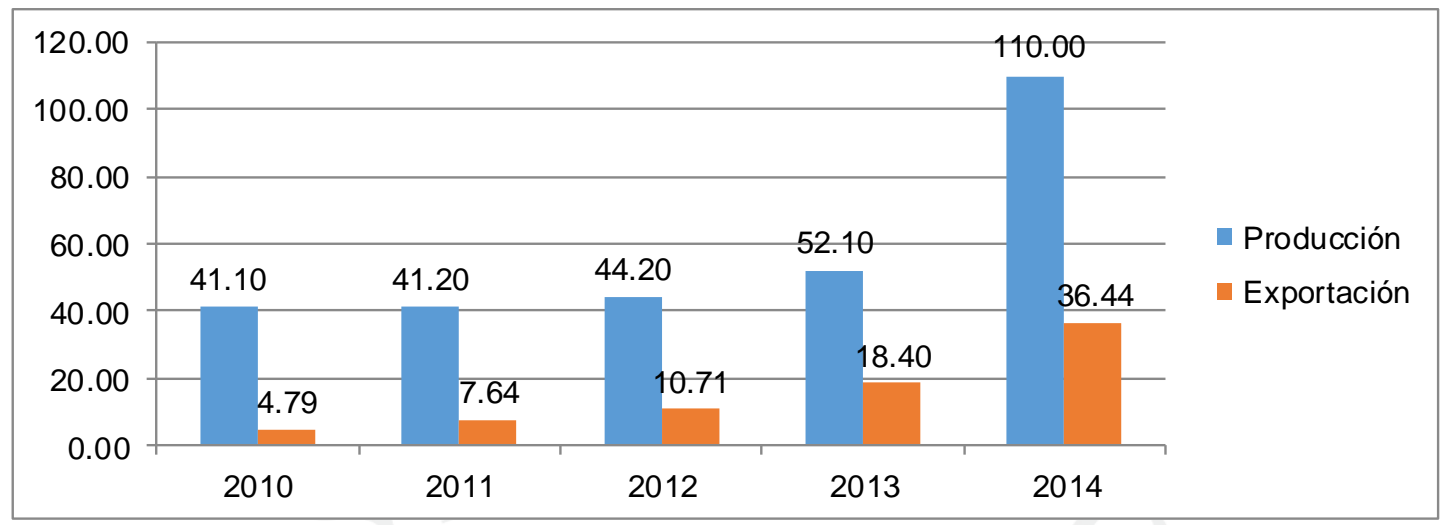

En el gráfico 3.3 se puede observar que tanto la producción nacional de quinua como la exportación de la misma han tenido una curva de crecimiento bastante constante hasta el año 2013, el cual fue declarado Año Internacional de la Quinua por lo que el gobierno Peruano a lo largo del mismo incentivo el desarrollo de la producción de la misma teniendo resultados en el año siguiente. En el año 2014 la producción tuvo un crecimiento mayor al $100 \%$ con respecto al año anterior.

Como consecuencia del incremento de la producción peruana de quinua y la promoción por parte de la FAO y el gobierno peruano con respecto al grano andino se observa en el año 2014 un crecimiento bastante notorio de $98.04 \%$ aproximadamente con relación al año anterior.

A continuación en el gráfico 3.4 se observa la distribución de la producción de quinua en el Perú, la cual en su mayoría se ve representada en la región de Puno que significa el $80 \%$ de la producción nacional de quinua, le sigue Cusco, Ayacucho y Junín cada una de ellas con una participación del 4\% en la producción del Perú. 


\section{Gráfico $N^{o}$ 3.4: Producción de quinua en el Perú}

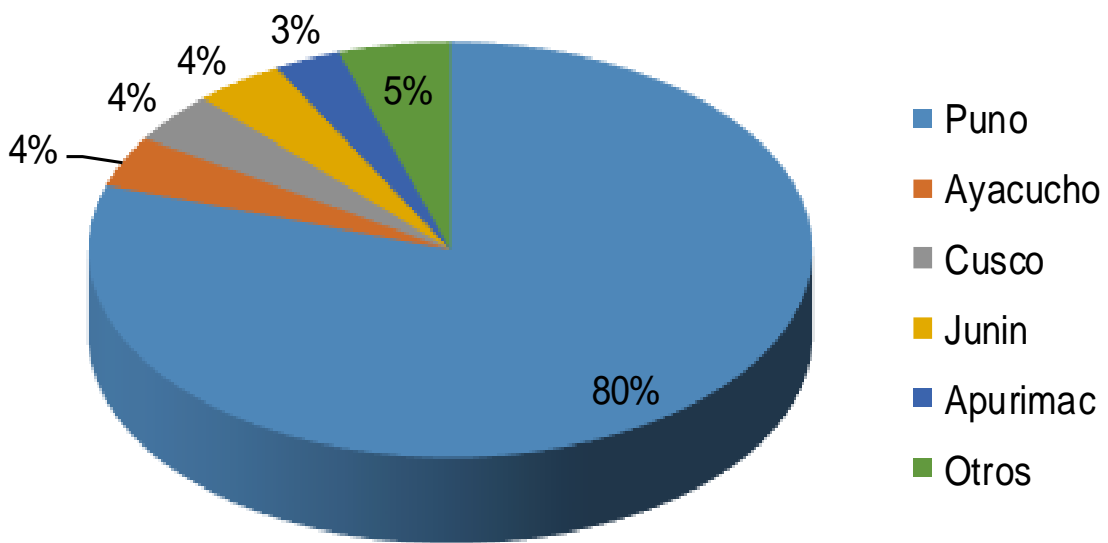

Fuente: Minagri

Por otro lado, la quinua en el Perú se puede cultivar desde el nivel del mar hasta los 4,000 $\mathrm{m}$ de altitud. Tiene un tiempo de crecimiento que oscila entre los 90 y 220 días, el cual depende de la variedad de quinua que se está cultivando. En una hectárea se puede llegar a producir entre 3 y 5 toneladas de grano de quinua, asimismo se obtiene por cada hectárea una aproximada de 4 toneladas de materia seca con un contenido de $18 \%$ de proteínas, que le da un potencial como planta forrajera.

Imagen $N^{o}$ 3.2: Producción de quinua en el Perú 


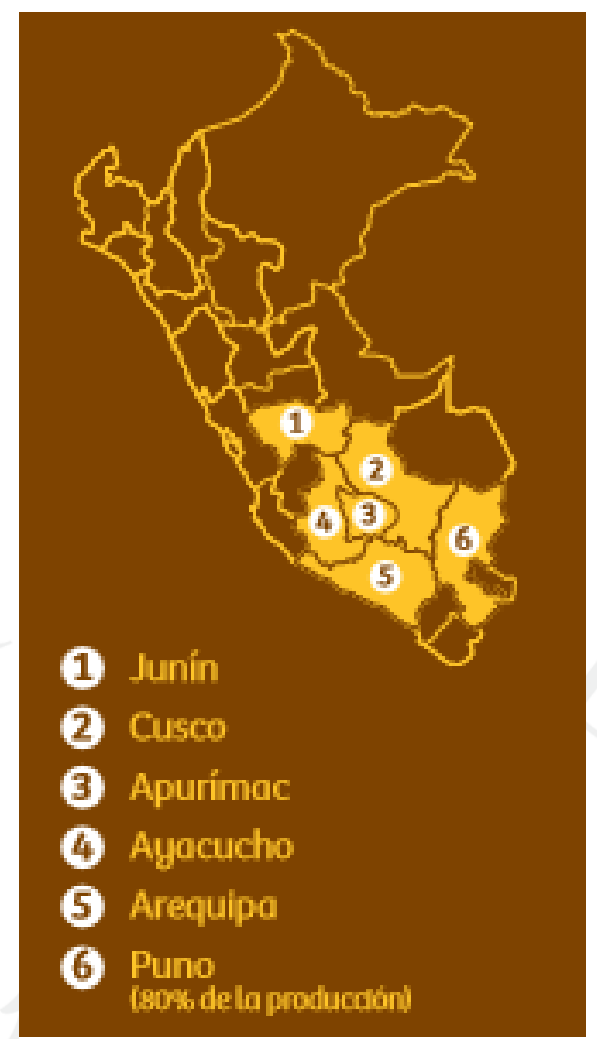

Fuente: Quinua.pe

Para nuestro proyecto la ubicación estratégica será Lima (Metropolitana) al ser distribuido la quinua la empresa Agrícola Anahui S.AC

\subsubsection{Demanda histórica y presente}

Tabla $N^{o}$ 3.6: Demanda histórica y presente de Canadá en Peso Neto (Kg) y Valor FOB de la Partida Arancelaria 1904100000: Productos a base de Cereales, obtenido por inflado o tostado.

\begin{tabular}{|c|r|r|}
\hline Años & Peso Neto (Kg) & Valor FOB (USD) \\
\hline 2009 & 61.96 & 256.22 \\
\hline 2010 & 34.76 & 189.59 \\
\hline
\end{tabular}




\begin{tabular}{|l|r|r|}
\hline 2011 & $2,011.13$ & $5,642.57$ \\
\hline 2012 & $30,200.62$ & $121,493.51$ \\
\hline 2013 & $5,121.91$ & $35,537.74$ \\
\hline 2014 & $14,306.33$ & $73,343.78$ \\
\hline
\end{tabular}

Fuente: http://www.siicex.gob.pe/promperustat/frmPaises_x_Partida.aspx

Gráfico $N^{o}$ 3.5: Demanda Histórica Anual de la Partida Arancelaria 1904100000: Productos a base de Cereales, obtenido por inflado o tostado.

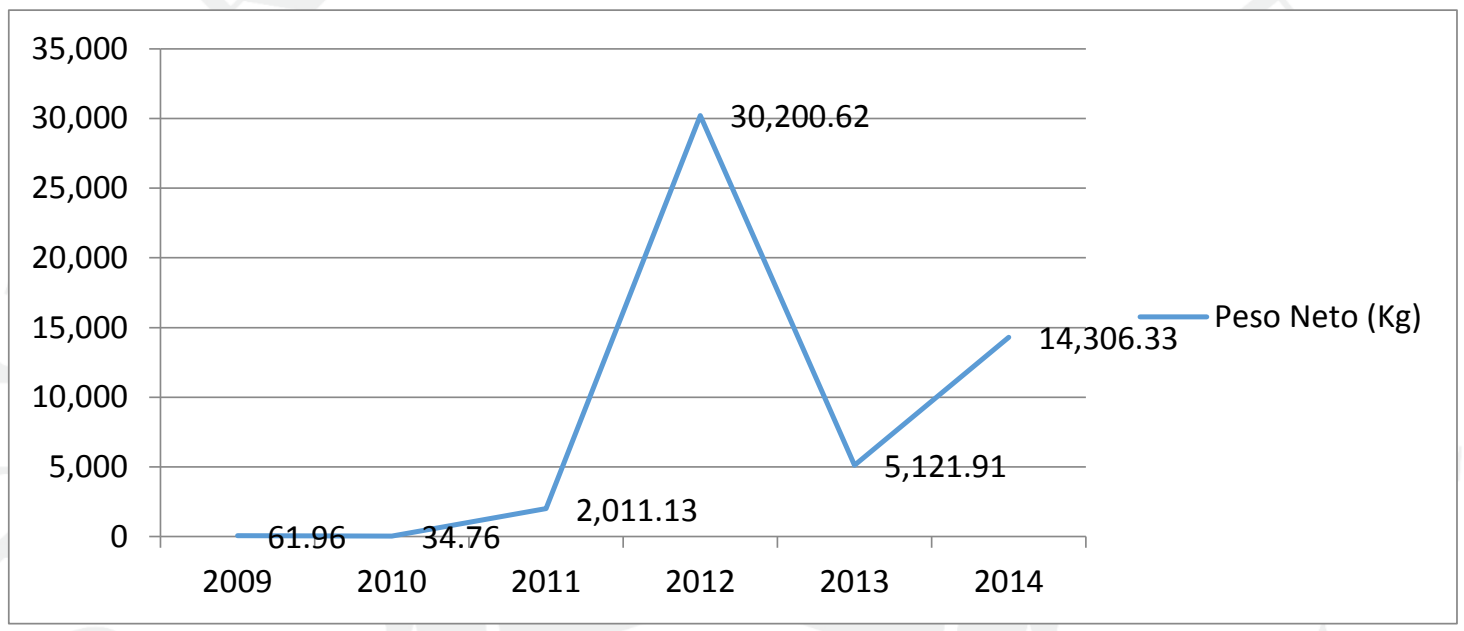

Fuente: http://www.siicex.gob.pe/promperustat/frmPaises_x_Partida.aspx

Se puede observar en el gráfico $\mathrm{N}^{\circ} 3.5$ que desde el año 2009 hasta el 2010 la demanda histórica y presente en peso neto $(\mathrm{kg})$ y valor FOB (USD) es ligeramente constante y a partir de fines del año 2010 comienza a tener crecimiento en la demanda, teniendo un aumento significativo en el año 2012 con el ingreso de nuevas empresas peruanas exportadoras de la partida arancelaria 190401, la cual se ha mencionado anteriormente que es muy general para determinar la demanda histórica de nuestro producto. En el año 2013 las exportaciones de esta partida arancelaria cayeron debido a que la economía en el Perú en el sector agroexportador empieza a contraerse y las exportaciones son menores. 
Los años más significativos son el 2010 por tener la menor cantidad exportada hacia Canadá (34.76 kilogramos) y menos valor FOB anual (USD 189.59). Adicionalmente el año 2012 por ser el de mayor cantidad exportada de la partida arancelaria hacia el mercado de destino (30, 200.62 kilogramos) que equivale al mayor valor FOB anual (USD 121,493.51).

Asimismo, se debe recalcar como ya se ha mencionado en la investigación Canadá es el segundo destino de exportación de quinua peruana y poco a poco se está teniendo mayor confianza en este insumo en el mercado de destino obteniendo como resultado una mayor demanda de productos derivados de la misma.

\section{Gráfico 3.6: Exportaciones de Quinua Peruana a Canadá}

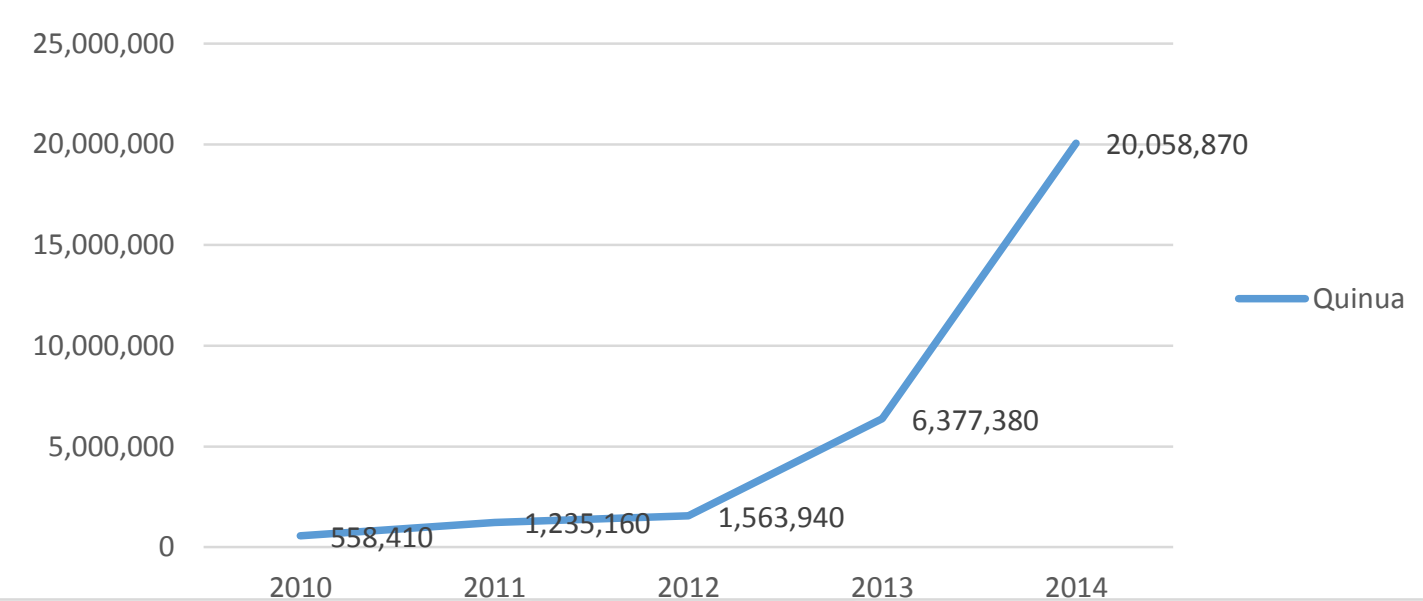

Fuente: Minagri

Como se ha mencionado en el párrafo anterior, Canadá es el segundo mercado de destino al cual se dirigen las exportaciones de quinua, el gráfico 3.6 nos permite tener un alcance del crecimiento del principal insumo de nuestras barras energéticas. En el año 2014 se puede observar que las exportaciones aumentan en más de un $100 \%$ con respecto al año anterior lo que posiciona a Canadá como un mercado con oportunidad de expansión y de productos a base de quinua. 


\subsubsection{Variables que afectan la demanda}

\subsubsection{Precio del bien}

El precio del bien es un factor importante a analizar, por lo tanto se debe tomar información histórica de los últimos 6 años (2009 al 2014). A continuación se muestra el detalle.

Tabla Nº 3.7: Valor FOB unitario de la Partida Arancelaria1904100000 Productos a base de Cereales, obtenido por inflado o tostado (USD/kg).

\begin{tabular}{|c|r|r|c|}
\hline Años & Peso Neto (Kg) & Valor FOB (USD) & Valor FOB unitario (USD/kg) \\
\hline 2009 & 61.96 & 256.22 & 4.14 \\
\hline 2010 & 34.76 & 189.59 & 5.45 \\
\hline 2011 & $2,011.13$ & $5,642.57$ & 2.81 \\
\hline 2012 & $30,200.62$ & $121,493.51$ & 4.02 \\
\hline 2013 & $5,121.91$ & $35,537.74$ & 6.94 \\
\hline 2014 & $14,306.33$ & $73,343.78$ & 5.13 \\
\hline
\end{tabular}

Fuente: http://www.siicex.gob.pe/promperustat/frmPaises_x_Partida.aspx

Gráfico Nº 3. 7: Valor FOB unitario de la Partida Arancelaria1904100000 Productos a base de Cereales, obtenido por inflado o tostado (USD/kg).

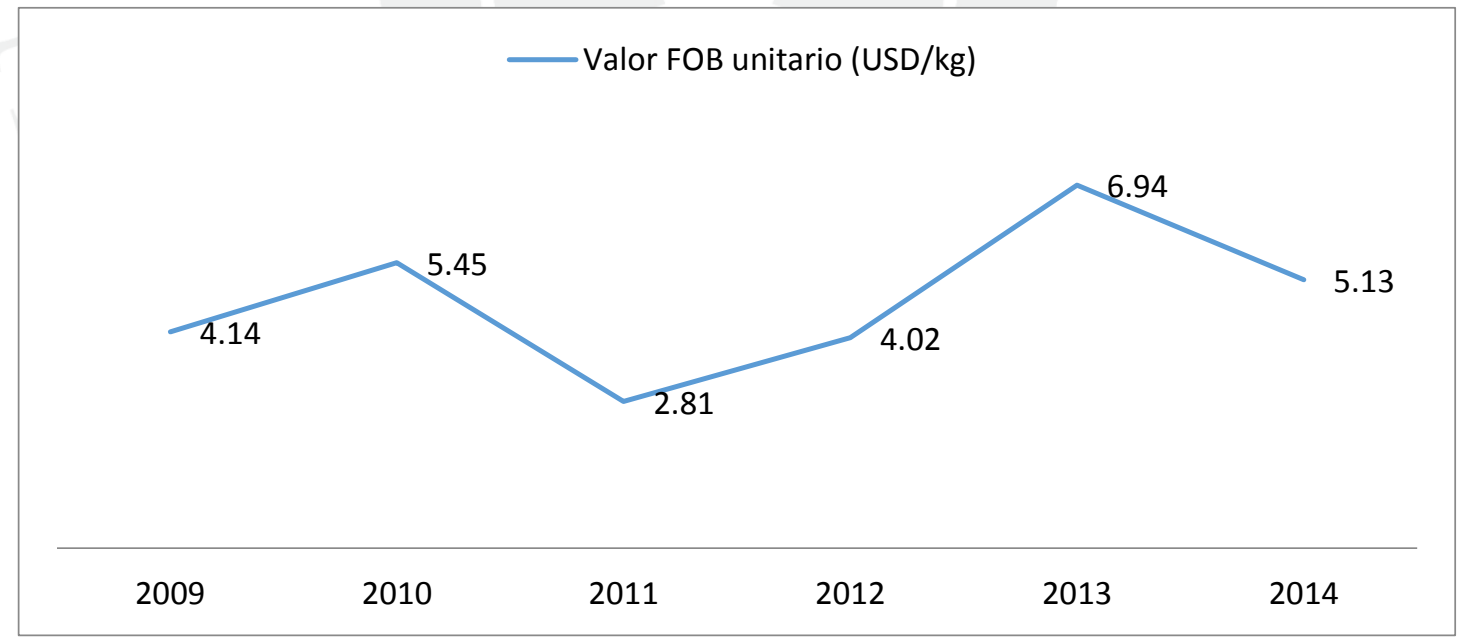

Fuente: http://www.siicex.gob.pe/promperustat/frmPaises_x_Partida.aspx

\subsubsection{Gustos y preferencias}

Actualmente, Canadá cuenta con un hábito de consumo de productos alimenticios que "ha incentivado las compras de porciones 
individuales de alimentos, que además deben ser naturales y ofrecer beneficios para la salud... el consumidor canadiense tiene gran aceptación por productos tipo Gourmet, generando oportunidades para alimentos orgánicos que sean prácticos y de fácil asimilación”. (PROEXPORT COLOMBIA, 2012, pág. 1)

Según Euromonitor, los productos con cualidades bien definidas y relevantes tuvieron un buen desempeño, mientras que los productos que fueron enriquecidos con carbohidratos fracasaron. Por ejemplo, "FF snack bar" tuvieron mucha actividad en la última parte del periodo de revisión porque el formato snack-bar se presta bien para la fortificación del cuerpo. Alto contenido de proteínas y fibra en los productos que el buen gusto fueron abrazados por los consumidores y vieron fuertes retornos.

\subsubsection{Tendencias en el mercado de destino (PROMPERU, Perfil de producto-mercado, 2011).}

Las tendencias en Canadá dependen de ciertos aspectos, tales como:

- Comportamiento del consumidor.- Mayor consciencia de los problemas medioambientales y de consumo excesivo. Se ve más de cerca la calidad de un producto, como también su origen, composición y precio.

- Perfil de consumidor y poder adquisitivo.- Nuestro nicho de mercado son personas mayores de 45 años, que tienen como característica principal una gran preocupación por su alimentación siendo el motivo principal por lo que no dudan en comprar productos a base de insumos naturales y orgánicos.

- Inmigración.- Se está presentando una fuerte inmigración al oeste de Canadá, sobretodo en British Columbia y Alberta. Los inmigrantes provienen en su mayoría de origen asiático y esto ha generado una combinación de culturas y preferencias con distintos hábitos de consumo y alimentación. 
- Salud.- Se requiere de dietas más nutritivas pues se tiene una mayor concientización de la salud y el envejecimiento de la población. Por lo mismo que se prefieren productos naturales como frutas $\mathrm{y}$ verduras.

\subsubsection{Demanda futura}

\subsubsection{Demanda potencial}

Para determinar la demanda potencial, se ha utilizado información de Euromonitor International, quienes indican que los alimentos en barras se dividen en 4 categorías:

- Barras de desayuno

- Barras nutritivas y energéticas

- Barras de frutas

- Barras de granola

- Otras barras

Euromonitor nos permite cuantificar la cantidad de alimentos en barra que se consume en Canadá. Para finales del 2015, se proyecta que su consumo alcance las 52.50 mil toneladas. Nuestro producto, barras energéticas a base de quinua, está dentro de la categoría de "Barras nutritivas y energéticas". La demanda potencial para este año es de 5.50 mil toneladas.

El sistema de Euromonitor permite proyectar el consumo para los próximos años. En la siguiente tabla se presenta la demanda potencial proyectada.

Tabla $N^{o}$ 3.8: Demanda anual proyectada de Canadá de barras snack por categoría. ('000 toneladas)

\begin{tabular}{|l|c|c|c|c|c|}
\hline & $\mathbf{2 0 1 5}$ & $\mathbf{2 0 1 6}$ & $\mathbf{2 0 1 7}$ & $\mathbf{2 0 1 8}$ & $\mathbf{2 0 1 9}$ \\
\hline Barras de desayuno & 13.30 & 13.40 & 13.40 & 13.50 & 13.50 \\
\hline $\begin{array}{l}\text { Barras nutritivas y } \\
\text { energéticas }\end{array}$ & 5.50 & 5.50 & 5.60 & 5.70 & 5.70 \\
\hline Barras de fruta & 5.40 & 5.50 & 5.50 & 5.50 & 5.50 \\
\hline
\end{tabular}




\begin{tabular}{|l|c|c|c|c|c|}
\hline Barras de granola/muesli & 26.50 & 26.80 & 27.00 & 27.30 & 27.50 \\
\hline Otras barras & 1.80 & 1.80 & 1.80 & 1.80 & 1.80 \\
\hline Total & $\mathbf{5 2 . 5 0}$ & $\mathbf{5 3 . 0 0}$ & $\mathbf{5 3 . 3 0}$ & $\mathbf{5 3 . 8 0}$ & $\mathbf{5 4 . 0 0}$ \\
\hline
\end{tabular}

Fuente: Euromonitor

En el siguiente gráfico se puede observar la demanda proyectada exclusivamente para barras nutritivas y energéticas en el mercado Canadiense para los próximos cinco años, adicionalmente se puede observar que tiene una tendencia positiva con un crecimiento aproximado de $1.81 \%$ cada dos años.

Gráfico $N^{\circ}$ 3.8: Proyección de la demanda de Canadá de barras nutritivas y energéticas (toneladas).

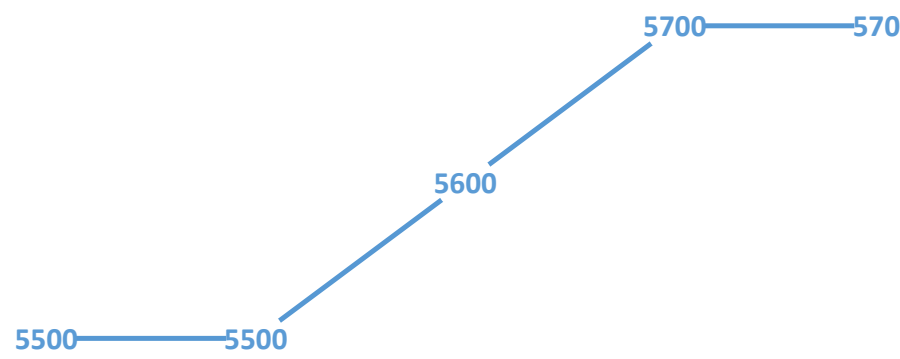

$\begin{array}{lllll}2015 & 2016 & 2017 & 2018\end{array}$

Fuente: Euromonitor

Con el fin de mostrar la demanda proyectada del año 2015 al 2019 de manera cuantitativa y exclusivamente del producto barras nutritivas y energéticas, se detalla en el siguiente cuadro las cantidades en toneladas:

Tabla $N^{o}$ 3.9: Demanda proyectada de barras nutritivas y energéticas.

\begin{tabular}{l|l} 
Año & Cantidad
\end{tabular}




\begin{tabular}{|l|l|}
2015 & 5,500 \\
\hline 2016 & 5,500 \\
\hline 2017 & 5,600 \\
\hline 2018 & 5,700 \\
\hline 2019 & 5,700 \\
\hline
\end{tabular}

Fuente: Euromonitor

\subsubsection{Demanda objetivo}

Primero se debe definir el segmento de mercado al cual se dirige el producto, para poder obtener el cálculo de la demanda objetivo, actualmente Canadá está compuesto por $35^{\prime} 540,400$ habitantes de los cuales 6’055,700 habitan en Toronto, que es nuestro mercado meta. Adicionalmente, como se ha mencionado anteriormente en esta investigación nuestro producto está dirigido a una población de 45 años en adelante, tanto hombres como mujeres, de los cuales el $15.7 \%$ son mayores de 65 años.

Nuestra demanda objetivo incrementará paulatinamente en los próximos cinco años, a continuación se detalla la misma. 
Tabla $N^{o}$ 3.10: Proyección de la participación de mercado en Canadá con barras nutritivas y energéticas.

\begin{tabular}{|c|c|}
\hline Año & Cantidad \\
\hline 2015 & $0.11 \%$ \\
\hline 2016 & $0.13 \%$ \\
\hline 2017 & $0.15 \%$ \\
\hline 2018 & $0.16 \%$ \\
\hline 2019 & $0.19 \%$ \\
\hline
\end{tabular}

Tabla No 3.11: Demanda anual objetivo (toneladas).

\begin{tabular}{|c|c|}
\hline Año & Cantidad \\
\hline 2015 & 5.88 \\
\hline 2016 & 7.05 \\
\hline 2017 & 8.23 \\
\hline 2018 & 9.40 \\
\hline 2019 & 10.58 \\
\hline
\end{tabular}

Gráfico 3.9: Demanda anual objetivo (toneladas)

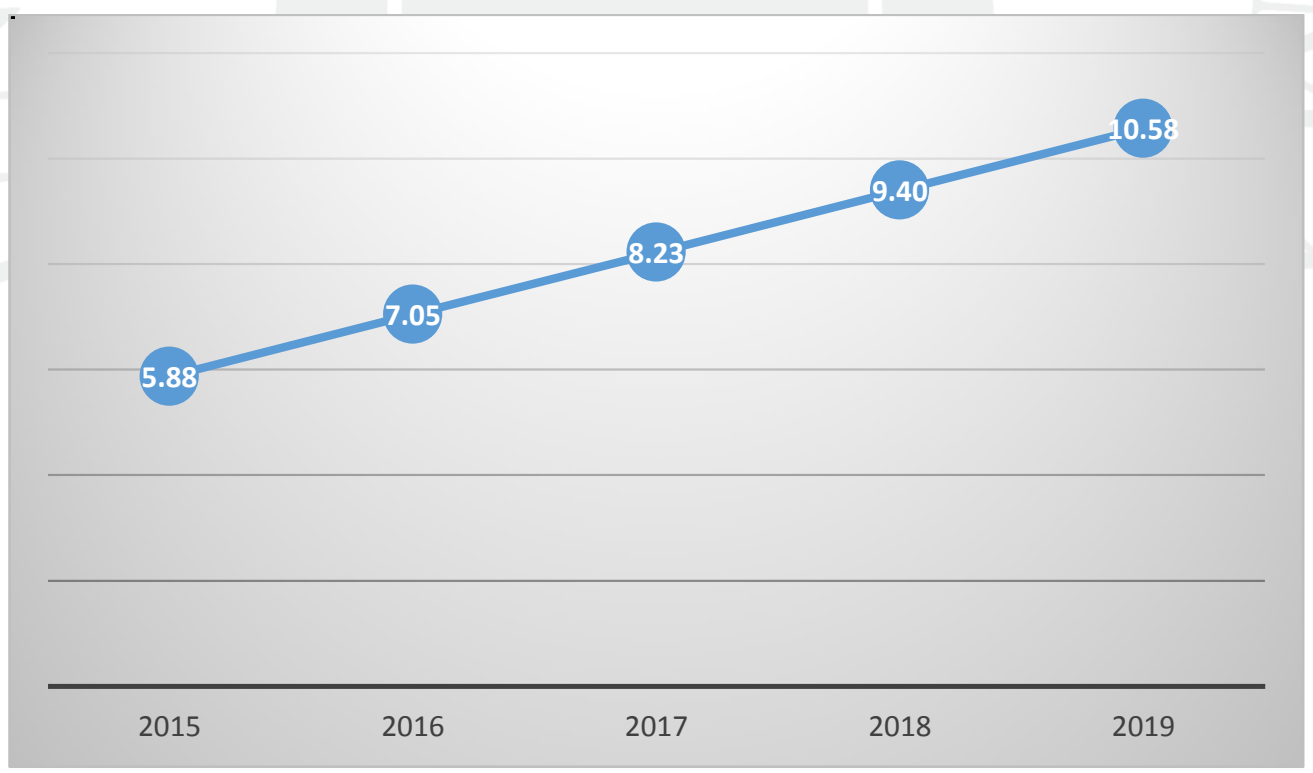

Elaboración Propia

En el gráfico $\mathrm{N}^{\circ} 3.8$ se puede observar que la demanda objetivo va a aumentar al 2019 en $80.00 \%$ respecto al 2015 lo cual se considera un potencial desarrollo del producto en destino. 


\subsubsection{Análisis de la competencia}

\subsubsection{Análisis de la competencia local}

Las barras energéticas a base de quinua se encuentran dentro de la partida bolsa 1904100000. En el año 2014, 37 empresas peruanas exportaron con esta partida a 27 mercados. Canadá no se encuentra dentro de los principales destinos de exportación ( $13^{\circ}$ puesto). Los principales 5 países son Ecuador, Estados Unidos, Bolivia, Colombia y Panamá.

Gráfico $N^{\circ}$ 3.10: Distribución de los principales mercados de exportación de la partida arancelaria 1904100000: Productos a base de Cereales, obtenido por inflado o tostado, en el año 2014.

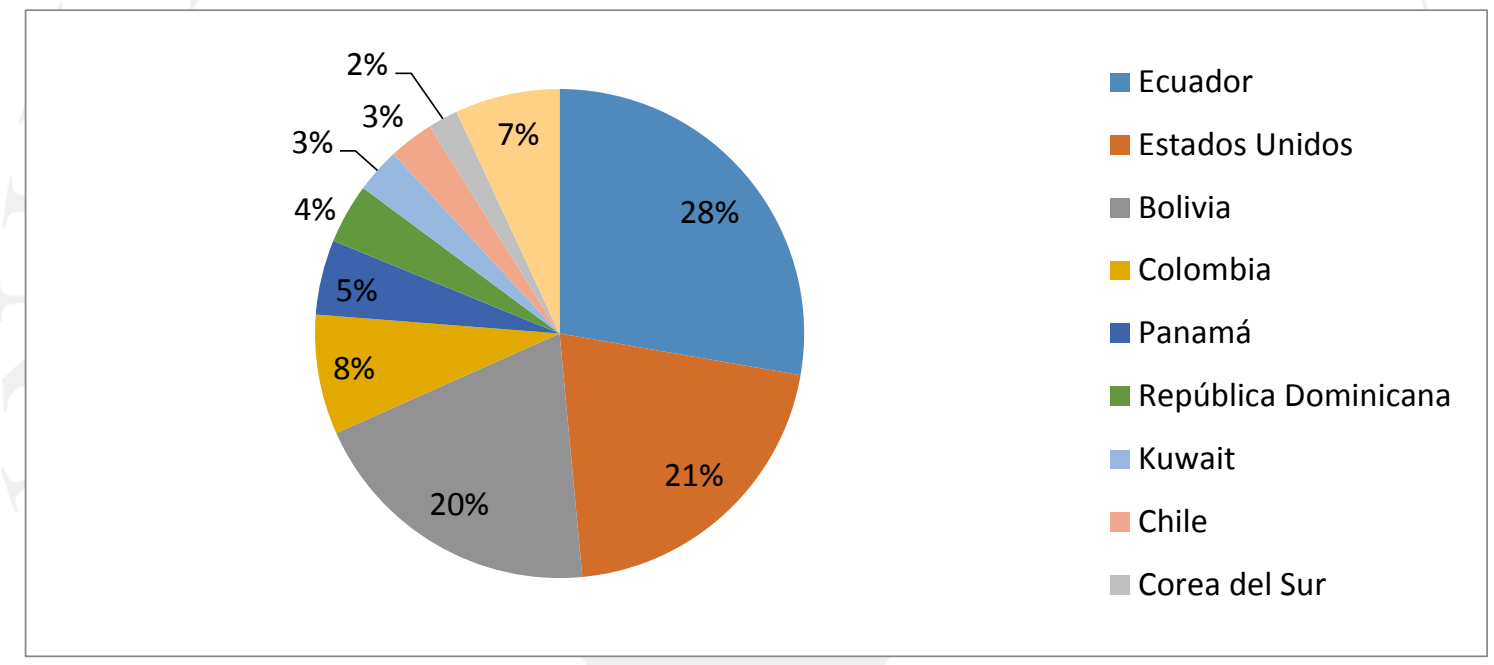

Fuente: SIICEX.

Solo son 3 las empresas que exportaron el 2014 a Canadá con la partida mencionada anteriormente. De esto se puede concluir que la rivalidad dentro de esta industria es leve, y que podemos salir a competir al mismo nivel que ellos.

\subsubsection{Principales empresas exportadoras peruanas}

Como se explicó en el punto anterior, solo 3 empresas exportaron con la partida 1904100000 a Canadá el 2014:

- Inka Crops S.A (USD 48,738.00) 
- De Guste Group S.A.C. (USD 24,528.42)

- $\quad$ Top Grade S.A.C. (USD 77.36)

\section{Gráfico $N^{o}$ 3.11: Principales empresas exportadoras peruanas de la partida} arancelaria 1904100000

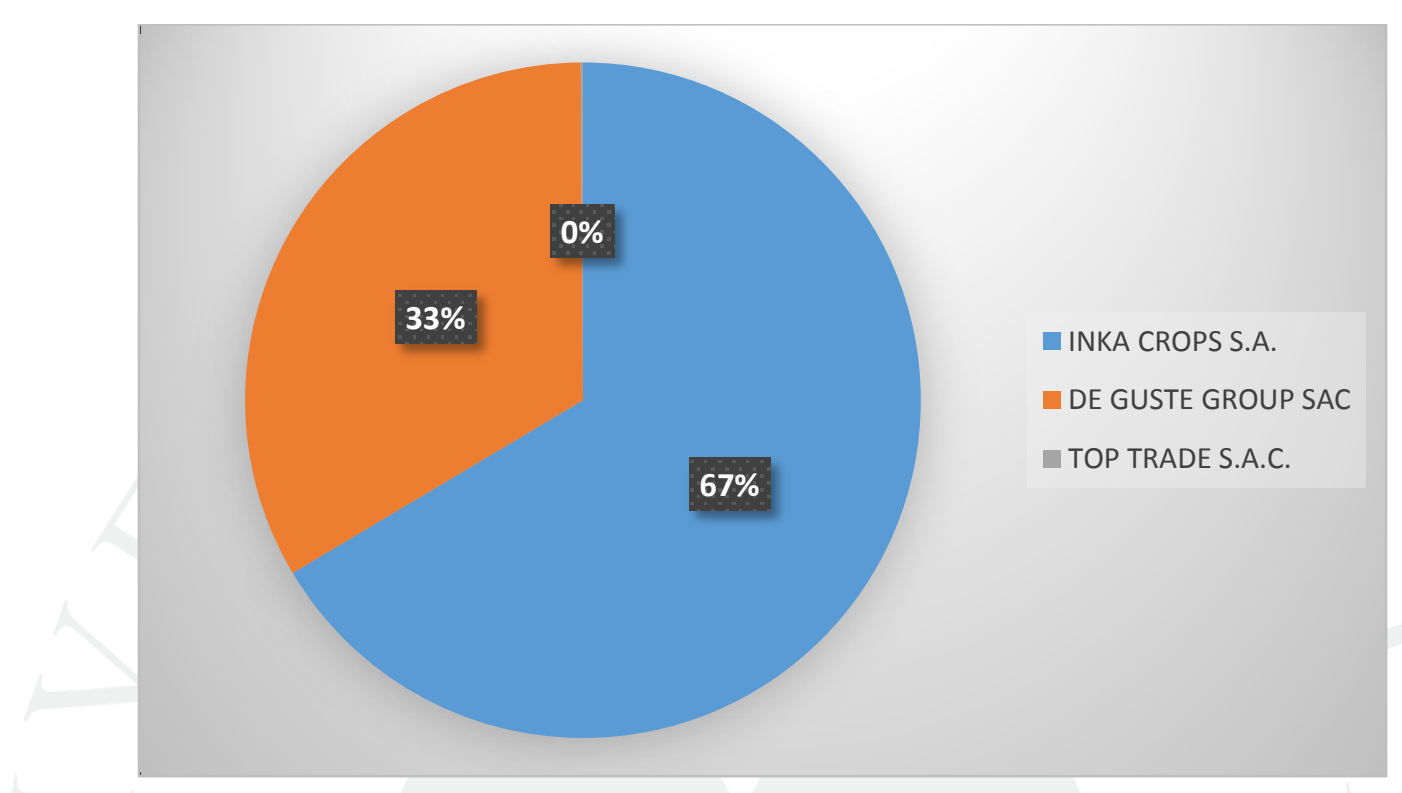

A pesar que la empresa Inka Crops S.A., De Guste Group S.A.C. y Top Grade S.A.C. salen como empresas exportadoras, éstas no son competidoras directas porque ofrece productos a base de diferentes cereales en los cuales no incluye la quinua para la producción de los mismos, por lo tanto se concluye que no existe competencia directa a nuestro producto en este listado.

\subsubsection{Análisis de la competencia internacional}

Según información obtenida en Trademap, el principal exportador de la sub-partida armonizada 190410 es Alemania abarcando el 14\% del mercado. Los principales mercados de exportación son Francia (15.30\%), Reino Unido (12.7\%) y Suecia (8.20\%).

Le sigue como segundo exportador a nivel mundial de la subpartida armonizada 190410 Estados Unidos con 12.4\% de participación en el mercado mundial. Sus principales importadores son Canadá (66.00\%), República Dominicana (12.10\%) y México (5.00\%). 
Por último, Reino Unido es el tercer país exportador de la subpartida armonizada 190401 con una participación de $11.9 \%$ y sus principales mercados de destino son Irlanda (30.60\%), Francia (12.20\%) e Italia $(6.80 \%)$.

Correspondiente a Canadá, Estados Unidos es el principal proveedor de dicho mercado con una participación del $96.29 \%$, el resto de países se reparten $3.71 \%$. Por eso, se puede concluir que las principales empresas que son competencia a nivel internacional se encuentran en USA.

\subsubsection{Principales proveedores del producto al mercado de destino}

Según TRADEMAP, las principales empresas estadounidenses exportadoras de la partida 140910 a Canadá son:

Gráfico $N^{o}$ 3.11: Principales empresas exportadoras de la sub-partida sistema armonizado 140910: Productos a base de Cereales, obtenido por inflado o tostado.

\begin{tabular}{|c|c|c|c|c|}
\hline $\begin{array}{c}\text { Nombre de la } \\
\text { empresa }\end{array}$ & $\begin{array}{c}\text { Número de } \\
\text { categorías de } \\
\text { productos } \\
\text { comercializados } \\
\end{array}$ & $\begin{array}{l}\text { Número de } \\
\text { empleados }\end{array}$ & Ciudad & Sitio web \\
\hline 4C Foods Corporation & 30 & $101-250$ & Brooklyn & http://www.4c.com \\
\hline $\begin{array}{c}\text { Avis Sales } \\
\text { Corporation } \\
\end{array}$ & 772 & nov-20 & Brooklyn & \\
\hline DM Shivtex, Inc. & 14 & 01-oct & Irving & http://www.shivtex.com \\
\hline $\begin{array}{c}\text { GISAS Distribution } \\
\text { LLC }\end{array}$ & 2 & 01-oct & Indianapolis & \\
\hline I-X Global Trade & 10 & 01-oct & Roseville & http://www.ixglobaltrade.com \\
\hline IBS Commodities & 2 & 01-oct & Newtonville & http://www.ibscommodities.com \\
\hline $\begin{array}{c}\text { International } \\
\text { American } \\
\text { Supermarkets }\end{array}$ & 34 & $21-50$ & Piscataway & http://www.iasusa.com \\
\hline $\begin{array}{l}\text { J.D. Honigberg } \\
\text { International, Inc. }\end{array}$ & 279 & $21-50$ & Northbrook & http://www.jdhintl.com \\
\hline $\begin{array}{c}\text { LinkSpot Global } \\
\text { Trade, LLC } \\
\end{array}$ & 7 & 01 -oct & Stratford & http://www.linkspotonline.com \\
\hline MTD Trading & 3 & Unknown & New York & http://www.mtdtrading.com \\
\hline $\begin{array}{l}\text { Pacific Harbor } \\
\text { Trading } \\
\end{array}$ & 8 & $\begin{array}{c}5001 \text { and } \\
\text { more }\end{array}$ & Gig Harbor & http://www.pacificharbortrading.com \\
\hline Qarver International & 7 & 01 -oct & Brooklyn & http://www.qarver.com \\
\hline Source Trade Partners & 5 & 01 -oct & Preston & \\
\hline $\begin{array}{c}\text { World Commodity } \\
\text { Services }\end{array}$ & 3 & 01-oct & Haddon & http://www.worldcommodityservices.com \\
\hline
\end{tabular}

Fuente: TRADEMAP, 2014 
Ninguna de las empresas listadas exporta barras energéticas a base quinua, están enfocadas en elaborar barras pero con otros insumos.

\subsubsection{Marco legal de la competencia}

El marco legal de la competencia está dado por las barreras arancelarias y no arancelarias, las cuales gracias al Tratado de Libre Comercio entre Perú y Canadá que entró en vigencia el 1 de Agosto del 2009 son en menor medida. Es así como este "otorga grandes ventajas arancelarias a la industria peruana" (PROMPERU, 2013, pág. 7).

Los productos exportados a Canadá, deben cumplir con diversos estándares para poder aprobar su ingreso a este mercado. "Todos los productos alimenticios que se comercializan en Canadá deben cumplir con los patrones de salud y seguridad de alimentos establecidos por la Canadian Food Inspection Agency (CFIA), que prohíben el comercio de alimentos adulterados o mal etiquetados y regula los aditivos y colorantes que pueden ser utilizados" (SIICEX, 2009, pág. 16).

Por otro lado, "la ley de Aduanas de Canadá regula los procedimientos para importaciones de Canadá, el cual corresponde a un modelo de liberalización de comercio internacional, por lo cual, la mayoría de los productos importados no requieren licencias." (PROMPERU, 2013, pág. 8). Además que existen varios organismos que están presentes en la regularización de importaciones en el mercado canadiense es así que "El Export and Imports Permits Acts, incluye una lista de control de importaciones...las solicitudes de licencia de importación deben ir acompañadas de factura proforma. Las autoridades aduaneras pueden exigir más documentos. El período de validez de una licencia es de 30 días. Las solicitudes de licencia se pueden tramitar a través de un agente de aduanas o bien en una de las oficinas del Export and Imports Bureau (EICB)" (PROMPERU, 2013, pág. 8). 
Finalmente, a la partida arancelaria 1904100000 exportada por Perú, se le aplica un arancel de importación en Canadá de 0\% según lo detallado en la tabla $\mathrm{N}^{\circ} 3.13$.

Tabla No 3.12: Arancel aplicado por Canadá a la Partida Arancelaria 1904100000: Productos a base de Cereales, obtenido por inflado o tostado.

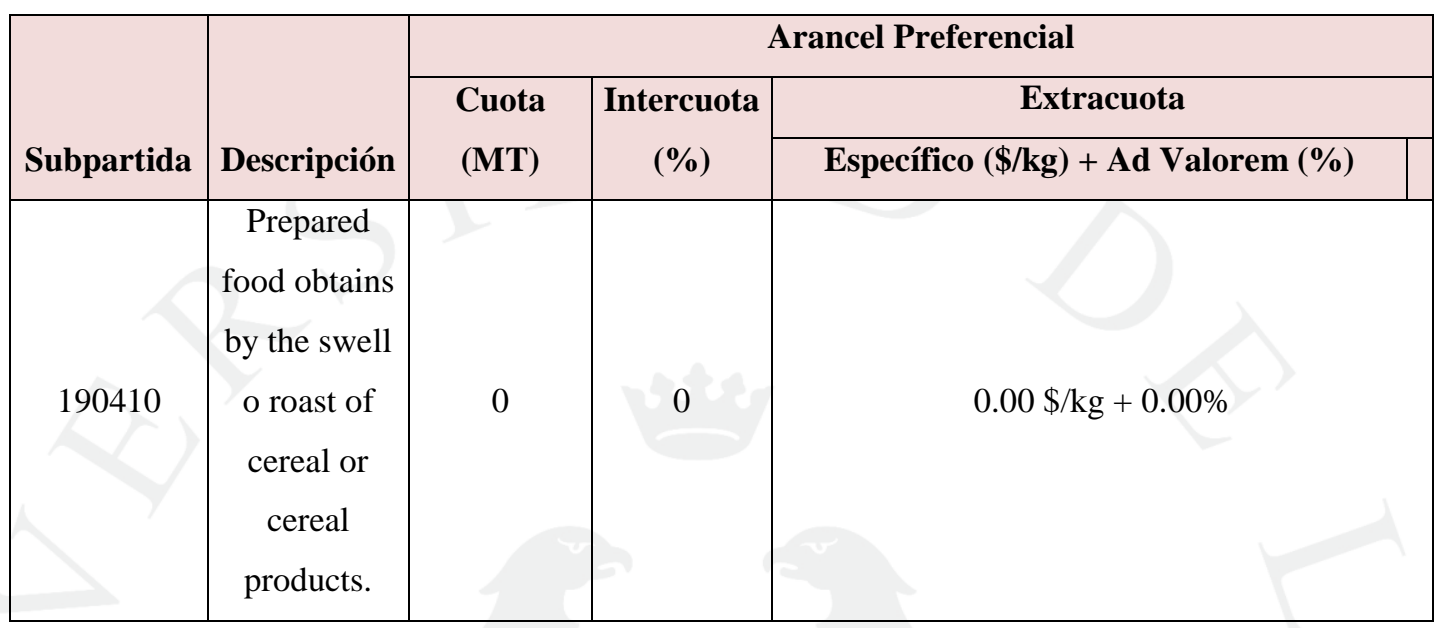

Fuente: SIICEX

\subsubsection{Análisis FODA de la competencia}

\subsubsection{Fortalezas:}

- Disponibilidad de la materia prima para la elaboración de las barras energéticas a base de quinua.

- Alta disponibilidad de tierras y buenas condiciones climáticas para el desarrollo de cultivos.

- Reconocida calidad de la oferta nacional.

\subsubsection{Oportunidades:}

- El consumidor canadiense está tomando conciencia con respecto a su alimentación.

- Mayor demanda internacional de productos a base de quinua, la cual es conocida como un "superfood."

- Aumento del consumo mundial de alimentos nutritivos y saludables.

\subsubsection{Debilidades:}

- Ausencia de certificaciones internacionales. 
- El no conocimiento público del contenido alimenticio del producto.

- Aproximadamente del $70 \%$ de los cultivos son de quinua convencional.

\subsubsection{Amenazas:}

- Mayor competencia de países como Bolivia y Ecuador.

- Mayor competencia de sustitutos, pues en mercado de destino existen cinco grupos de barras snack.

- Altas tarifas en flete.

\subsubsection{Análisis de la comercialización}

\subsubsection{Decisiones sobre el producto}

\subsection{Ficha técnica del producto}

Tabla $N^{o}$ 3.13: Ficha técnica del producto barras energéticas a base de quinua.

\begin{tabular}{|c|c|c|c|}
\hline Denominación del producto & \multicolumn{3}{|c|}{ Barras energéticas a base de quinua } \\
\hline País de origen & \multicolumn{3}{|c|}{ Perú } \\
\hline \multirow{11}{*}{ Factores de calidad } & \multirow{4}{*}{ Organolépticas } & Sabor & Dulce \\
\hline & & Textura & Sólida \\
\hline & & Olor & Característico \\
\hline & & Color & $\begin{array}{l}\text { Amarillo por fuera y } \\
\text { por dentro }\end{array}$ \\
\hline & \multirow{7}{*}{$\begin{array}{l}\text { Fisicoquímico } \\
\text { (medida base } \\
25 \mathrm{~g} \text { ) }\end{array}$} & Calorías & $70 \mathrm{Kcal}$ \\
\hline & & Grasas totales & $4 g$ \\
\hline & & Colesterol $0 \mathrm{mg}$ & $0 \%$ \\
\hline & & Sodio $65 \mathrm{mg}$ & $3 \%$ \\
\hline & & Carbohidratos totales & $4 \%$ \\
\hline & & Proteínas & $4 g$ \\
\hline & & Hierro & $2 \%$ \\
\hline \multirow{2}{*}{ Calidad microbiológica } & \multirow{2}{*}{ Especifico } & Mosca de la Fruta & Ausencia \\
\hline & & Salmonella & Ausencia \\
\hline Envase & \multicolumn{3}{|c|}{ Bolsas de polietileno de $25 \mathrm{~g}$} \\
\hline Vida útil & \multicolumn{3}{|c|}{12 meses } \\
\hline Recomendaciones de almacenaje & $\begin{array}{r}\text { 1. Almacenar er } \\
3 .\end{array}$ & $\begin{array}{l}\text { lugares frescos y secos } \\
\qquad \text { a } 20^{\circ} \mathrm{C} \\
\text { 2. Una vez abierto, co } \\
\text { ebe estar protegido de }\end{array}$ & $\begin{array}{l}\text { e recomienda de } 18^{\circ} \mathrm{C} \\
\text { umir } \\
\text { luz solar }\end{array}$ \\
\hline Certificaciones & \multicolumn{3}{|c|}{ 1. USDA Organic } \\
\hline Aplicaciones o uso & \multicolumn{3}{|c|}{ Consumo directo, en snacks } \\
\hline Información adicional & \multicolumn{3}{|c|}{$\begin{array}{l}\text { 1. Producto libre de organismos modificados genéticamente } \\
\text { 2. Producto no irradiado }\end{array}$} \\
\hline
\end{tabular}

Elaboración Propia

\subsection{Envase}


Las barras energéticas deberán de empacarse con la finalidad que el producto quede debidamente protegido. Adicionalmente, los materiales que se va a utilizar para la fabricación del envase deben de estar limpios y tener un control de calidad previo, lo cual nos permitirá evitar cualquier daño externo o interno del producto. Para el sellado y etiquetado del producto se utilizará una maquina empacadora, impresos con tinta y pegamento no tóxico.

El producto unitario será comercializado en bolsas de polietileno especiales para alimento y cada barra contará con las medidas de $10 \mathrm{~cm}$ largo x $3 \mathrm{~cm}$ de ancho x $2 \mathrm{~cm}$ de grosor y estarán agrupados en 6 barras energéticas a base de quinua dentro de una cartulina plegadiza con capacidad de $150 \mathrm{grs}$ con las medidas de $12 \mathrm{~cm}$ largo x $10 \mathrm{~cm}$ ancho x $5 \mathrm{~cm}$ grosor.

\section{Imagen $N^{o}$ 3.3: Caja de 6 unidades de barras energéticas.}

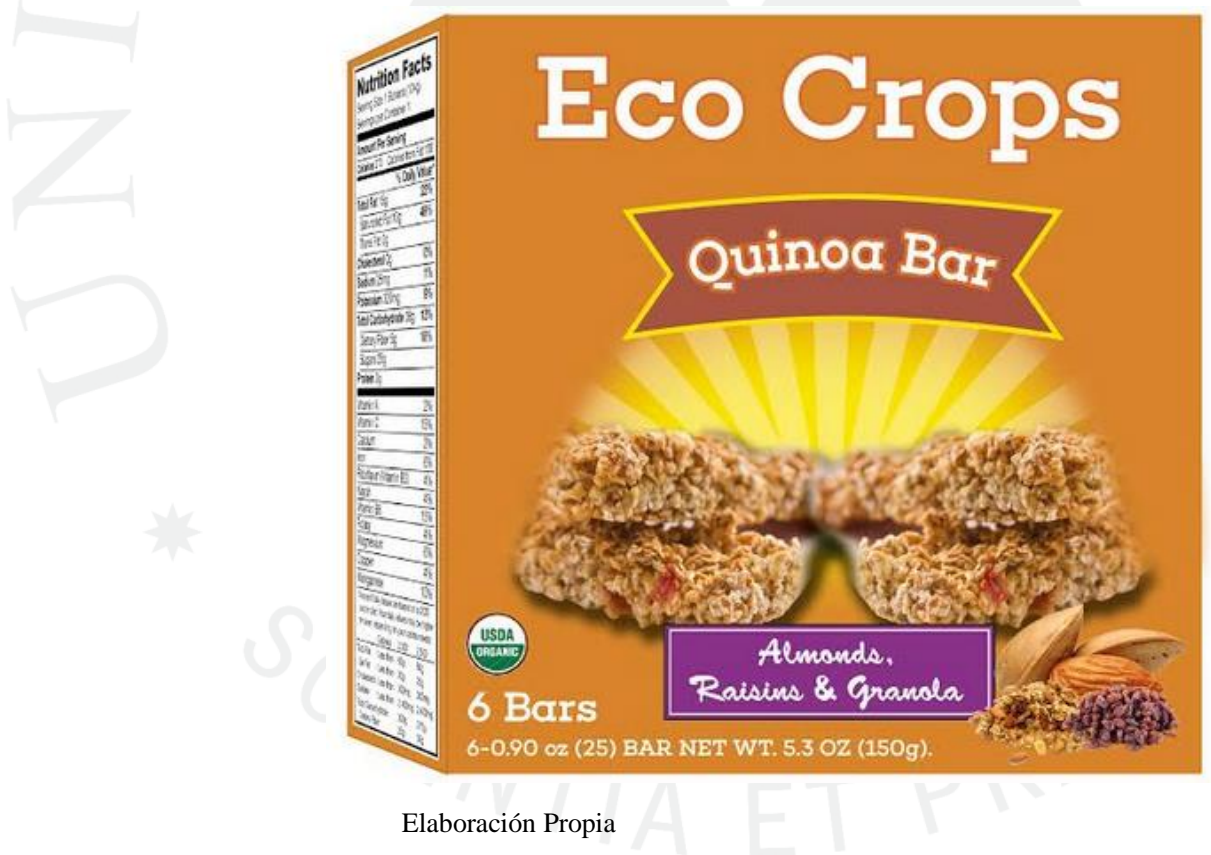

\subsection{Embalaje}

El embalaje serán cajas máster con medidas de $40 \mathrm{~cm}$ largo x $35 \mathrm{~cm}$ ancho x $50 \mathrm{~cm}$ de alto. Las unidades, que constan de 6 barras, se guardarán de la siguiente manera: en cada piso van 3 filas de 6 cajitas cada una, la cual estará a lo largo del costado de $40 \mathrm{~cm}$ de la caja. En cada caja van 5 pisos de cajitas. Esto quiere decir que caben 82 envases 
en cada caja máster, con un peso aproximado de 12.24 kilos por cada caja conteniendo 492 barras.

La unitarización será en pallets de 120x100x20 centímetros, con una capacidad de contener 32 cajas máster.

\subsection{Marca}

Se buscará difundir la marca Eco Crops con la finalidad de dar a conocer nuestro producto como de excelente calidad y gran valor nutricional, utilizando a su vez la marca Perú como medio de diferenciación.

\subsection{Etiquetado (TFO, Guía de etiquetado a Canadá, 2009, pág. 21)}

El etiquetado de los productos exportados a Canadá debe tener un etiquetado en inglés y sólo en francés en caso se dirija a la zona francófona del país. Se divide en dos secciones, las cuales se detallan a continuación y son explicados por la TFO, en la Guia de etiquetado a Canadá (2009, pág.21):

"Etiquetado General. Toda la información presente en las etiquetas debe ser fácil de leer y presentarse de manera clara y visible. Dado que Canadá reconoce al francés y al inglés como sus idiomas oficiales, toda la información deber estar escrita en ambos idiomas. En lo que a las unidades de medición se refiere deben responder al sistema métrico internacional. Los elementos por considerar en el etiquetado general son los siguientes:

- Nombre común del producto.

- Declaración de la cantidad neta.

- Lista de ingredientes, enumerados en orden descendente según cantidad presente en el alimento.

- Vida útil, para lo cual se requiere una declaración "Best- before".

- País de origen.

- Tabla nutricional. 
Etiquetado Nutricional. Las enmiendas realizadas a ley de medicamentos y alimentos (Food and Drug Act) establecieron que a partir del 12 de diciembre del 2005, la presencia de información nutricional en las etiquetas de los alimentos pre empacados será obligatoria. Los componentes que se deben indicar en esa información son los siguientes: Porción, Calorías, Grasa, Grasa saturada, Ácidos grasos trans, Colesterol, Sodio, Vitaminas, entre otros".

A continuación se presenta el etiquetado nutricional al mercado canadiense del producto barras energéticas a base de quinua.

\section{Imagen $N^{o}$ 3.4: Ejemplo de etiquetado nutricional del producto de la empresa Eco}

Crops S.A.C

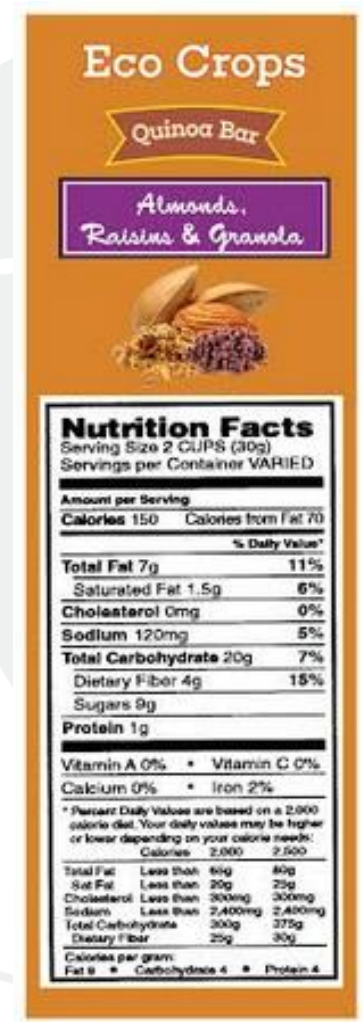

Elaboración Propia

\subsection{Modo de uso del producto}

La barra energética a base de quinua, puede utilizarse como snack con el concepto to-go pudiéndose llevar a todos los lugares que nosotros frecuentemos. Se debe tener en cuenta que el tamaño de la barra es 
pequeño, por lo mismo que está destinado a un consumo inmediato pues aporta las calorías y nutrientes necesarios.

\subsubsection{Decisiones sobre el precio}

\subsubsection{Método para la determinación del precio}

Según lo indicado en los objetivos del plan de negocio, se utilizará el método de costing para establecer los precios en base a los costos de elaboración del producto final. Adicionándole un margen de utilidad por el uso de insumos orgánicos.

\subsubsection{Fijación de precio}

Se fijará un precio de USD 1.98 FOB Callao por cada caja de 6 barras que hacen un total de 150 gramos equivalente a $5.8 \mathrm{oz}$ en los primeros dos años. Ello se obtuvo a través de la consideración de un costo total por caja de USD 151.25 a lo cual se le agregó un margen de ganancia de $15 \%$, obteniendo un precio de venta por caja de USD 177.94.

Es así como contaríamos con un precio por debajo del de la competencia con un precio de USD 5.0 por 5.8 oz (150 gramos).

\subsubsection{Política de pago}

El medio de pago a utilizar será CAD (Cash Against Documents) debido a que es menos riesgoso que trabajar con transferencia directa y menos costosa que una carta de crédito.

Para realizar la cobranza al cliente, nosotros tendremos que tener los documentos originales de exportación, luego se procederá a enviar a nuestro banco, quien se encargará de enviarlo al banco del importador. Este último revisará los documentos y procederá con el pago. 


\subsubsection{Decisiones sobre la plaza}

\subsubsection{Cobertura del mercado}

El producto está dirigido al mercado de Canadá, Ontario, Ciudad de Toronto el cual es detallado en el inciso 3.2.4.2, está compuesto por 35'540,400 habitantes de los cuales 6'055,700 habitan en Toronto, que es nuestro mercado meta. Adicionalmente, nuestro producto está dirigido a una población de 40 años en adelante, tanto hombres como mujeres.

De acuerdo a un informe de la Asociación Canadiense de Comercio Orgánico "el canal con mayor participación lo conforman las tiendas minoristas convencionales (45\% del total). Estas tiendas están representadas por cadenas como Loblaw, Metro, Sobeys, Safeway, Whole Foods, entre otros. El segundo lugar lo ocupan las tiendas en línea, abarcando un $29 \%$ del mercado (www.eatit.ca, www.trulyorganicfoods.com,www.goorganiccanada.com, http://well.ca). Finalmente, en tercer lugar figuran las tiendas de productos naturales y los servicios alimenticios (catering, restaurantes, etc.), ambos con 13\% de participación”. (PROMPERU, 2014, pág. 5)

\section{Imagen $N^{o}$ 3.5: Canales de Distribución y Comercialización para Quinua.}

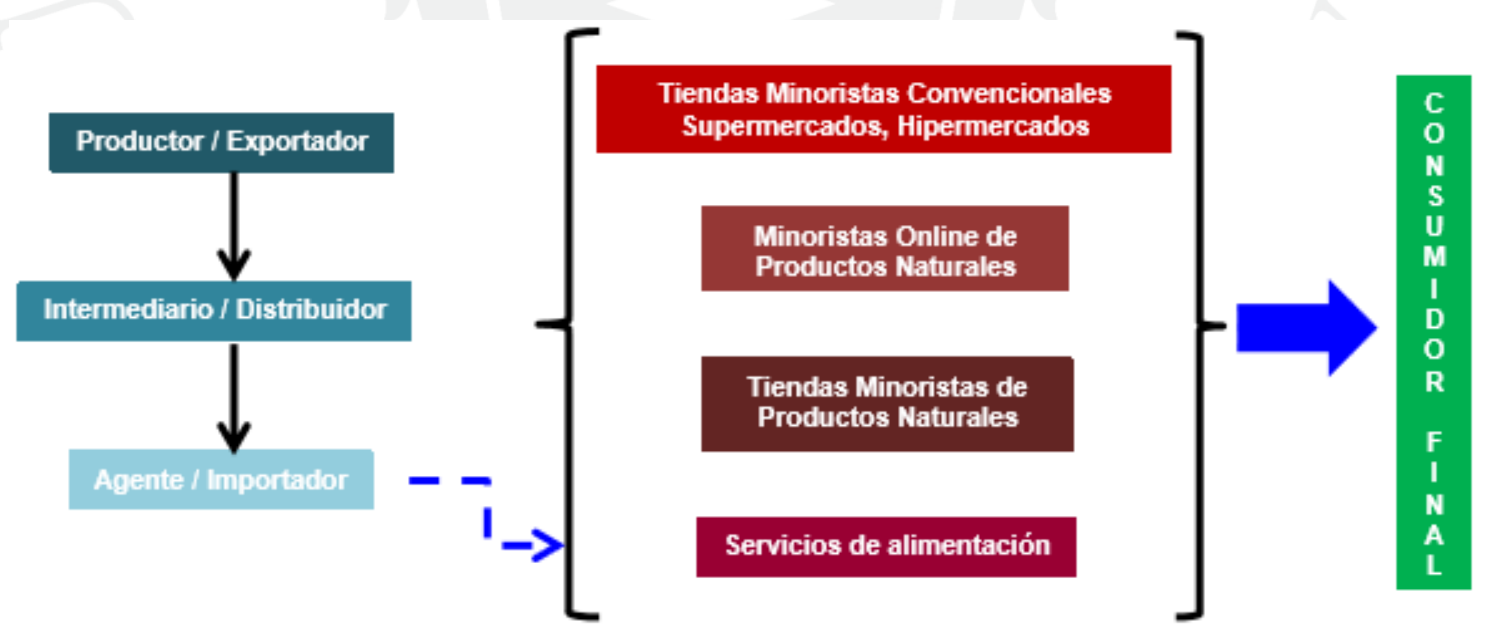

Fuente: PROMPERU, Perfil Producto-Mercado, Quinua-Canadá, pág. 4

\subsubsection{Logística}

Se utilizará el Incoterm 2010 FOB CALLAO, para la venta de nuestro producto barras energéticas a base de quinua. 
En el mercado de destino el importador asumirá los gastos de handling en destino y los incurridos en la comercialización en los centros de consumo adecuados para el producto.

\section{Tabla No 3.14: Costo de Fletes Promedio hacia Canadá}

\begin{tabular}{|c|c|c|}
\hline Medio de transporte & Unidad & Flete \\
\hline Aéreo & Kilogramos & $\$ 2.64$ \\
\hline Marítimo & Metro cúbico & $\$ 100.00$ \\
\hline
\end{tabular}

Fuente: Internacional Forwarder Agency

Elaboración Propia

\subsubsection{Decisiones sobre promoción}

\subsubsection{Mensaje}

El mensaje que se quiere trasmitir al consumidor final, es que contamos con un producto que está hecho a base de productos naturales los cuales no han sufrido alteraciones por compuestos químicos, además que tiene un buen sabor y es muy nutritivo, es decir, que no solo está comprando un producto que le va a gustar, sino que debería ser parte de su dieta diaria ya que es saludable.

\subsubsection{Posicionamiento}

Se quiere posicionar en la mente del consumidor como un producto de valor agregado diferente en el mercado pues su insumo base es orgánico $\mathrm{y}$ aporta un gran valor nutricional y beneficioso para la salud del consumidor. Se espera que el posicionamiento de la marca Eco Crops S.A.C sea el de un producto peruano en el mercado canadiense de gran calidad y sabor. 


\subsection{Estudio Técnico}

\subsubsection{Tamaño del proyecto}

El tamaño del proyecto se basa en la demanda objetivo proyectada ya mencionada anteriormente en la investigación. Adicionalmente, la empresa es catalogada como microempresa (MYPE) según la Ley $\mathrm{N}^{\circ}$ 28015; DS $\mathrm{N}^{\circ}$ 009-2003 en donde se indica que las ventas de las mismas MYPES deben ser desde 150 UIT hasta 1,700 UIT, siendo 1 UIT equivalente a USD 1,242. Es así como las ventas anuales de Eco Crops S.A.C. en el primer año son de USD 85,412.75, en el segundo año de USD 102,495.30, en el tercer año de USD 130,931.07, en el cuarto año de USD 149,635.51 y finalmente en el quinto año las ventas ascienden a USD 168,339.94.

\subsubsection{Factores determinantes del tamaño}

\subsubsection{Demanda objetivo proyectada}

Como se ha explicado en el inciso 3.2.4.2 Demanda Objetivo, nuestra demanda para el primer y segundo año es de $0.19 \%$ de la participación de la proyección lo cual representa 10,440 kilos, en el tercer año se desea tener una exportación de 11,200 kilos que representa el $0.20 \%$ de la participación de mercado. Asimismo, se espera que para el cuarto y quinto año nuestra participación aumente a $0.21 \%$ con 11,970 kilos. Por lo tanto, la demanda objetivo del proyecto aumentará progresivamente a través de los años, considerando a Toronto como un mercado potencial para nuestra oferta debido a que como se ha mencionado a lo largo del proyecto el consumidor tiene preferencia por el consumo de productos beneficiosos para la salud y que sean fáciles de llevar como un snack.

\subsubsection{Disponibilidad de insumos}

“A diciembre del año 2012, el rendimiento promedio es alrededor de $1,148 \mathrm{~kg} / \mathrm{ha}$ de quinua, con una variación de $-1.1 \%$ en comparación al mismo periodo del año 2011. Se destaca el rendimiento del departamento de Arequipa que es aproximadamente de 2,834 kg/ha, el mejor a nivel nacional.” (Principales aspectos de la cadena agro productiva, 2013, pág. 
15) El principal departamento productor de quinua por excelencia continúa siendo Puno con un rendimiento de $1,100 \mathrm{~kg} / \mathrm{ha}$.

Asimismo, existen meses de mayor cosecha y de menor cosecha de quinua los cuales son importantes conocer. Sin embargo ello no es impedimento para el proyecto porque se cuenta con un proveedor que tiene disponibilidad de quinua todo el año.

Tabla No 3.15: Estacionalidad de Quinua en el Perú

\begin{tabular}{|l|l|l|l|l|l|l|l|l|l|l|l|}
\hline Ene & Feb & Mar & Abr & May & Jun & Jul & Ago & Set & Oct & Nov & Dic \\
\hline & & & & & & & & & & & \\
Cosecha Menor & Cosecha Mayor
\end{tabular}

Fuente: Recuperado el 23 de Marzo del 2015 de,

http://agroaldia.minag.gob.pe/biblioteca/download/pdf/agroeconomia/agroeconomia_quinua.pdf

\subsubsection{Proceso Productivo}

El proceso productivo de las barras energéticas a base de quinua es el siguiente:

a) Recepción de la materia prima: Recepción de la quinua en óptimas condiciones, pesos y calidad.

b) Selección y clasificación: Selección de la quinua según características físicas.

c) Mezclado: Mezcla de la quinua con los demás insumos (almendras, granola, panela, pasas, entre otros).

d) Horneado: Se coloca la preparación en el horno industrial.

e) Moldeado: Se moldea lo que se ha horneado con moldeadores universales.

f) Control de calidad: Se debe revisar que el producto cuente con las condiciones adecuadas para pasar siguiente paso. 
g) Empaquetado y embalaje: Empaquetado del producto en bolsas plásticas, sellado y embalaje en cajas de cartón

h) Comercializado: Comercialización del producto final a Toronto, Canadá como mercado meta.

\subsubsection{Proceso y tecnología}

\subsubsection{Descripción de los principales procesos del proyecto}

a) Recepción de la materia prima: En este primer paso se recepciona la quinua de la empresa Agrícola Anahui S.AC realizándose un control de peso, calidad, color y el insumo debe estar en debe estar la fruta deshidratada en óptimas condiciones.

b) Selección y clasificación: Se inspecciona y controla de manera visual y física la quinua desechando aquellos granos que puedan estar de otro color.

c) Mezclado: Se procede a mezclar la quinua con los demás insumo necesarios para la elaboración de las barras energéticas hasta obtener una especie de pasta donde los ingredientes están muy bien integrados.

d) Horneado Se coloca la pasta en el horno industrial a $100^{\circ} \mathrm{C}$, haciendo que todas las partes del alimento se cocinen uniformemente y se encuentren completamente cocidas.

e) Moldeado: En este paso, se procede a ser moldeado para lo cual se utilizan unos moldeadores universales que estrujen la masa, con el fin de separarla, darle forma y tamaño a cada una de las barras según sea necesario. Posteriormente a ser desmoldado se debe de realizar un control de calidad donde se observa si el producto tiene las características adecuadas para ser exportable.

f) Empaquetado y embalaje: Una vez finalizado el proceso de moldeado, el producto está listo para ser empaquetado y embalado. Se retira el producto de los moldes y se colocan las barras sobre las mesas de acero inoxidable con la finalidad de pesarlas y distribuirlas 
en bolsas plásticas de 25 gramos $(10 \mathrm{~cm} \times 2 \mathrm{~cm} \times 3 \mathrm{~cm})$ las cuales cuentan con la marca, descripción del producto y demás requisitos del mercado canadiense; estas son llevadas a la maquilla sellador. Posteriormente, se agruparan 6 barras energéticas en cajas hechas de cartulina plegadiza $(15 \mathrm{~cm} \times 4 \mathrm{~cm} \times 14 \mathrm{~cm})$. Una vez agrupadas las barras, será serán introducidas en las cajas máster (35 $\mathrm{cm} \times 40 \mathrm{~cm} \times 50 \mathrm{~cm})$ donde caben 72 cajitas de 6 barras, dando un total de 432 barras energéticas. Dichas cajas serán transportadas al almacén de productos terminados.

g) Comercializado: Las cajas máster serán transportadas al Puerto del Callao, apiñadas 32 cajas por pallet, listas para la exportación.

\subsubsection{Diagrama de flujo del proceso de producción}

De acuerdo a lo mencionado en el inciso 3.3.2.3. Proceso productivo, se procederá a graficar el proceso productivo del producto:

Gráfico $N^{o} 3.12$ : Proceso productivo de barras energéticas a base de quinua.

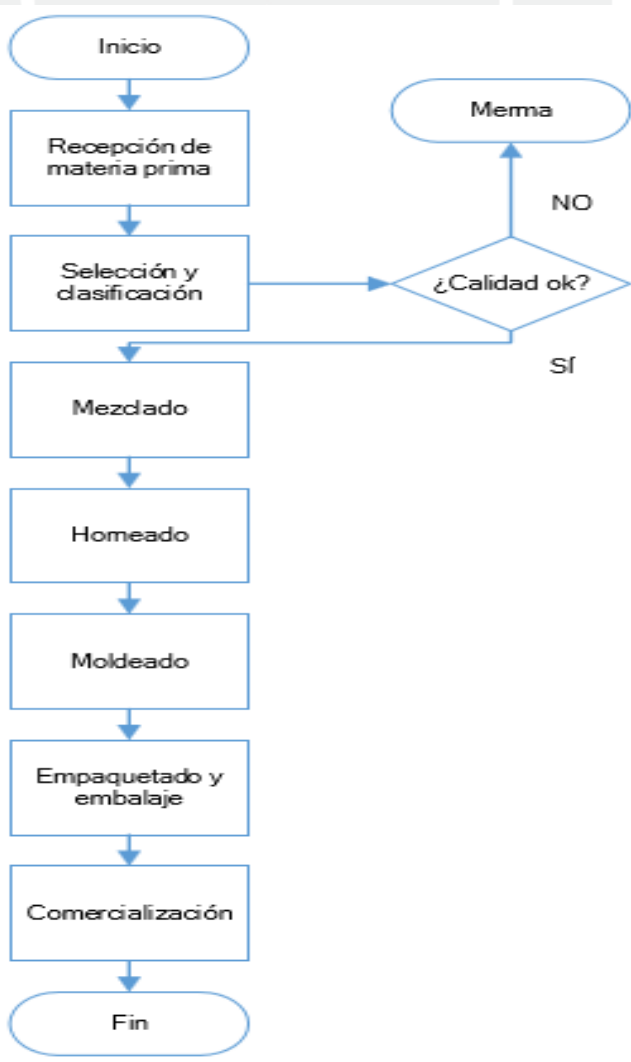

Elaboración propia 


\subsubsection{Localización}

\subsubsection{Macro localización}

La empresa estará localizada en Lima debido a que los proveedores del proyecto que abastecerán de los insumos se encuentran ubicados en dicho departamento.

\subsubsection{Micro localización}

Para la micro localización de la empresa Eco Crops S.A.C se evaluará los distritos de San Miguel y Ate Vitarte. Se procede con el método "cualitativo por puntos", para el cual se valorizan los factores de acuerdo a la escala mostrada en la tabla $\mathrm{N}^{\circ} 3.16$ según los criterios de cercanía con puerto de salida, seguridad, obtención de permiso y alquiler del local. Las calificaciones asignadas se pueden observar en la tabla $\mathrm{N}^{\circ} 3.17$.

Tabla $N^{o}$ 3. 16: Escala de valores

\begin{tabular}{|l|c|}
\hline \multicolumn{2}{|c|}{ Escalas } \\
\hline Muy malo & 1 \\
\hline Malo & 2 \\
\hline Regular & 3 \\
\hline Bueno & 4 \\
\hline Muy bueno & 5 \\
\hline
\end{tabular}

Elaboración Propia

Tabla $N^{o}$ 3.17: Evaluación de los distritos según el método "cualitativo por puntos"

\begin{tabular}{|l|c|c|c|c|c|}
\hline \multirow{2}{*}{ Factor } & \multirow{2}{*}{ Peso } & \multicolumn{2}{c|}{ Distrito 1 } & \multicolumn{2}{c|}{ Distrito 2 } \\
\cline { 3 - 6 } & & San Miguel & Calificación & Ate Vitarte & Calificación \\
\hline Obtención de permiso & 0.15 & 3 & $\mathbf{0 . 4 5}$ & 3 & $\mathbf{0 . 4 5}$ \\
\hline Seguridad & 0.25 & 3 & $\mathbf{0 . 7 5}$ & 3 & $\mathbf{0 . 7 5}$ \\
\hline Alquiler del local & 0.3 & 4 & $\mathbf{1 . 2}$ & 3 & $\mathbf{0 . 9}$ \\
\hline Accesos al puerto & 0.3 & 4 & $\mathbf{1 . 2}$ & 1 & $\mathbf{0 . 3}$ \\
\hline TOTAL & $\mathbf{1}$ & & $\mathbf{3 . 6}$ & & $\mathbf{2 . 4}$ \\
\hline
\end{tabular}

Elaboración Propia 
De acuerdo a las calificaciones obtenidas para cada uno de los distritos analizados, la decisión a elegir para el establecimiento será en el distrito de San Miguel, tras haber alcanzado la mejor calificación de 3.60 siendo calificado como Muy Bueno. Además la cercanía del distrito con el Puerto del Callao es una gran ventaja frente al distrito Ate Vitarte que alcanzo una puntuación de 2.40 calificado como Bueno. Cabe recalcar que el peso y calificación asignados en la evaluación han sido a criterio del formulador.

\subsubsection{Almacenes en San Miguel}

La empresa Eco Crops S.A.C contara con un almacén que estará ubicado en San Miguel, el cual cuenta con una cercanía de $6 \mathrm{~km}$ aproximadamente al Puerto del Callao; lo cual se valora como una ventaja pues convierte a este distrito más atractivo para la ejecución del proyecto pues nos permitirá reducir el costos del flete interno.

\subsubsection{Especificación del local en la situación actual}

En base a la localización anteriormente determinada, se alquilará un local que contará con un área de $200 \mathrm{~m} 2$ de los cuales $150 \mathrm{~m} 2$ de ellos serán destinados a la planta y $\operatorname{los} 50 \mathrm{~m} 2$ restantes para el área administrativa. A continuación se encuentra el detalle de las características:

\section{Tabla $N^{o}$ 3.18: Características del local en la situación actual}

\begin{tabular}{|l|l|}
\hline \multicolumn{1}{|c|}{ Ítem } & \multicolumn{1}{c|}{ Características } \\
\hline Dimensiones & El área total es de $200 \mathrm{~m}^{2}$ \\
\hline $\mathrm{N}^{\circ}$ de espacios & 3 oficinas, 1 comedor, 2 baños, 1 almacén. \\
\hline Puertas - ventanas & $\begin{array}{l}13 \text { puertas entre internas y externas de madera con cerrajería simple, } \\
7 \text { ventanas entre internas y externas }\end{array}$ \\
\hline Cerrajería & Los cerrojos del inmueble son simples y presentan cierta antigüedad \\
\hline Pisos & Pisos de cemento pulido en buen estado \\
\hline Techos & $\begin{array}{l}\text { Techo sucio propio del ambiente con cierto grado de deterioro por } \\
1 \text { luvias }\end{array}$ \\
\hline $\begin{array}{l}\text { Conexiones eléctricas } \\
\text { sanitarias }\end{array}$ & Conexiones eléctricas y sanitarias en buen estado \\
Elaboración propia &
\end{tabular}




\subsubsection{Especificación del local en la situación del proyecto}

Para poder utilizar el local adecuadamente, se debe de acondicionar con las maquinarias y equipos necesarios como el horno industrial, refrigeradora industrial, moldeadora y demás para tener un desarrollo idóneo de la producción. En lo que respecta al área administrativa, se amoblará con escritorios de oficinas, sillas, computadoras, estantes archivadores e impresoras multifuncionales. Asimismo se debe cumplir con las normas brindadas por Defensa Civil y DIGESA con la finalidad de operar de manera apropiada.

Para poder obtener una licencia de funcionamiento por parte de Defensa Civil, se debe cumplir con los siguientes requisitos: (SUNAT, Evaluación y Requisitos para obtención de Licencia de Funcionamiento, 2014, pág.133)

1. "Solicitud de Licencia de Funcionamiento con carácter de declaración jurada, que incluya:

1.1 Número de RUC y DNI o carné de extranjería del solicitante, tratándose de personas jurídicas o naturales, según corresponda.

1.2 DNI o carné de extranjería del representante legal en caso de personas jurídicas u otros entes colectivos, o tratándose de personas naturales que actúen mediante representación.

2. Vigencia de poder del representante legal, en el caso de personas jurídica. Tratándose de representación de personas naturales, se requerirá carta poder con firma legalizada.

3. Declaración Jurada de Observancia de Condiciones de Seguridad o Inspección Técnica de Seguridad en Defensa Civil de Detalle o Multidisciplinaria según corresponda."

Para obtener un registro sanitario otorgado por DIGESA, se necesita cumplir con los siguientes requisitos:

1. "Formato dirigido al Director Ejecutivo de Higiene Alimentaria y Zoonosis, con carácter de Declaración Jurada, que contenga $\mathrm{N}^{\mathrm{o}}$ de RUC, 
firmada por el Representante Legal. (Ver formato para productos nacionales o para productos)

2. Resultado de los análisis físicos, químicos y microbiológicos del producto terminado, confirmando su aptitud de acuerdo a la normatividad sanitaria vigente, otorgado por un laboratorio acreditado o del laboratorio de control de calidad de la fábrica.

3. Certificado de Libre Comercialización o similar o Certificado Sanitario emitido por la Autoridad Competente del país de origen, en original o copia refrendado por el consulado respectivo, cuando el alimento o bebida sea importado.

4. Rotulado de los productos etiquetados.

5. Los Alimentos y Bebidas de regímenes especiales, deberán señalar sus propiedades nutricionales, acompañando el correspondiente análisis bromatológico practicado por laboratorio acreditado por INDECOPI.

6. Declaración Jurada de ser MYPE, cuando corresponda.

7. Certificado de Validación de recurso y producto natural, para su uso en salud otorgado por CENSI. (Requisito Eliminado)

8. Comprobante de Pago de Derecho de Trámite. (10\% UIT)"

A continuación se detalla la distribución de áreas principales.

Tabla 3.19: Distribución del local en la situación del proyecto

\begin{tabular}{|l|l|}
\hline \multicolumn{1}{|c|}{ Ítems } & \multicolumn{1}{c|}{ Características } \\
\hline \multirow{2}{*}{ Dimensiones } & El área total es de $200 \mathrm{~m} 2$ \\
\hline \multirow{2}{*}{$\mathrm{N}^{\circ}$ de espacios } & 3 oficinas \\
\cline { 2 - 2 } & 2 baños \\
\cline { 2 - 2 } & 1 almacén \\
\cline { 2 - 2 } & 1 comedor \\
\cline { 2 - 2 } & 1 Planta de Preparación \\
\hline
\end{tabular}

Elaboración Propia 


\section{Imagen $N^{o}$ 3.6: Plano del local en la situación del proyecto}

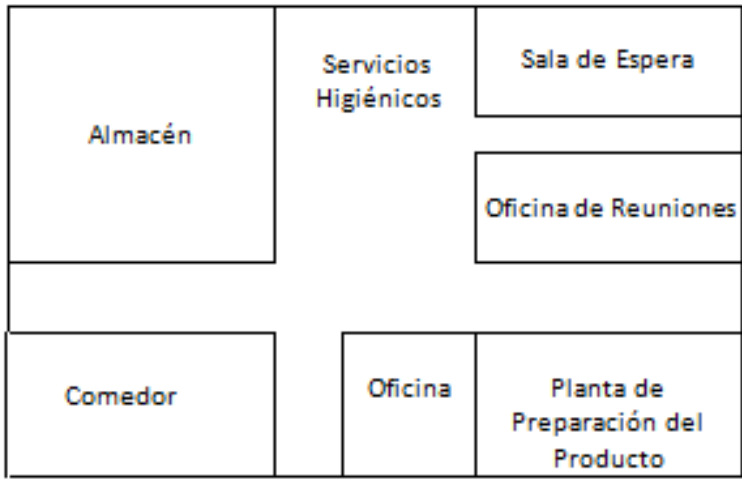

Elaboración Propia

\subsubsection{Maquinaria, equipo y mobiliario}

En la tabla a continuación, se presentan los requerimientos de maquinaria y equipo para el desarrollo del producto.

Tabla $N^{o}$ 3.20: Requerimiento de maquinaria y equipo

\begin{tabular}{|c|c|c|c|c|}
\hline Imagen & Máquina & Cantidad & Características & Precio Unitario (USD) \\
\hline & $\begin{array}{c}\text { Máquina } \\
\text { Alta Velocidad }\end{array}$ & 1 & $\begin{array}{c}\text { Marca: Famipack } \\
\text { Modelo: Flow Pack }\end{array}$ & $\$ 1,451.61$ \\
\hline & $\begin{array}{c}\text { Móquina } \\
\text { Universal }\end{array}$ & 1 & $\begin{array}{c}\text { Molde regulable según } \\
\text { dimensiones que se } \\
\text { requiera }\end{array}$ & $\$ 1,500.00$ \\
\hline & Horno Industrial & 1 & $\begin{array}{c}\text { Modelo: Rotativa } \\
\text { Acero inoxidable } \\
\text { 1 puerta }\end{array}$ & $\$ 1,000.00$ \\
\hline & 6 & Bandeja & Acero Inoxidable & \\
\hline
\end{tabular}




\begin{tabular}{|c|c|c|c|c|}
\hline & Mandil & 2 & $\begin{array}{c}\text { Material: Drill } \\
\text { Talla única } \\
\text { Medidas: 83x63cm }\end{array}$ & $\$ 3.60$ \\
\hline Laptop & 3 & $\begin{array}{c}\text { Memoria Ram Kingston } \\
\text { 4 GB } \\
\text { Monitor LED 16" } \\
\text { Intel Core i5 }\end{array}$ & $\$ 419.35$ \\
\hline & $\begin{array}{c}\text { Impresora } \\
\text { multifuncional }\end{array}$ & 1 & $\begin{array}{c}\text { Modelo: Laserjet 3 } \\
\text { Funciones: Copiado, } \\
\text { Impresión y Escane }\end{array}$ & $\$ 103.23$ \\
\hline
\end{tabular}

Elaboración Propia

Los muebles requeridos son mostrados en la tabla a continuación.

Tabla $N^{o}$ 3.21: Requerimiento de mobiliario

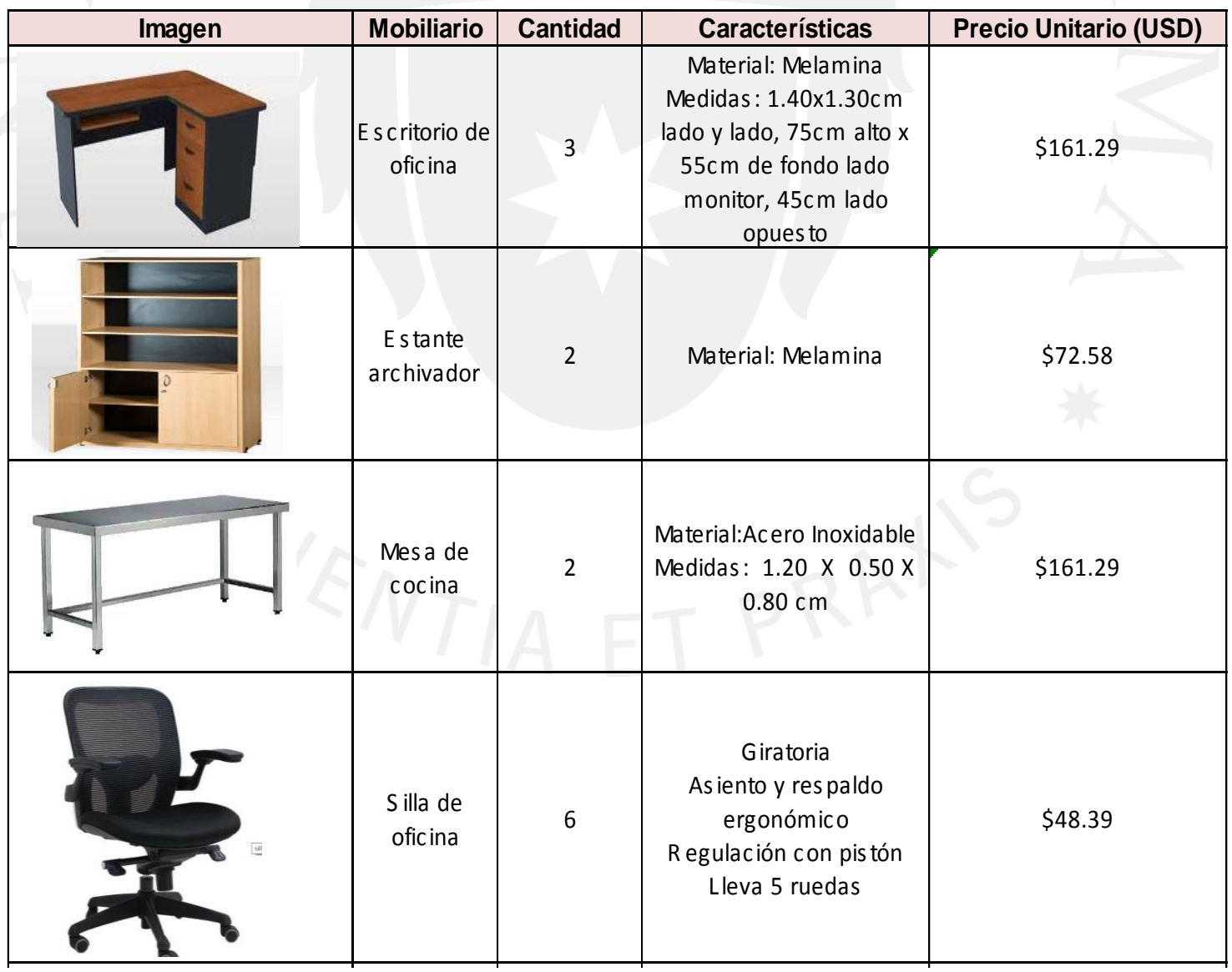




\begin{tabular}{|c|c|c|c|c|}
\hline 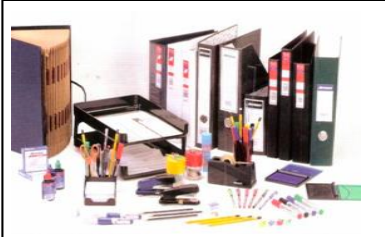 & $\begin{array}{l}\text { Útiles de } \\
\text { ofic ina }\end{array}$ & 1 & $\begin{array}{c}\text { Lapic eros, lápices, } \\
\text { folders, files manila, } \\
\text { sobres manila, notas } \\
\text { autoadhes ivas, pos tits, } \\
\text { calculadoras, } \\
\text { engrapadoras }\end{array}$ & $\$ 67.74$ \\
\hline
\end{tabular}

Elaboración Propia

\subsection{Estudio de la organización}

\subsubsection{Estructura organizativa}

\subsubsection{Organigrama funcional}

Gráfico $N^{o}$ 3.13: Organigrama de la empresa Eco Crops S.A.C

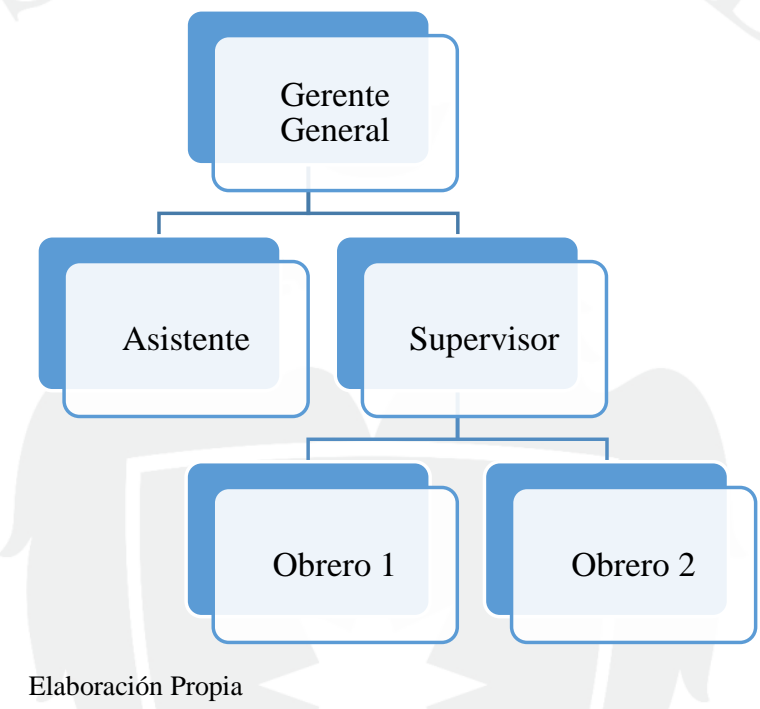

\subsubsection{Descripción del organigrama funcional}

La empresa Eco Crops S.A.C cuenta con 5 empleados cuyas funciones son las siguientes:

- Gerente General: Es el representante legal de la empresa, teniendo las responsabilidades de dirigir, coordinar, supervisar y dictar normas para el eficiente desarrollo de las actividades comerciales. También es el encargado de planear y desarrollar metas a corto y mediano plazo. A la vez se encarga de la asignación eficiente de los fondos de la empresa y adecuado cumplimiento de los objetivos del proyecto.

- Asistente: Es el encargado de las ventas y logística de la empresa; teniendo una constante comunicación con los proveedores de quinua. Asimismo debe revisar constantemente el progreso de la producción 
y ventas del producto final, así como las estrategias que serán utilizadas a fin de aumentar las ventas con el paso de los años.

- Supervisor: Encargado de liderar la planta, controlándola y estando seguro del adecuado funcionamiento de ésta; logrando eficiencia y efectividad. Supervisa el cumplimiento del proceso productivo y se encarga de dirigir a los obreros en el mismo.

- Obreros: Son personas capacitadas en el manejo de maquinarias, equipos y materias primas del proyecto, buscándose el óptimo cumplimiento del proceso productivo, desde la recepción de las materias primas hasta el empaquetado y embalaje. Además, deben cumplir con los requisitos sanitarios y manejo apropiado de las máquinas y equipos a fin de mantenerlos en perfecto estado.

\subsubsection{Visión, misión y valores}

\subsubsection{Visión}

Nuestra visión es ser reconocidos como una de las mejores empresas productoras y comercializadoras de barras energéticas a base de quinua en Perú, liderando siempre en temas de gestión, conocimiento y comercio exterior, satisfaciendo las exigencias de los mercados internacionales cumpliendo con los requisitos sanitarios y certificaciones.

\subsubsection{Misión}

Nuestra misión es abastecer a nuestros clientes un producto que cuenta con insumos peruanos orgánicos que generan un valor agregado, ofreciendo un producto de calidad.

\subsubsection{Valores}

La empresa Eco Crops S.A.C cuenta con los siguientes valores:

- Compromiso con nuestros clientes, la sociedad y el medio ambiente, brindado un servicio de calidad, respetando y cumpliendo las normas para la preservación medioambiental. 
- Respeto entre los trabajadores, considerándose un equipo en donde cada uno es igual de importante.

- Integridad y honestidad al demostrar coherencia entre lo que se dice y lo que se hace.

- Puntualidad con la entrega de los productos solicitados por parte de nuestros clientes, dando el producto en el momento y tiempo adecuado.

- Trabajo en equipo para poder obtener los mejores resultados, colaborando y aprendiendo el uno del otro.

\subsection{Estudio legal}

\subsubsection{Formas societarias}

Eco Crops S.A.C. se constituirá como persona jurídica, teniendo existencia legal más no existencia física y debe ser representada por una o más personas naturales. La empresa no depende de la vida de sus fundadores y es la misma la que responde por sus deudas, no los socios.

La forma societaria que se ha elegido es la de Sociedad Anónima Cerrada (S.A.C.), justificándose en el punto 3.5.1.1.

\subsubsection{Justificación de la forma societaria}

Se escoge como modalidad societaria la de Sociedad Anónima Cerrada por las siguientes razones:

- Constituida por dos accionistas, los cuales cuentan con responsabilidad limitada al no responder personalmente por deudas o daños de tercero.

- Se constituye por los fundadores al momento de otorgarse la escritura pública.

- El capital social está representado por acciones y se integra por aportes de cada uno de los socios, quienes no responden por las deudas en las que la sociedad incurra. 
- Sus acciones no pueden estar inscritas en el Registro Público de Mercado de Valores.

\subsubsection{Flujograma de creación de la empresa}

Gráfico $N^{o}$ 3.14: Flujograma de creación de la empresa Eco Crops S.A.C

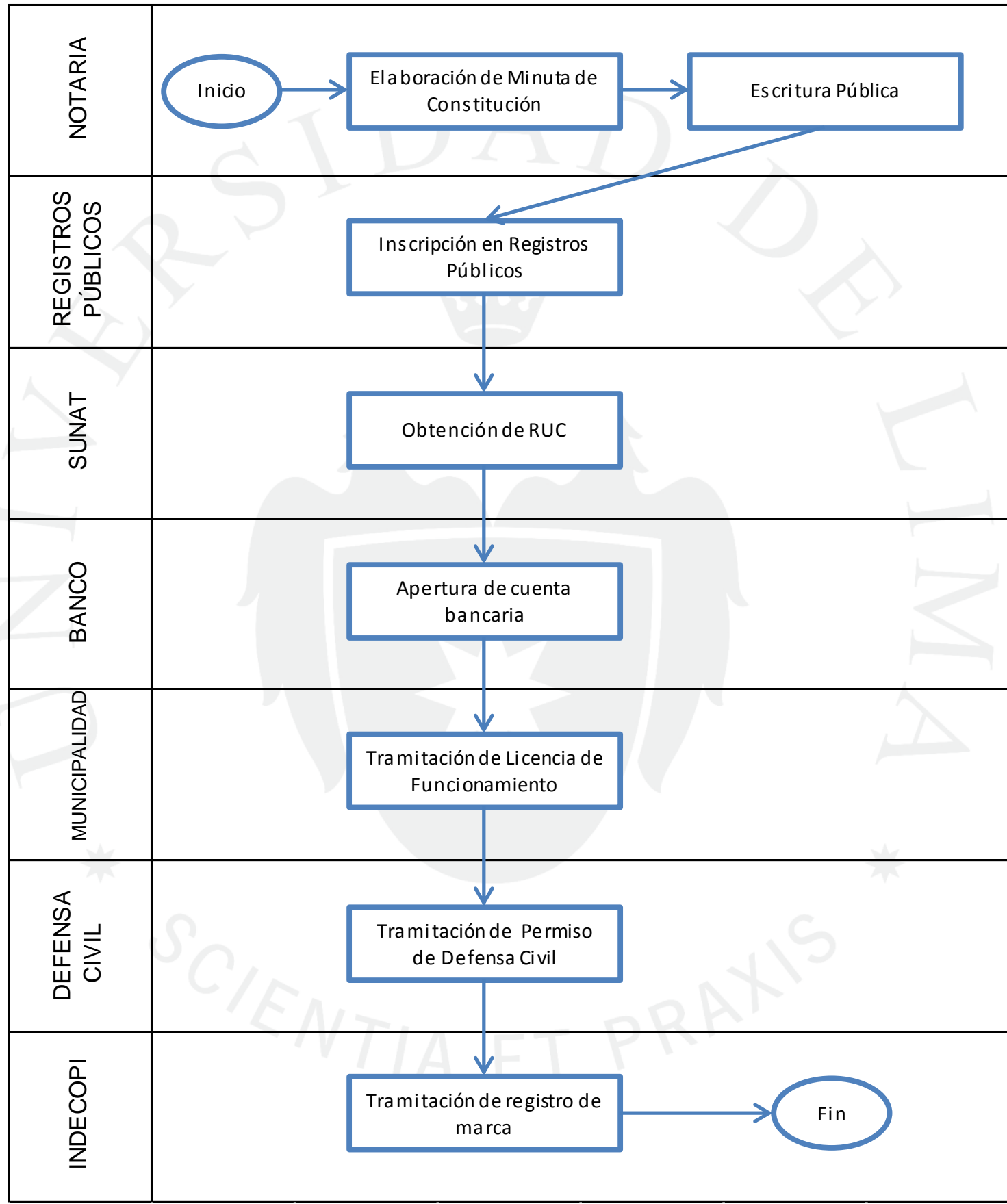

Fuente: Ministerio de Producción

Elaboración Propia 


\subsection{Fundamentos financieros}

\subsubsection{Estructura de costos fijos y variables}

\subsubsection{Costos fijos}

Los costos fijos mensuales de la empresa Eco Crops S.A.C. están compuestos por el alquiler del local y oficina ubicado en San Miguel, servicios de agua, luz, gas, comunicaciones (internet y telefonía), mantenimiento y limpieza, gastos de movilidad, sueldos administrativos y depreciación de los bienes y amortización de intangibles. Todo ello genera un total de costos fijos mensuales de USD 4,534.78

Tabla $N^{o}$ 3.22: Tabla $N^{\circ} 3.23:$ Estructura de costos fijos mensuales

\begin{tabular}{|l|c|c|c|c|}
\hline \multicolumn{1}{|c|}{ Descripción } & U.M. & Cantidad & $\begin{array}{c}\text { Valor } \\
\text { Unitario }\end{array}$ & Monto \\
\hline Alquiler local & mes & 1 & 781.25 & 781.25 \\
\hline Servicios (agua, luz, gas) & mes & 1 & 171.88 & 171.88 \\
\hline Comunicaciones & mes & 1 & 93.13 & 93.13 \\
\hline Mantenimiento y limpieza & mes & 1 & 93.75 & 93.75 \\
\hline Gastos de movilidad & mes & 1 & 187.50 & 187.50 \\
\hline Sueldos Administrativos & mes & 1 & $2,443.67$ & $2,443.67$ \\
\hline MOD mes & 1 & 646.49 & 646.49 \\
\hline Depreciación mes & 1 & 94.36 & 94.36 \\
\hline Amortización de intangibles & mes & 1 & 22.76 & 22.76 \\
\hline \multicolumn{2}{|c|}{ TOTAL COSTOS FIJOS MENSUAL } & & $\mathbf{4 , 5 3 4 . 7 8}$ \\
\hline
\end{tabular}

Los costos fijos anuales de la empresa se mantienen hasta el año 2, pues en los años 3,4 y 5 aumenta en un $20 \%$ por incremento en los sueldos y alquiler del local. 
Tabla $N^{o}$ 3. 23: Estructura de costos fijos anuales

\begin{tabular}{|l|c|c|c|c|c|}
\hline \multirow{2}{*}{ Concepto } & \multicolumn{5}{|c|}{ Monto US\$ } \\
\cline { 2 - 6 } & $\mathbf{1}$ año & $\mathbf{2}$ año & $\mathbf{3}$ año & $\mathbf{4}$ año & $\mathbf{5}$ año \\
\hline Costos fijos & $4,534.78$ & $4,534.78$ & $5,480.77$ & $5,480.77$ & $5,480.77$ \\
\hline
\end{tabular}

Elaboración Propia

Además, los costos fijos contemplan el pago de planilla al gerente general, asistente comercial, supervisor y operarios, los cuales están afectos a EsSalud (4.5\% por ser microempresa), vacaciones y aportes. Con todo ello se obtiene al mes un pago de planilla en el primer y segundo año de USD $38,437.50$, lo cual aumenta al tercer, cuarto y quinto año en $1.21 \%$ con USD $46,509.38$

Tabla Nº 3.24: Presupuesto planilla empresa Eco Crops S.A.C

\begin{tabular}{|c|c|c|c|c|c|}
\hline Rubros & Año 1 & Año 2 & Año 3 & Año 4 & Año 5 \\
\hline Mano de obra directa & $\$ 7,500.00$ & $\$ 7,500.00$ & $\$ 9,075.00$ & $\$ 9,075.00$ & $\$ 9,075.00$ \\
\hline Mano de obra administrativa & $\$ 30,937.50$ & $\$ 30,937.50$ & $\$ 37,434.38$ & $\$ 37,434.38$ & $\$ 37,434.38$ \\
\hline Total & $\$ 38,437.50$ & $\$ 38,437.50$ & $\$ 46,509.38$ & $\$ 46,509.38$ & $\$ 46,509.38$ \\
\hline
\end{tabular}

Elaboración Propia

\subsubsection{Costos variables}

Los costos variables de la empresa Eco Crops S.A.C. están compuestos por materia prima, envase y embalaje, costo de transporte entre otros. Todo ello genera un total de USD 82.01 por caja que es la unidad de medida equivalente a $12.24 \mathrm{~kg}$ del producto. Además se cuenta con USD 1.03 por cada caja de 6 barras equivalente a $0.150 \mathrm{~kg}$ y 5809.87 por 64 cajas equivalentes a $864 \mathrm{~kg}$. 
Tabla $N^{o}$ 3.25: Estructura de costos variables mensuales

\begin{tabular}{|l|c|c|c|}
\hline \multirow{2}{*}{\multicolumn{1}{|c|}{ COSTOS VARIABLES }} & \multicolumn{3}{c|}{ USD } \\
\cline { 2 - 4 } & UNIDAD 0.150 & CAJA 12.24 & 96 CAJAS 1,175 \\
KG & KG \\
\hline Materia prima & 0.90 & 73.44 & $7,050.24$ \\
\hline Envase y embalaje (caja inner y caja máster) & 0.04 & 0.50 & 32.00 \\
\hline Costo logístico & 0.09 & 8.00 & 543.87 \\
\hline Certificado de origen, fitosanitario y otros & 0.01 & 0.08 & 50.00 \\
\hline \multicolumn{1}{|c|}{ Costos Variables Acumulados } & $\mathbf{1 . 0 3}$ & $\mathbf{8 2 . 0 1}$ & $\mathbf{7 , 6 7 6 . 1 1}$ \\
\hline
\end{tabular}

Elaboración Propia

\subsubsection{Margen y determinación del precio de venta}

La determinación del precio se realizó bajo el método costing, fijando el precio de acuerdo a los costos en los cuales concurre la empresa. Es así como a través de un margen de ganancia de $15 \%$ se obtiene un precio de venta de USD 164.98 por caja de $12.24 \mathrm{~kg}$ y USD 1.83 por caja de 6 unidades de $0.15 \mathrm{~kg}$, lo cual está por debajo del de la competencia que es USD 310.50 por caja. Asimismo la empresa Eco Crops S.A.C. cuenta con un punto de equilibrio de 275 unidades detallado a continuación.

Tabla $N^{o}$ 3. 26: Determinación del margen de ganancia y precio para el primer y segundo año.

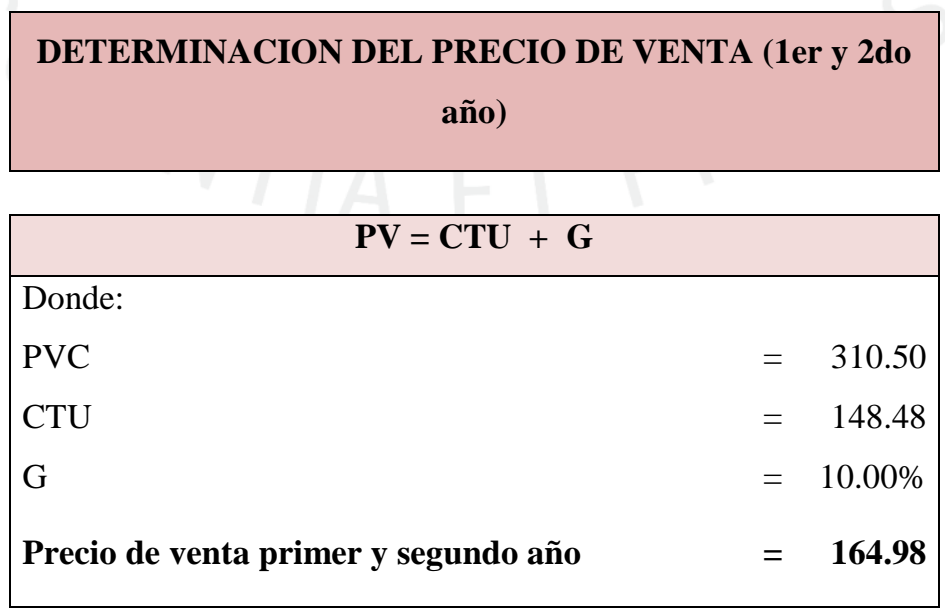

Precio antes del incremento de sueldos 
Tabla $N^{o}$ 3.27: Determinación del punto de equilibrio.

\section{DETERMINACION DEL PUNTO DE EQUILIBRIO (1er y 2do año)}

\begin{tabular}{|c|c|c|c|c|}
\hline \multirow[t]{2}{*}{ Punto de Equilibrio = } & Total de costos fijos & $\mathrm{PE}=$ & $\frac{4,534.78}{16.50}$ & \\
\hline & Margen de contribución & & & \\
\hline & & & & \\
\hline Costos fijos & $4,534.78$ & & & \\
\hline Costo variable unitario & 148.48 & & & \\
\hline PV & 164.98 & $\mathrm{PE}=$ & 45,348 & Moneda / dólares \\
\hline
\end{tabular}

Elaboración Propia

\subsubsection{Proyección de ventas}

Para realizar la proyección de ventas, se ha tomado como premisas las siguientes variables:

- Capacidad de producción

- Materia prima necesaria

- Demanda potencial

- Rentabilidad requerida para el proyecto

La unidad de medida es una caja, lo cual se proyecta vender en el primer año son 480 cajas, las cuales generan un valor de USD 79,189.59, en el segundo año vender 576 cajas generando ventas por USD 95,027.50. En el tercer año se proyecta que las ventas sean 672 cajas (8 veces al año, 96 cajas por vez) con lo cual se estaría vendiendo USD 128,385.34. En el cuarto año se venderán de 768 cajas teniendo ventas por USD 146,726.10. Finalmente en el quinto año se estima vender 864 cajas que significan un ascenso de las ventas a USD 165,066.87. 
Tabla $N^{o}$ 3.28: Proyección de ventas

\begin{tabular}{|l|c|c|c|c|c|}
\hline \multicolumn{1}{|l|}{ En Cajas } \\
\hline \multicolumn{1}{|c|}{ Producto } & Año 1 & Año 2 & Año 3 & Año 4 & Año 5 \\
\hline Total de cantidad & 480 & 576 & 672 & 768 & 864 \\
\hline
\end{tabular}

\begin{tabular}{|l|c|c|c|c|c|}
\hline \multicolumn{1}{|l|}{ En dólares } \\
\hline Producto & Año 1 & Año 2 & Año 3 & Año 4 & Año 5 \\
\hline Total de dinero & $79,189.59$ & $95,027.50$ & $128,385.34$ & $146,726.10$ & $165,066.87$ \\
\hline
\end{tabular}

Elaboración Propia

\subsubsection{Estructura de la inversión}

Eco Crops S.A.C. asumirá las inversiones tanto de activos fijos (USD 5,350.09) como capital de trabajo (USD 12,195.77) y gastos preoperativos (USD 2,731.25); todo ello genera un total de USD 21,586.80 lo cual se detalla en el siguiente cuadro.

\section{Tabla N $N^{o}$ 3.29: Estructura de la inversión}

\begin{tabular}{|c|c|c|c|c|}
\hline \multicolumn{5}{|c|}{ Inversiones US\$ } \\
\hline CONCEPTO & U.M. & CANT. & P.UNIT & TOTAL \\
\hline & & & $\$$ & $\$$ \\
\hline ACTIVOS FIJOS & & & & $6,659.78$ \\
\hline \multicolumn{5}{|l|}{ I. Maquinaria y equipo } \\
\hline Máquina empacadora de alta velocidad & und & 1 & $1,451.61$ & 1451.61 \\
\hline Máquina moldeadora universal & und & 1 & $1,500.00$ & 1500.00 \\
\hline Horno Industrial & und & 1 & $1,000.00$ & 1000.00 \\
\hline Bandejas de acero inoxidable & und & 6 & 5.00 & 30 \\
\hline Mandiles & und & 2 & 3.60 & 7.20 \\
\hline Computadoras & und & 3 & 419.35 & 1258.05 \\
\hline Impresora multifuncional & und & 1 & 103.23 & 103.23 \\
\hline \multicolumn{4}{|r|}{ Sub total US\$ } & $5,350.09$ \\
\hline \multicolumn{5}{|l|}{ II. Muebles y enseres } \\
\hline Escritorio de oficina & und & 3 & 161.29 & 483.87 \\
\hline Estante archivador & und & 2 & 72.58 & 145.16 \\
\hline Sillas de oficina & und & 6 & 48.39 & 290.34 \\
\hline Útiles de oficina & und & 1 & 67.74 & 67.74 \\
\hline Mesa de acero inoxidable & und & 2 & 161.29 & 322.58 \\
\hline
\end{tabular}




\begin{tabular}{|c|c|c|c|c|}
\hline & & & Sub total US\$ & $1,309.69$ \\
\hline \multicolumn{5}{|l|}{ CAPITAL DE TRABAJO } \\
\hline Costos variables & mes & 1 & $7,660.99$ & $7,660.99$ \\
\hline \multirow[t]{2}{*}{ Costos y gastos fijos } & mes & 1 & $4,534.78$ & $4,534.78$ \\
\hline & & \multicolumn{2}{|r|}{ Sub total US\$ } & $12,195.77$ \\
\hline \multicolumn{5}{|l|}{ GASTOS PREOPERATIVOS } \\
\hline Plan de negocio, estudios & und & 1 & 800.00 & 800.00 \\
\hline Licencias y constitución de empresa & und & 1 & 450.00 & 450.00 \\
\hline Página web & und & 1 & 700.00 & 700.00 \\
\hline Garantía & und & 1 & 781.25 & 781.25 \\
\hline \multicolumn{4}{|r|}{ Sub total US\$ } & $2,731.25$ \\
\hline \multicolumn{4}{|l|}{ TOTAL INVERSIONES } & $21,586.80$ \\
\hline
\end{tabular}

Elaboración Propia

A la vez es importante considerar la depreciación de los activos fijos, los cuales al quinto año cuentan con un valor residual de USD 998.32 .

Tabla $N^{o}$ 3.30: Depreciación de los activos fijos

\begin{tabular}{|c|r|r|r|}
\hline \multicolumn{4}{|c|}{ DEPRECIACIÓN DE ACTIVOS } \\
\hline Depreciación \% & Vida Util años & Depr. Anual & Depr. Mes \\
\hline $10 \%$ & 10 & $\$ 145.16$ & $\$ 12.10$ \\
\hline $10 \%$ & 10 & $\$ 150.00$ & $\$ 12.50$ \\
\hline $10 \%$ & 10 & $\$ 100.00$ & $\$ 8.33$ \\
\hline $33 \%$ & 3 & $\$ 10.00$ & $\$ 0.83$ \\
\hline $33 \%$ & 3 & $\$ 2.40$ & $\$ 0.20$ \\
\hline $33 \%$ & 3 & $\$ 419.35$ & $\$ 34.95$ \\
\hline $33 \%$ & 3 & $\$ 34.41$ & $\$ 2.87$ \\
\hline $20 \%$ & 5 & $\$ 29.77$ & $\$ 8.06$ \\
\hline $20 \%$ & 5 & $\$ 58.07$ & $\$ 2.42$ \\
\hline $20 \%$ & 5 & $\$ 22.58$ & $\$ 1.88$ \\
\hline $33 \%$ & 3 & $\$ 64.52$ & $\$ 5.38$ \\
\hline $20 \%$ & 5 & $\$ 1,132.29$ & $\$ 94.36$ \\
\hline TOTAL & & & \\
\hline
\end{tabular}

VALOR DE SALVAMENTO = O VALOR RESIDUAL

Elaboración Propia 
Tabla $N^{o}$ 3.31: Depreciación de activos fijos

\begin{tabular}{|c|r|r|r|}
\hline Año & \multicolumn{1}{|c|}{$\begin{array}{c}\text { Deprec. } \\
\text { Anual }\end{array}$} & Depr Acum. & Valor Residual \\
\hline 1 & $\$ 1,132.29$ & & $\$ 5,527.49$ \\
\hline 2 & $\$ 1,132.29$ & $\$ 2,264.58$ & $\$ 4,395.20$ \\
\hline 3 & $\$ 1,132.29$ & $\$ 3,396.87$ & $\$ 3,262.91$ \\
\hline 4 & $\$ 1,132.29$ & $\$ 4,529.16$ & $\$ 2,130.62$ \\
\hline 5 & $\$ 1,132.29$ & $\$ 5,661.46$ & $\mathbf{\$ 9 9 8 . 3 2}$ \\
\hline
\end{tabular}

Al cierre del 5to. año se tiene un Valor Residual de US\$

$\$ 998.32$

Elaboración Propia

\subsubsection{Financiamiento de la inversión}

El financiamiento de la inversión está cubierto en su totalidad por el aporte de los accionistas; aportando el accionista Constantino Ernesto Arcaya Vernal el 60\% y Natalia Arcaya del Aguila 40\%.

\subsubsection{Flujo de caja económico (COK, TIR y VAN)}

El flujo de caja económico proyectado a cinco años de la empresa Gold Chocolate S.A.C. se presenta en el siguiente cuadro:

Tabla $N^{o}$ 3.32: Flujo de caja económico de la empresa Eco Crops S.A.C

\begin{tabular}{|c|c|c|c|c|c|c|c|}
\hline \multicolumn{8}{|c|}{ FLUJO DE CAJA ECONOMICO } \\
\hline & Año 0 & Año 1 & Año 2 & Año 3 & Año 4 & Año 5 & Liquidación \\
\hline & & & & & & & \multirow{2}{*}{$\begin{array}{l}\text { Valor de } \\
\text { rescate }\end{array}$} \\
\hline & & & & & & & \\
\hline \multicolumn{8}{|l|}{ Ingresos } \\
\hline Ventas totales & & $79,189.59$ & $95,027.50$ & $128,385.34$ & $146,726.10$ & $165,066.87$ & \\
\hline & & & & & & & \\
\hline \multicolumn{8}{|l|}{ Egresos } \\
\hline Inversión total & $21,586.80$ & & & & & & 998.32 \\
\hline Activo fijo & $6,659.78$ & & & & 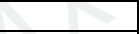 & & - \\
\hline Capital de trabajo & $12,195.77$ & & & & +2 & & - \\
\hline \multirow[t]{2}{*}{ Gastos pre-operativos } & $2,731.25$ & $\omega_{2}$ & +2 & 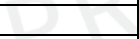 & 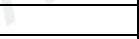 & & - \\
\hline & & 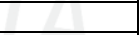 & +2 & 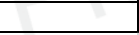 & & & \\
\hline Recuperación de capital de trabajo & & - & - & & & $12,195.77$ & - \\
\hline Costos & & $74,440.96$ & $100,212.63$ & $119,876.48$ & $128,382.48$ & $135,040.96$ & \\
\hline Costos fijos & & $36,278.24$ & $54,417.35$ & $65,769.30$ & $65,769.30$ & $65,769.30$ & \\
\hline Costos variables & & $38,162.73$ & $45,795.27$ & $54,107.18$ & $62,613.18$ & $69,271.66$ & \\
\hline Costos y gastos totales & & $74,440.96$ & $100,212.63$ & $119,876.48$ & $128,382.48$ & $135,040.96$ & \\
\hline & & & & & & & \\
\hline Ventas menos costos & & $4,748.62$ & $-5,185.12$ & $8,508.87$ & $18,343.62$ & $30,025.91$ & \\
\hline Depreciación & & $1,132.29$ & $1,132.29$ & $1,132.29$ & $1,132.29$ & $1,132.29$ & \\
\hline Utilidad antes de impuestos & & $5,880.91$ & $-4,052.83$ & $9,641.16$ & $19,475.92$ & $31,158.20$ & \\
\hline Impuesto a la renta & & $1,764.27$ & $-1,215.85$ & $2,892.35$ & $5,842.77$ & $9,347.46$ & \\
\hline Flujo de caja económico & $-21,586.80$ & $2,984.35$ & $-3,969.27$ & $17,812.29$ & $24,696.62$ & $33,872.54$ & \\
\hline
\end{tabular}


A través de la tabla $\mathrm{N}^{\circ} 3.33$ se puede observar que la empresa Eco Crops S.A.C. contará con ganancias desde el primer año de operaciones (USD 2,984.35), lo cual aumentará al quinto año de operaciones a USD 33,872.54, pudiendo recuperar el capital de trabajo invertido equivalente a USD 12, 353.61.

Cabe mencionar que en el año 2 se obtiene un FCE negativo, esto debido a que en comparación del año 1, solo se tomó en consideración la segunda mitad del año por lo que los costos no fueron significativos debido al periodo corto en evaluación, esta situación cambia en el año 2 porque se evalúa el año entero y así los costos si representan un papel significativo en los cálculos.

Respecto a indicadores como el COK (Costo de Oportunidad de Capital), TIR (Tasa Interna de Retorno) y el VAN (Valor Actual Neto), la empresa cuenta con el siguiente resultado:

Tabla N 3.33: COK, VAN, TIR de la empresa Eco Crops S.A.C

\begin{tabular}{|r|r|}
\hline COK & $15.39 \%$ \\
\hline VANE & 20,101 \\
\hline TIRE & $36.07 \%$ \\
\hline
\end{tabular}

Elaboración Propia

Como se observa en la tabla $\mathrm{N}^{\circ} 3.34$, el COK es $15.39 \%$ para lo cual se utilizó la siguiente fórmula: $\mathrm{COK}=\mathrm{Rf}+\mathrm{B}(\mathrm{Rm}-\mathrm{Rf})+\mathrm{Riesgo}$ País; con datos del sector alimenticio. Rf es la tasa libre de riesgo (2.62\%), Rm es la tasa de riesgo del mercado (15.98\%), B es beta (0.85) y el Riesgo país es $1.49 \%$.

Por otro lado, se obtuvo un VAN de USD 20,101 y una TIR de $36.07 \%$. Con dicha información se puede determinar que el proyecto es viable al contar con un VAN mayor a cero y un COK menor al TIR. 


\subsubsection{Indicadores financieros}

\subsubsection{Estado de ganancias y pérdidas}

Se puede observar en el cuadro $\mathrm{N}^{\circ} 3.35$ que la empresa obtendrá ganancias desde el segundo año, obteniendo en los cinco primeros años un resultado acumulado de USD 20,367.14. Por lo tanto, el proyecto es considerado rentable al lograr recuperar el capital invertido por los socios.

Tabla $N^{o}$ 3. 34: Estado de Ganancias y Pérdidas de la empresa Eco Crops S.A.C

\begin{tabular}{|l|c|c|c|c|c|}
\hline \multicolumn{7}{|c|}{ ESTADO DE GANANCIAS Y PÉRDIDAS } \\
\hline & Año 1 & Año 2 & Año 3 & Año 4 & Año 5 \\
\hline Ventas & $79,189.59$ & $95,027.50$ & $128,385.34$ & $146,726.10$ & $165,066.87$ \\
\hline (-) Costo de producción & $38,162.73$ & $38,162.73$ & $53,427.82$ & $61,060.36$ & $69,271.66$ \\
\hline Utilidad bruta & $\mathbf{4 1 , 0 2 6 . 8 6}$ & $\mathbf{5 6 , 8 6 4 . 7 7}$ & $\mathbf{7 4 , 9 5 7 . 5 2}$ & $\mathbf{8 5 , 6 6 5 . 7 4}$ & $\mathbf{9 5 , 7 9 5 . 2 1}$ \\
\hline $\begin{array}{l}\text { (-) Gastos administrativos y } \\
\text { ventas }\end{array}$ & $50,941.94$ & $53,941.94$ & $62,293.88$ & $65,293.88$ & $65,293.88$ \\
\hline Utilidad operativa & $\mathbf{- 9 , 9 1 5 . 0 8}$ & $\mathbf{2 , 9 2 2 . 8 4}$ & $\mathbf{1 2 , 6 6 3 . 6 4}$ & $\mathbf{2 0 , 3 7 1 . 8 6}$ & $\mathbf{3 0 , 5 0 1 . 3 2}$ \\
\hline (-) Depreciación & $1,132.29$ & $1,132.29$ & $1,132.29$ & $1,132.29$ & $1,132.29$ \\
\hline $\begin{array}{l}\text { (-) Amortización de } \\
\text { intangibles }\end{array}$ & 136.56 & 273.13 & 273.13 & 273.13 & 273.13 \\
\hline Utilidad antes de impuestos & $\mathbf{- 1 1 , 1 8 3 . 9 3}$ & $\mathbf{1 , 5 1 7 . 4 2}$ & $\mathbf{1 1 , 2 5 8 . 2 2}$ & $\mathbf{1 8 , 9 6 6 . 4 4}$ & $\mathbf{2 9 , 0 9 5 . 9 1}$ \\
\hline (-) Impuesto a la renta (30\%) & 0.00 & 455.23 & $3,377.47$ & $5,689.93$ & $8,728.77$ \\
\hline Utilidad neta & $\mathbf{- 1 1 , 1 8 3 . 9 3}$ & $\mathbf{1 , 0 6 2 . 2 0}$ & $\mathbf{7 , 8 8 0 . 7 6}$ & $\mathbf{1 3 , 2 7 6 . 5 1}$ & $\mathbf{2 0 , 3 6 7 . 1 4}$ \\
\hline
\end{tabular}

Elaboración Propia

\subsubsection{Balance General}

Al año 0 la empresa Eco Crops S.A.C. cuenta con un total de activos de USD 21,769.84 al igual que de pasivo y patrimonio neto. Al año 5 esto aumentará a un total de activos, pasivo y patrimonio neto a USD 107,934.97. Así mismo, al quinto año se contará con un total de utilidades retenidas por USD 8,146.85; demostrando que la empresa obtendrá ganancias. 
Tabla $N^{o}$ 3.35: Balance General de la empresa Eco Crops S.A.C

\begin{tabular}{|c|c|c|c|c|c|}
\hline BALANCE & Año 1 & Año 2 & Año 3 & Año 4 & Año 5 \\
\hline \multicolumn{6}{|l|}{ ACTIVO } \\
\hline \multicolumn{6}{|l|}{ Activo Corriente } \\
\hline Caja y bancos & $21,250.09$ & $10,748.00$ & $18,000.37$ & $19,847.94$ & $22,205.03$ \\
\hline Cuentas por cobrar & $79,189.59$ & $95,027.50$ & $128,385.34$ & $146,726.10$ & $165,066.87$ \\
\hline Total Activo Corriente & $100,439.68$ & $105,775.50$ & $145,994.11$ & $166,574.04$ & $187,271.90$ \\
\hline \multicolumn{6}{|l|}{ Activo No Corriente } \\
\hline Activo fijo & $6,659.78$ & $6,659.78$ & $6,659.78$ & $6,659.78$ & $6,659.78$ \\
\hline Depreciación Acumulada & - & $-2,264.58$ & $-3,396.87$ & $-4,529.16$ & $-5,661.46$ \\
\hline Activos intangibles & $2,731.25$ & - & - & - & - \\
\hline Amortización de intangibles & -273.13 & & & & \\
\hline Total Activo No Corriente & $9,117.91$ & $4,395.20$ & $3,262.91$ & $2,130.62$ & 998.32 \\
\hline Total Activo & $109,557.58$ & $110,170.70$ & $149,257.02$ & $168,704.66$ & $188,270.22$ \\
\hline \multicolumn{6}{|l|}{ PASIVO } \\
\hline Pasivo Corriente & & + & & & \\
\hline Parte corriente del préstamo & - & - & - & +2 & - \\
\hline CTS por pagar & 885.75 & 885.75 & $1,571.63$ & $1,571.63$ & $1,571.63$ \\
\hline Remuneraciones por pagar & $29,324.06$ & $29,324.06$ & $36,995.07$ & $36,995.07$ & $36,995.07$ \\
\hline Proveedores por pagar & $7,632.55$ & $9,159.05$ & $10,685.56$ & $12,212.07$ & $13,738.58$ \\
\hline Serv. Administrativos por pagar & $8,057.71$ & $14,895.41$ & $14,895.41$ & $14,895.41$ & $14,895.41$ \\
\hline Dividendos por pagar & & +2 & $4,728.45$ & $7,965.90$ & $12,220.28$ \\
\hline \multicolumn{6}{|l|}{ Otras cuentas por pagar } \\
\hline Total Pasivo Corriente & $45,900.06$ & $54,264.28$ & $68,876.13$ & $73,640.09$ & $79,420.98$ \\
\hline \multicolumn{6}{|l|}{ Pasivo No Corriente } \\
\hline Préstamo a largo plazo & - & - & - & - & - \\
\hline Total Pasivo No Corriente & - & - & - & - & - \\
\hline Total Pasivo & $45,900.06$ & $54,264.28$ & $68,876.13$ & $73,640.09$ & $79,420.98$ \\
\hline \multicolumn{6}{|l|}{ PATRIMONIO NETO } \\
\hline Capital social & $21,586.80$ & - & - & - & - \\
\hline Utilidades del periodo & - & $1,062.20$ & $7,880.76$ & $13,276.51$ & $20,367.14$ \\
\hline Utilidades retenidas & - & 424.88 & $3,152.30$ & $5,310.60$ & $8,146.85$ \\
\hline Total Patrimonio Neto & $21,586.80$ & $1,487.07$ & $11,033.06$ & $18,587.11$ & $28,513.99$ \\
\hline Total Pasivo y Patrimonio Neto & $67,486.86$ & $55,751.35$ & $79,909.19$ & $92,227.20$ & $107,934.97$ \\
\hline
\end{tabular}

Elaboración Propia 


\section{CONCLUSIONES}

- A través de este estudio de investigación se observa que existe un mercado en crecimiento para barras energéticas a base de quinua en el estado de Toronto, Canadá. En la actualidad los consumidores canadienses son más exigentes y demandantes de productos orgánicos beneficiosos para su salud, generándose así un mercado que se debe explotar, ofreciendo un producto diferenciado y de gran calidad.

- El mercado de destino cuenta con un poder adquisitivo elevado lo que le otorga una disponibilidad por pagar un mayor precio por un producto beneficioso para la salud.

- Canadá es considerado un mercado en búsqueda de productos innovadores y que sean "to-the-go", siendo este uno de los principales motivos por los cuales el consumo de snack es elevado. Se considera que el $51 \%$ de la población consumen por lo menos un snack al día.

- Con esta investigación se determina que la implementación de una empresa para exportar barras energéticas es factible tanto comercial, logística como económicamente.

- Comercialmente debido al aumento de demanda de productos orgánicos o hechos a base de insumos orgánicos. Logísticamente es gracias a la comunicación, la cual logra que nuestro producto llegue a importadores en la zona de influencia. Económicamente se debe a la viabilidad del proyecto por contar con una Tasa Interna de Retorno de 36.07\%, un Valor Actual Neto positivo de USD 20,101.00 y un Costo de Oportunidad de Capital 15.39\%; obteniendo un margen de ganancia de $10 \%$ con un precio de USD 1.83 por cada caja de 6 unidades que hace un total de 150 gramos del producto. 


\section{RECOMENDACIONES}

- Se recomienda analizar periódicamente el mercado meta, comportamiento del cliente, requerimientos, requisitos para ingresar al mercado, variaciones culturales y demás a fin de poder adaptarnos a los cambios y ofrecerle al cliente un producto que satisfaga sus necesidades.

- Se recomienda promocionar tanto el producto como la marca comercial a fin de elevar la demanda del bien y que el mercado vea la marca Eco Crops S.A.C. como sinónimo de calidad y excelente sabor, siendo $100 \%$ natural; razón por la cual en un mediano plazo estén dispuestos a pagar más por un producto que satisface sus necesidades.

- Por último, se recomienda aprovechar que actualmente Canadá cuenta con fuerte migración que prefiere sabores e insumos étnicos, siendo utilizado como benchmarket o mercado estratégico el cual logra dar a la empresa una oportunidad de aprendizaje que puede usarla para otros mercados similares. Permitiendo con ello, conocer el movimiento del mercado, determinación de consumo y comportamiento de clientes para aplicarlo en mercados parecidos. 


\section{BIBLIOGRAFÍA}

\section{Libros consultados}

Czinkota, M. (2008). Marketing Internacional. México D.F.: Cengage Learning, 8va edición.

Kotler, P., \& Armstrong, G. (2008). Fundamentos de Marketing. México D.F.: Pearson Educación de México, 8va edición.

Porter, M. (2009). Estrategia Competitiva. Técnicas para Análisis de los Sectores Industriales. Madrid: Editorial Pirámide.

\section{Documentos consultados}

Banco Central de Reserva (2013). Competitividad en el Perú: Situación y Agenda Pendiente.

Euromonitor International (2014). Snack bars in Canada.

Food and Drug Administration (2009). Guía de etiquetado para Canadá.

Organización para la Cooperación y Desarrollo Económico (2014). Obesity Update.

PROMPERU (2013). Guía de mercado Canadá.

PROMPERU (2014). Perfil producto-mercado, Quinua-Canadá.

World Economic Forum (2014).The Global Competitiviness Report 2013-2014.

\section{Páginas consultadas}

Adex Data Trade. Recuperado el 25 de abril del 2015, de

http://www.adexdatatrade.com/

Agencia Nacional de Estadísticas Canadá. Recuperado el 15 de enero de 2015, de http://www.statcan.gc.ca/start-debut-eng.html

Bloomberg. (2014). Recuperado el 05 de Noviembre de 2014, de http://www.bloomberg.com/ 
Canadian Institute for Health Information. Recuperado el 24 de Octubre de 2014, de http://www.cihi.ca/CIHI-ext-portal/internet/EN/Home/home/cihi000001

Consumo orgánico y conciencia ambiental de los consumidores. Recuperado el 24 de Octubre de 2014, de http://www.revistas.unam.mx/index.php/pde/article/view/7763

De Perú. (2014). Constitución Política del Perú (1993) - Actual. Recuperado el 05 de Noviembre de 2014, de http://www.deperu.com/abc/constituciones/235/constitucionpolitica-del-peru1993-actual

Esperanza de vida en Canadá. Recuperado el 20 de enero de 2015 de http://www.datosmacro.com/

Estacionalidad de la quinua en Perú. Recuperado el 23 de marzo de 2015 de, http://agroaldia.minag.gob.pe/biblioteca/download/pdf/agroeconomia/agroeconomia_qu inua.pdf

Evolución de la población en Canadá. Recuperado el 20 de enero de 2015 de http://www.datosmacro.com/

Evolución del acceso a internet en Canadá. Recuperado el 21 de enero de 2015 de http://cira.ca/factbook/2014/the-canadian-internet.html

Evolución Tasa de Crecimiento del PBI en Canadá. Recuperado el 20 de enero de 2015 de http://www.datosmacro.com/

Industria en Canadá. Recuperado el 21 de enero de 2015 de http://www.ic.gc.ca/eic/site/icgc.nsf/eng/home

Ministerio de Agricultura y Riego. Estadística de producción y exportación de Quinua Peruana. Recuperado el 29 de enero de 2015 de http://www.minag.gob.pe/portal/

Ministerio de producción. Recuperado el 23 de marzo de 2015 de, http://www.produce.gob.pe/

Quinua.pe. Portal Promovido por la Primera Dama Nadine Heredia, Recuperado el 20 de Noviembre de 2014, de http://quinua.pe/noticias-del-sector/

SIICEX. Estadísticas de la partida arancelaria 190410, Recuperado el 20 de enero de 2015 de http://www.siicex.gob.pe/promperustat/ 
Trade Data Online. Industry Canada. Recuperado el 15 de abril de 2015 de, http://www.ic.gc.ca/eic/site/tdo-dcd.nsf/eng/Home

Trademap. Estadística de partida arancelaria 190410. Recuperado el 05 de febrero de 2015 de http://www.trademap.org/ 
ANEXOS 


\section{ANEXO 1}

Presentación Final del producto: barras energéticas a base de quinua elaboradas por la empresa Eco Crops S.A.C.
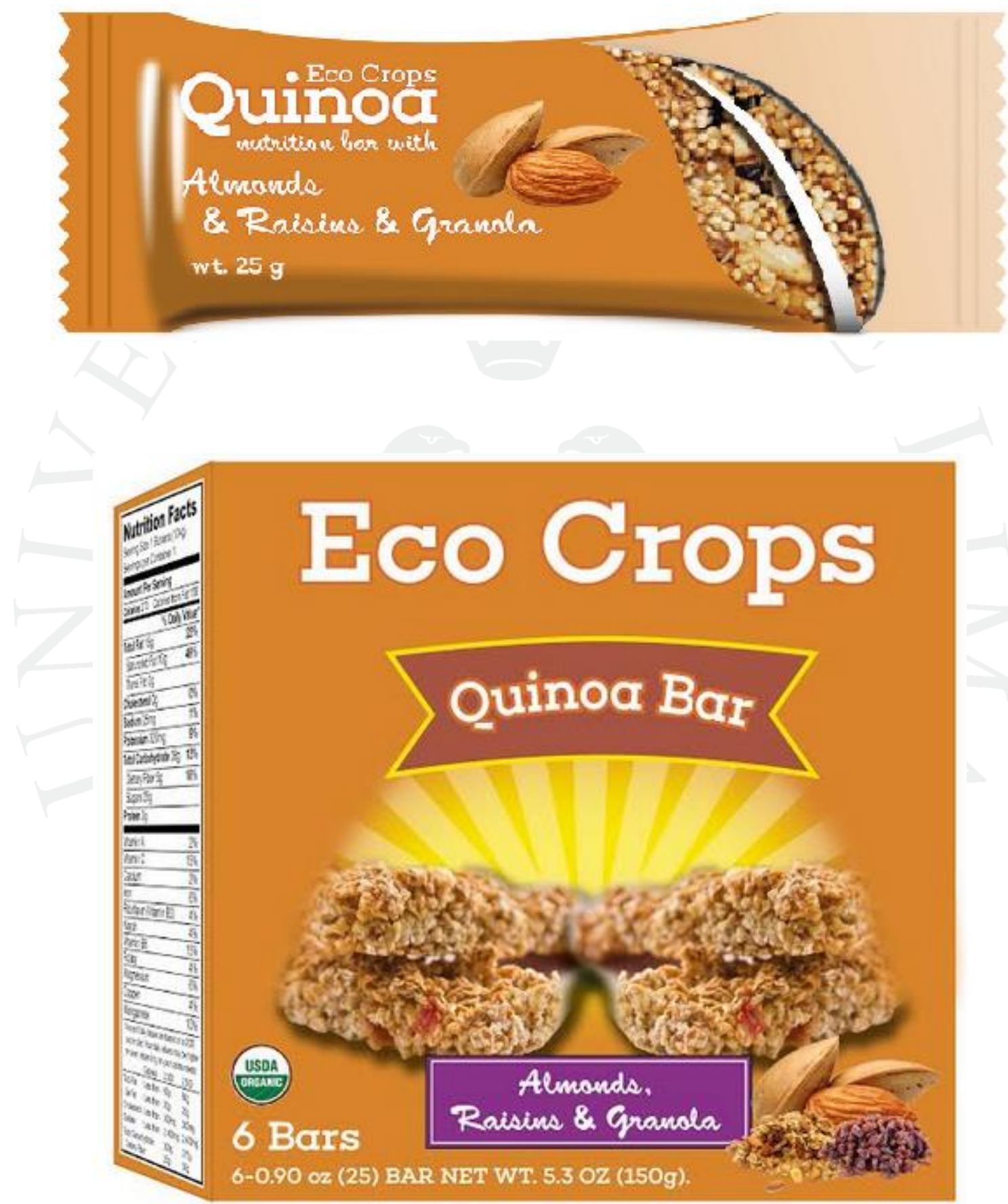


\section{Eco Crops}

Quinod Bats

2
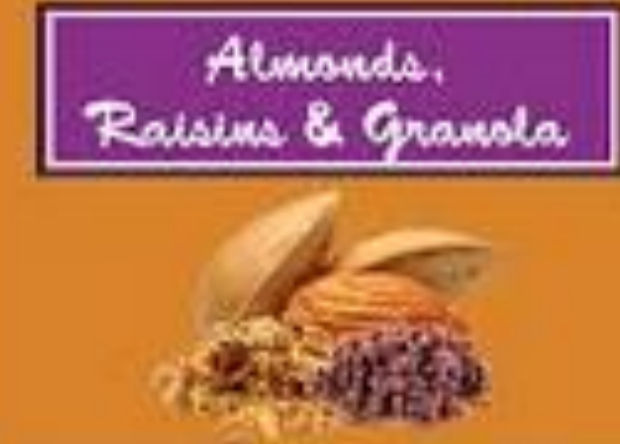

\section{Nutrition Facts}

Serving szo 2 Cups (aop)

Sorvings per Container VARIFD

Anowint per therving

Calories 150 Cabones from 1 in? 7 .

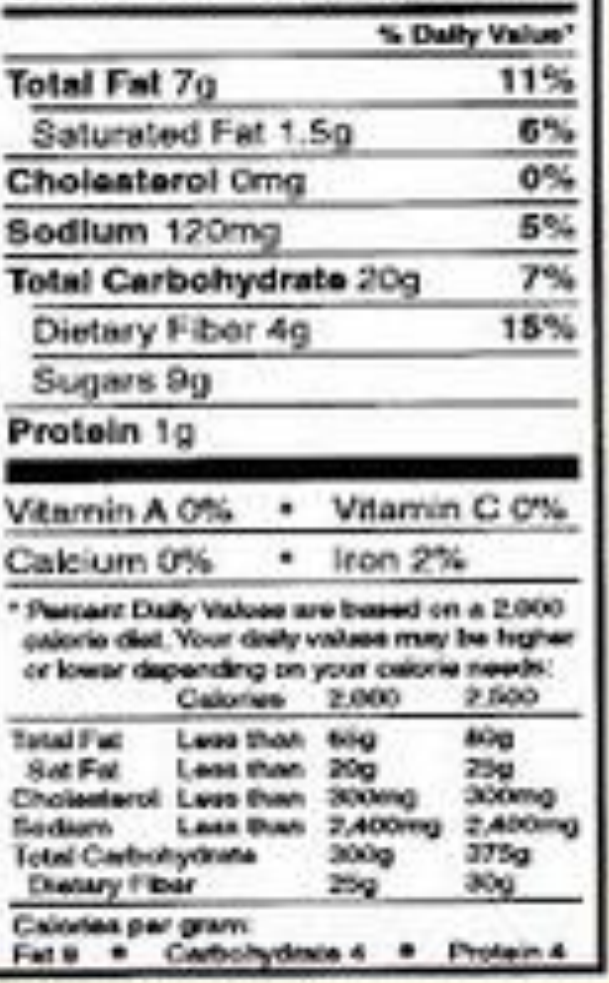




\begin{abstract}
ANEXO 2
Extracto de Reglamento para Uso de la Marca País

La Marca Perú se puede otorgar para Uso Institucional, para Uso en Productos y para Uso en Eventos, siendo uno de los requisitos en el primer caso que dicha empresa, nacional o extranjera, promocione la imagen del país en los aspectos ya mencionados; en el segundo caso es requisito que al registrarse portafolios de productos, estos sean como mínimo un $\mathbf{8 0 \%}$ de productos peruanos; y en el tercer caso, que dicho evento promocione también la imagen del país, el turismo, las exportaciones o las inversiones en el país. También se puede otorgar la licencia para el uso de la Marca Perú, en el caso de los productos, a productos peruanos de marca blanca que sean de exportación, así como productos de derechos de autor, correctamente registrados y legalizados (requisito fundamental).
\end{abstract}

Cumpliendo con lo dicho, es necesario pasar por un procedimiento en el cual se solicitará a PROMPERÚ la licencia para el uso de la Marca Perú. Las etapas del procedimiento son:

Presentación de la Solicitud de Licencia de Uso: Será presentada por personas naturales con negocios o personas jurídicas que desarrollen actividades económicas. En la solicitud la persona se dirigirá a PROMPERÚ de acuerdo a los términos del Reglamento para el Uso de la Marca País. Asimismo, se adjuntará, en cuanto resulte aplicable, la copia de la ficha del RUC, la copia de la vigencia de poder, la copia del DNI de la persona titular del RUC, la copia de licencia de funcionamiento, el certificado de registro de la marca, la copia del registro sanitario, la copia de la autorización de uso de la Denominación de Origen, la copia de la carta de referencia emitida por el Consulado Peruano (en caso de extranjería de la persona jurídica), la declaración jurada de la autoría de obras (en caso de derechos de autor) y la declaración jurada adjunta en el Reglamento para el Uso de la Marca País.

Evaluación: En cuanto a la evaluación de la Solicitud será realizada por el órgano competente, teniendo en cuenta los criterios de Formalidad (que todo esté conforme a las leyes peruanas y cuente con la documentación necesaria),Reputación (cumplimiento de obligaciones tributarias y comerciales, buena 
imagen), Calidad y origen de los productos y servicios (buena calidad de productos y servicios, certificados y reconocimientos) y Uso alineado con la Marca País (la Solicitud debe estar alineada a los objetivos de la Marca País: imagen del país, promoción del turismo, exportación, inversiones extranjeras, etc.).

Pronunciamiento: Luego de realizada la evaluación, el órgano competente emitirá un pronunciamiento, el cual, de ser favorable, extenderá el Certificado para la Licencia de Uso de la Marca Perú, y, de ser denegatorio, será notificado mediante carta notificada a quien lo solicitó, siendo en ambos casos entregada la respuesta en la sede de PROMPERÚ.

Reevaluación: De obtener una denegatoria, el solicitante podrá pedir una única reevaluación de dicho pronunciamiento denegatorio.

El proceso, en total, dura 25 días calendario, salvo excepciones. Como se dijo antes, la Licencia para usar la Marca Perú será otorgada por un periodo máximo de 2 años, pudiendo presentarse luego de dicho periodo una solicitud de renovación de la licencia. 


\begin{abstract}
ANEXO 3
Carta de crédito - Scotiabank.

Se trata de un medio de pago de Comercio Exterior por el cual un importador (ordenante) instruye a su banco en el exterior a emitir una Carta de Crédito a favor de un exportador peruano (beneficiario) por una operación de compra - venta de mercaderías/servicios. Las Cartas de Crédito pueden ser AVISADAS y
\end{abstract}

CONFIRMADAS según las responsabilidades que asuman los bancos en cada caso.

\title{
Ventajas
}

- Estructuramos, avisamos y confirmamos sus cartas de crédito, de acuerdo con términos y condiciones establecidos, en la amplia red de corresponsales con los que contamos.

- Confidencialidad en el manejo de sus documentos y cumplimientos de las reglas y usos vigentes.

- Contamos con personal técnico que le brindará asesoramiento especializado y personalizado en sus operaciones.

- Podrá dar seguimiento de las operaciones de sus cuentas desde sus oficinas a través de Telebanking con tecnología de punta que brinda agilidad a sus operaciones.

- Comisiones competitivas.

- Con este instrumento podrá obtener liquidez a través de financiamientos pre y post embarque y compra de documentos internacionales.

\section{$\underline{\text { Características }}$}

Le permite enviar su mercadería al exterior con tranquilidad, confianza y total seguridad gracias a este medio de pago gestionado por su compra.

\section{$\underline{\text { Requisitos }}$}

- Indicarle a su importador en el exterior la dirección Swift del Banco. 
- Una vez exportada la mercadería, y de acuerdo a las cláusulas de la carta de crédito, presentar los documentos requeridos por el importador a Banco (factura comercial, conocimiento de embarque, packing list, certificaciones, etc).

\section{Tarifario de cartas de crédito de exportación}




\section{Scotiabank}

\begin{tabular}{|c|c|c|c|c|}
\hline \multirow[b]{2}{*}{ Concepto } & \multicolumn{2}{|c|}{ Tarifas } & \multirow{2}{*}{$\begin{array}{l}\text { Forma de } \\
\text { Aplicación }\end{array}$} & \multirow[b]{2}{*}{ Obeervaciones } \\
\hline & M. N. & $\begin{array}{l}\text { M. E. } \\
\text { [USs] }\end{array}$ & & \\
\hline \multicolumn{5}{|l|}{ Comisiones } \\
\hline 4.1 Por aviso (") & $\begin{array}{l}\text { Equik a } \\
\text { USs. } 60.00\end{array}$ & $\begin{array}{l}\text { USS } 60.00 \\
\text { (SI. } 162.00)\end{array}$ & Flat & \\
\hline 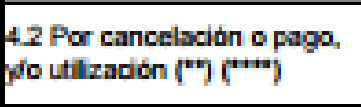 & $\begin{array}{c}0.27 \% \\
\text { Min Equiv a } \\
\text { US\$\$\$S.00 }\end{array}$ & $\begin{array}{c}0.27 \% \\
\text { Min US\$ } 56.00 \\
\text { (SI. 148.50) }\end{array}$ & Flat & $\begin{array}{l}\text { Sobre el valor de las } \\
\text { documentos. }\end{array}$ \\
\hline $\begin{array}{l}\text { 4.2.1 Por Aceptación / Pago } \\
\text { Diferido }\end{array}$ & $\begin{array}{c}1.70 \% \\
\text { Min Equik a } \\
\text { USs } 500.00 \\
\end{array}$ & $\begin{array}{c}1.70 \% \\
\text { Min US\$ } 60.00 \\
\text { (\$1. 162.00) }\end{array}$ & Por afo & $\begin{array}{c}\text { Si la carta de credino es a } \\
\text { plazo se cobrard por juego de } \\
\text { documentos }\end{array}$ \\
\hline $\begin{array}{l}\text { 4.3 Por Confirmacion / } \\
\text { Nominacion }\end{array}$ & $\begin{array}{c}0.20 \% \\
\text { Min Equh a } \\
\text { USs5s5.00 }\end{array}$ & $\begin{array}{c}0.20 \% \\
\text { Min US\$ } 56.00 \\
\text { (SI. 148.50) }\end{array}$ & $\begin{array}{l}\text { Trimestre o } \\
\text { fraccion }\end{array}$ & $\begin{array}{c}\text { E pordentaje aplica sobre ed } \\
\text { monto maximo de la carta de } \\
\text { crédito. }\end{array}$ \\
\hline 4.4 Por incremento ("N) ("x") & $\begin{array}{c}0.20 \% \\
\text { Min Equik a } \\
\text { USs } 56.00\end{array}$ & $\begin{array}{c}0.20 \% \\
\text { Min USs } 55.00 \\
\text { (SI. 148.50) }\end{array}$ & $\begin{array}{l}\text { Trimestre o } \\
\text { fraccion }\end{array}$ & $\begin{array}{l}\text { E pordentaje aplica sobre el } \\
\text { incremento }\end{array}$ \\
\hline $\begin{array}{l}4.5 \text { Por probrroga / fuera del } \\
\text { periodo inicial }\left({ }^{* *}\right)\left({ }^{* *}\right)\end{array}$ & $\begin{array}{c}0.20 \% \\
\text { Min Equh a } \\
\text { USSES.00 }\end{array}$ & $\begin{array}{c}0.20 \% \\
\text { Min USs } 56.00 \\
\text { (S). 148.50) }\end{array}$ & $\begin{array}{l}\text { Trimestre o } \\
\text { fraccion }\end{array}$ & $\begin{array}{l}\text { E pordentaje aplica sobre el } \\
\text { monto de la carta de credino }\end{array}$ \\
\hline $\begin{array}{l}4.6 \text { Por Pre aviso, por } \\
\text { Modificacion, anulación, } \\
\text { descargo o próroga, } \\
\text { sulenticacion de LiC, LC sin } \\
\text { enlezar ("*) }\end{array}$ & $\begin{array}{l}\text { Equik a } \\
\text { uss.40.00 }\end{array}$ & $\begin{array}{l}\text { USS } 40.00 \\
\text { (SI. 108.00) }\end{array}$ & Por tramite & $\begin{array}{l}\text { Dentro del periodo de apertura } \\
\text { inicial. }\end{array}$ \\
\hline $\begin{array}{l}\text { 4.7 Por Transferendia de } \\
\text { Carta de creditio (") }\end{array}$ & $\begin{array}{c}0.20 \% \\
\text { Min Equh a } \\
\text { US\$\$\$ } \$ 5.00 \\
\end{array}$ & $\begin{array}{c}0.20 \% \\
\text { Min US\$ } 56.00 \\
\text { (SI. 148.50) }\end{array}$ & Flat & $\begin{array}{c}\text { 日 pordentaje aplica sobre el } \\
\text { monto transterible }\end{array}$ \\
\hline 4.8 Por discrepancias & $\begin{array}{c}\text { Equiv a } \\
\text { USS. } 55.00\end{array}$ & $\begin{array}{l}\text { USS } 55.00 \\
\text { (SL. 148.50) }\end{array}$ & Por tramihe & \\
\hline $\begin{array}{l}4.9 \text { Por emision de Cartas } \\
\text { Compromiso }\end{array}$ & $\begin{array}{c}\text { Equik a } \\
\text { Usș. } .35 .00\end{array}$ & $\begin{array}{l}\text { USS } 35.00 \\
(\$ 1.94 .50) \\
\end{array}$ & Por tramite & $\begin{array}{c}\text { Adcionaimenie se cobra } \\
\text { Comision de Swift }\end{array}$ \\
\hline $\begin{array}{l}\text { 4.10 Por transferencia de } \\
\text { fondas o emisidn de giros o } \\
\text { de cheques ("*) }\end{array}$ & & & Por tramite & Aplica sobre el importe a emtir \\
\hline 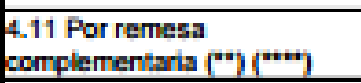 & $\begin{array}{c}\text { Equik a } \\
\text { USș.11.00 }\end{array}$ & $\begin{array}{l}\text { USS } 11.00 \\
\text { (SI. 29.70) }\end{array}$ & Por tramite & \\
\hline $\begin{array}{l}\text { 4.12 Por revision de } \\
\text { documentas }\end{array}$ & $\begin{array}{l}\text { Equir a } \\
\text { Uss. } .56 .00\end{array}$ & $\begin{array}{l}\text { USS } 85.00 \\
\text { (SI. 148.50) }\end{array}$ & Por tramite & $\begin{array}{c}\text { Por unlizaciones fallidas yfo } \\
\text { revisiones adicionales ylo } \\
\text { juegos mútiples }\end{array}$ \\
\hline
\end{tabular}




\section{Scotiabank}

\begin{tabular}{|c|c|c|c|c|}
\hline \multirow[b]{2}{*}{ Cancopto } & \multicolumn{2}{|c|}{ Taritas } & \multirow{2}{*}{$\begin{array}{l}\text { Forming do } \\
\text { Aplicaciton }\end{array}$} & \multirow[b]{2}{*}{ Qheurariones } \\
\hline & H. N. & $\begin{array}{l}\text { H. E. } \\
\text { [uBs] }\end{array}$ & & \\
\hline $\begin{array}{l}\text { 4.13 Por gestibn ante d } \\
\text { eCRP }\end{array}$ & $\begin{array}{l}\text { Equh a } \\
\text { US5.10.00 }\end{array}$ & $\begin{array}{l}\text { USs } 10.00 \\
(0.27 .00)\end{array}$ & $\begin{array}{c}\text { Por tramile, } \\
\text { al reembolso } \\
\text { o pago }\end{array}$ & $\begin{array}{l}\text { Trantite documentario } \\
\text { ante BCFP }\end{array}$ \\
\hline Por Gesion de Swit & $\begin{array}{c}\text { EquFa } \\
\text { UBS.2.00 }\end{array}$ & $\begin{array}{l}\text { US5 } 2200 \\
\text { (9. 59.40) } \\
\end{array}$ & & $\begin{array}{c}\text { Preparacibn y envio de } \\
\text { mensajes ofrados }\end{array}$ \\
\hline Por Cestion de Portes & $\begin{array}{l}\text { Equk a } \\
\text { LSST.11.00 }\end{array}$ & $\begin{array}{l}\text { USS 11.00 } \\
\text { (8.29.70) }\end{array}$ & & $\begin{array}{c}\text { Generadibn y envilo de } \\
\text { informaxidn }\end{array}$ \\
\hline Por Modfílación & $\begin{array}{c}\text { EquF a } \\
\text { US5.40.00 } \\
\end{array}$ & $\begin{array}{l}\text { USS } 4000 \\
\text { (81. 108.00) }\end{array}$ & & \\
\hline Por Courier, si aplica & & & & Se trasiada el cosio del courier \\
\hline \multicolumn{5}{|l|}{ Gastona } \\
\hline 4.14 Por Conveno Aladi & $\begin{array}{l}\text { 0.025 } \\
\text { Min Equh } \\
\text { ussi.00 }\end{array}$ & $\begin{array}{l}0.025 \\
\text { uss } 1.00 \\
(9.2 .70)\end{array}$ & Por trämile & $\begin{array}{c}\text { Be fraslada costo del BCFP } \\
\text { por converio de la Asoc. } \\
\text { Lathoamericana de } \\
\text { Iniegranón. }\end{array}$ \\
\hline \multicolumn{5}{|c|}{ 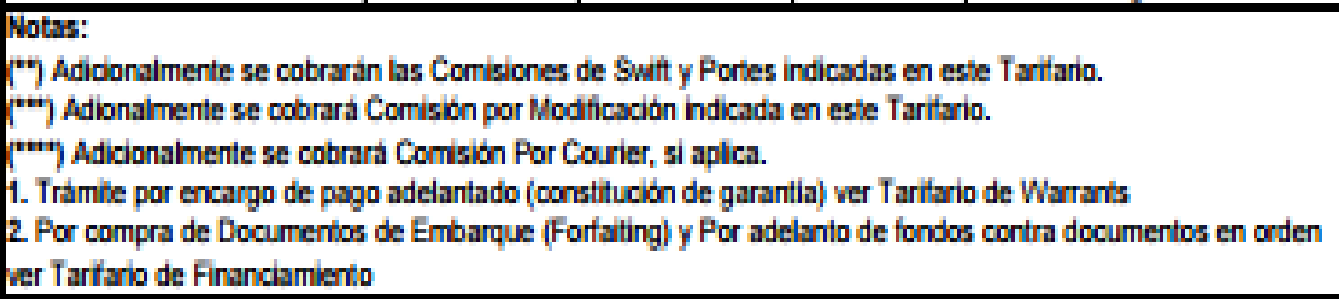 } \\
\hline \multicolumn{5}{|c|}{ 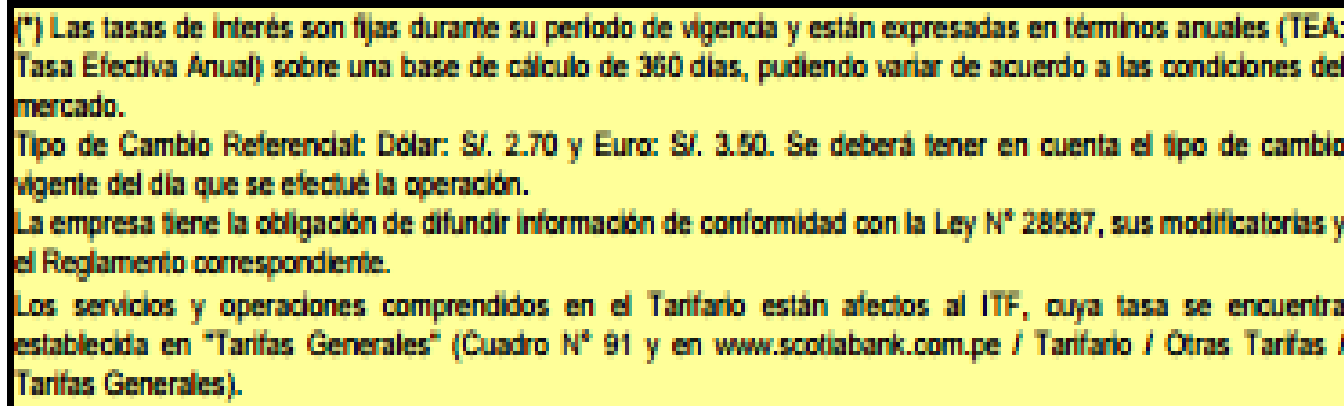 } \\
\hline
\end{tabular}

Fuente: Scotiabank. Tarifario de carta de crédito de exportación. Recuperado el 06 de Abril del 2015 , de http://www.scotiabank.com.pe/Empresas/Comercio-Exterior/Medios-de-Pago/carta-de-credito-de-exportacion 


\begin{abstract}
ANEXO 4
Condiciones para ser Micro Empresa y para ser Pequeña Empresa.

La Ley de Impulso al Desarrollo Productivo y al Crecimiento Empresarial - Texto Único Ordenado aprobado mediante el D.S. 013-2013-PRODUCE publicado el 28.12.2013 - regula las condiciones y beneficios relativos a las MIPYME (Micro Empresas, Pequeñas Empresas y Medianas Empresas). Las MIPYME, constituyen uno de los pilares de la economía nacional porque además de generar el autoempleo, promueven la competitividad y formalización de la economía, redundando en el crecimiento y desarrollo del país; de ahí el interés del Estado de promover a estas pequeñas unidades económicas con capitales pequeños dedicadas a la extracción, transformación, producción o comercialización para que se desarrollen.
\end{abstract}

\title{
MICRO EMPRESA
}

Ventas anuales Hasta monto máximo de 150 UIT (*)

\section{PEQUEÑA EMPRESA}

Ventas anuales Mayores a 150 UIT hasta monto máximo de 1,700 UIT (*)

\section{MEDIANA EMPRESA}

Ventas anuales

Mayores a 1,700 UIT hasta monto máximo de 2,300 UIT (*)

(*) La UIT para el año 2015 es de S/ 3,850 nuevos soles.

Fuente: SUNAT. Guía Tributaria. Recuperado el 06 de Abril de 2015, de http://www.guiatributaria.sunat.gob.pe/index.php/contribuyentes/empresas-y-negocios/mypes/51901-condiciones-para-ser-microempresa-y-para-ser-pequena-empresa 


\section{ANEXO 5}

Características INCONTERM FOB 2010

Término utilizado exclusivamente cuando el transporte de la mercancía se realiza por barco (mar o vías fluviales de navegación interior).

El vendedor cumple con su obligación de entrega cuando la mercancía ha sobrepasado la borda del buque en el puerto de embarque convenido. El vendedor tiene que despachar la mercancía de exportación.

\section{Obligaciones del comprador}

- Pagar lo dispuesto en el contrato de compra-venta y conseguir, por su propia cuenta y riesgo, cualquier licencia de importación u autorización oficial precisa, así como llevar a cabo todas las formalidades aduaneras para la importación de la mercancía.

- Contratar el transporte de la mercancía desde el puerto de embarque designado y recibir la entrega de la mercancía.

- Asumir todos los riesgos de pérdida o daño de la mercancía, así como todos los gastos desde el momento en que haya sobrepasado la borda del buque en el puerto de embarque, si no da aviso suficiente o si el buque no llega a tiempo debe soportar todos los riesgos de pérdida o daño que pueda sufrir la mercancía a partir de la fecha de expiración del plazo fijado para la entrega.

- Pagar todos los gastos de derechos, impuestos y otras cargas oficiales.

- Pagar los costes posteriores generados a la entrega de la mercancía (flete, descarga en el puerto de destino, trámites de aduana de importación).

- Avisar sobre el nombre del buque, el punto de carga y la fecha de entrega requerida, aceptará la prueba de la entrega y pagará los gastos de la inspección previa al embarque, excepto si la inspección ha sido ordenada por las autoridades del país exportador.

- Otras obligaciones como son pagar los gastos y cargas en que se haya incurrido para la obtención de los documentos y reembolsar los efectuados por el vendedor al prestar su ayuda al respecto.

- Posibilidad de contratar seguro para cubrir el riesgo durante el transporte en barco. 


\section{Obligaciones del vendedor}

- Suministrar la mercancía y la factura comercial de conformidad con el contrato de venta, obtener cualquier licencia de exportación y cualquiera otra autorización oficial precisa así como llevar a cabo los trámites aduaneros necesarios para la exportación de la mercancía.

- Entregar la mercancía a bordo del buque designado por el comprador.

- Soportar los riesgos de pérdida o daño de la mercancía, así como los gastos, hasta el momento en que haya sobrepasado la borda del buque en el puerto de embarque fijado y dará al comprador aviso suficiente de que la mercancía ha sido entregada a bordo. Le proporcionará al comprador el documento usual de prueba de la entrega, pagará los gastos de las operaciones de verificación necesarias para entregar la mercancía y proporcionará a sus expensas el embalaje requerido para el transporte de la mercancía.

- Asumir los costes aduaneros necesarios para la exportación.

- Otras obligaciones a las que el vendedor tiene que hacer frente son las de prestar al comprador, a petición suya, la ayuda precisa para obtener cualquier documento emitido en el país de embarque y/o de origen que pueda necesitar el comprador para la importación de la mercancía y para su paso en tránsito por otros países, así como la información necesaria para conseguir un seguro.

\section{Documentación mínima a aportar por el vendedor}

- Factura comercial.

- Lista de contenido (en el supuesto de que la expedición esté compuesta por más de un bulto).

- Otros documentos dependiendo de las características del producto:

- Certificado Sanitario.

- Certificado de Metrología.

- Certificado de Pesos.

- Certificado CITES.

- Otras Certificaciones relativas al producto a tramitar en el país de origen. 
- En función del Régimen Comercial de Exportación, el vendedor podrá precisar para el despacho Aduanero de Exportación algunos de los siguientes documentos:

- Licencia de Exportación.

- Autorización Administrativa de Exportación.

- Documento de Vigilancia Comunitaria.

- Notificación Previa de Exportación.

\section{$\underline{\text { Medios de pago habituales }}$}

- Transferencia.

- Remesa simple.

- Remesa Documentaria.

- Crédito Documentario.

\section{Gráfico}

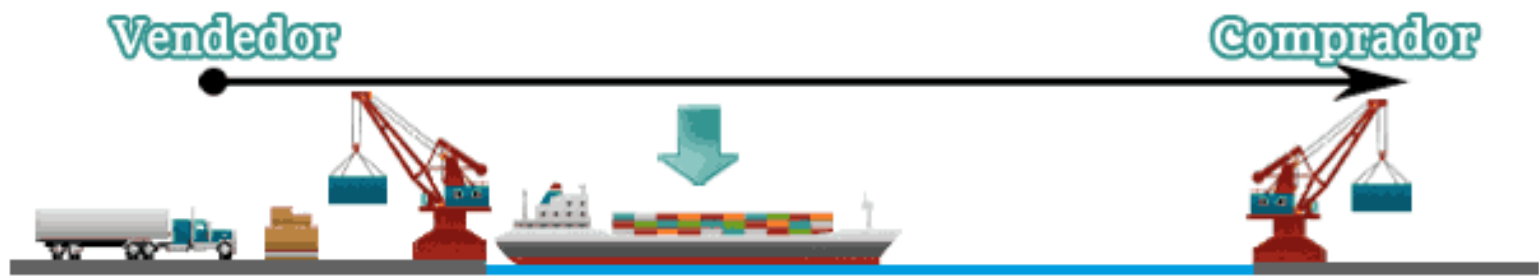

Fuente: Área de PYMES. FOB: Free On Board (Libre a bordo, Puerto de carga convenido). Recuperado el 06 de Abril del 2015 de, http://www.areadepymes.com/?tit=fob-free-on-board-libre-a-bordo-puerto-de-carga-convenido-guia-de-incoterms$2010 \&$ name $=$ Manuales $\&$ fid $=$ em 0 bcae 


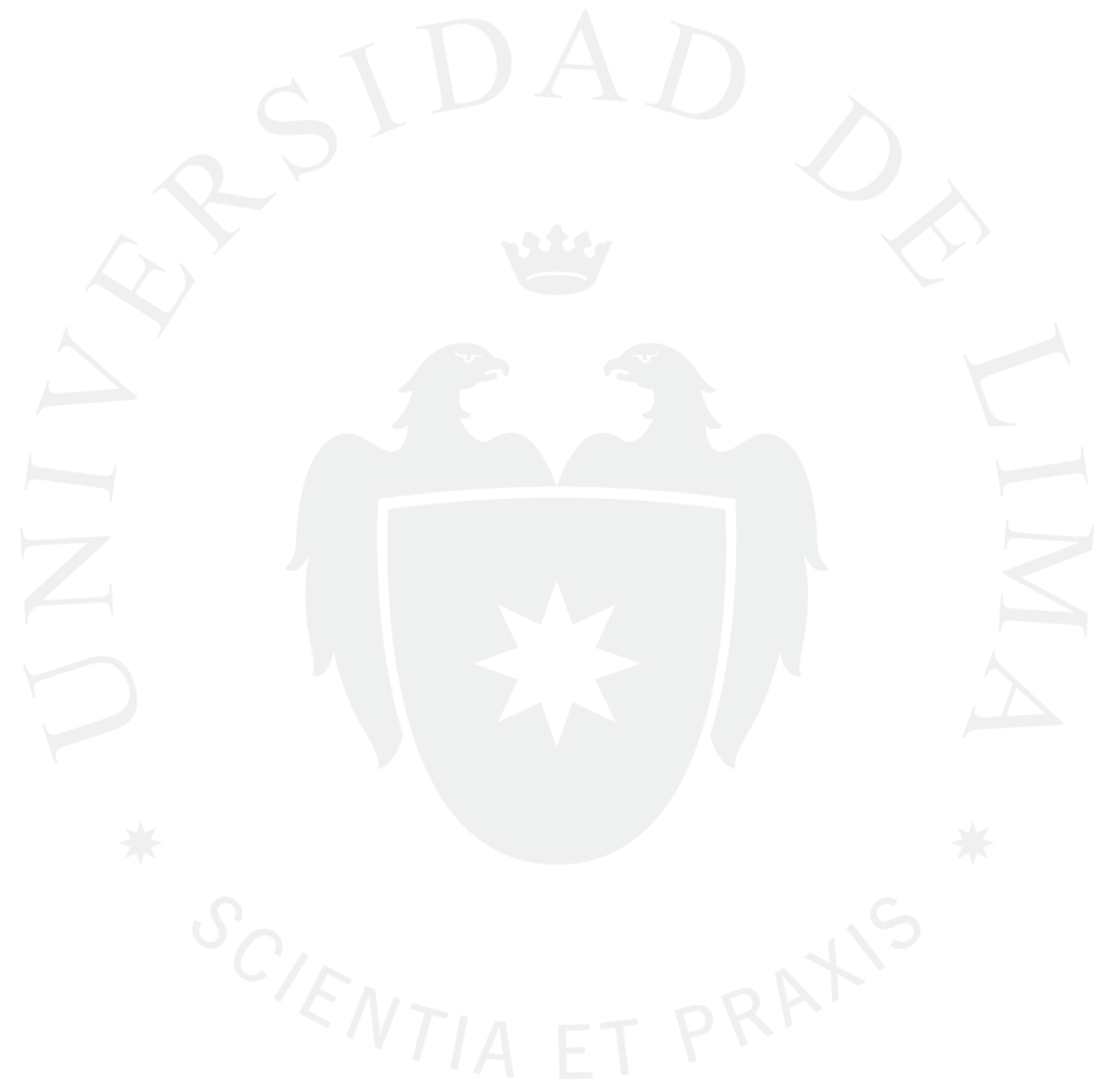




\section{ANEXO 6}

Documentos básicos de exportación para barras energéticas a base de quinua:

- Invoice o factura comercial.

- Packing List.

- Certificado de origen, en nuestro caso por ser un producto que se dirige a Canadá existe la autocertificación. Gracias al Tratado de Libre Comercio que existe entre Perú y Canadá, el exportador es el responsable de emitir el certificado de origen.

\begin{tabular}{|l|l||l|}
\hline $\begin{array}{l}\text { Tratado de Libre Comercio Perú } \\
\text { Canadá }\end{array}$ & $\begin{array}{l}\text { Capitulo 3: Reglas de Origen } \\
\text { (Español) (Inglés) (Francés) } \\
\text { Anexo 301: Requisitos Especificos de Origen } \\
\text { (Español) } \\
\text { Capitulo 4: Procedimientos de Origen y Facilitación dell } \\
\text { Comercio } \\
\text { (Español) (Inglés) (Francés) }\end{array}$ & $\begin{array}{l}\text { (Español) } \\
\text { (Inglés) } \\
\text { (Francés) }\end{array}$ \\
\hline
\end{tabular}

- Permiso fitosanitario. 


\section{ANEXO 7}

Minuta de constitución.

ACTO CONSTITUTIVO DE SOCIEDAD ANONIMA CERRADA CON DIRECTORIO -

CON APORTE DINERARIO

SEÑOR NOTARIO,

SÍRVASE EXTENDER EN SU REGISTRO DE ESCRITURAS PÚBLICAS UNA CONSTITUCIÓN SIMULTÁNEA DE SOCIEDAD ANONIMA CERRADA, QUE OTORGAN:

A NATALIA ARCAYA DEL AGUILA DE NACIONALIDAD PERUANA, PROFESIÓN NEGOCIOS INTERNACIONALES CON D.N.I. 46498929, ESTADO CIVIL SOLTERO; A CONSTANTINO ERNESTO ARCAYA VERNA DE NACIONALIDAD PERUANA, PROFESIÓN INGENIERO CIVIL CON D.N.I. 10310910, ESTADO CIVIL CASADO, SEÑALANDO DOMICILIO COMUN PARA EFECTOS DE ESTE INSTRUMENTO EN: JR. ENRIQUE LEON GARCIA 473, DISTRITO DE SANTIAGO DE SURCO, PROVINCIA DE LIMA Y DEPARTAMENTO DE LIMA.

\section{EN LOS TERMINOS SIGUIENTES:}

PRIMERO.- POR EL PRESENTE PACTO SOCIAL, LOS OTORGANTES MANIFIESTAN SU LIBRE VOLUNTAD DE CONSTITUIR UNA SOCIEDAD ANONIMA CERRADA, BAJO LA DENOMINACION DE "ECO CROPS SOCIEDAD ANONIMA CERRADA", PUDIENDO UTILIZAR LA DENOMINACIÓN ABREVIADA DE "ECO CROPS S.A.C.”; SE OBLIGAN A EFECTUAR LOS APORTES PARA LA FORMACION DEL CAPITAL SOCIAL Y A FORMULAR EL CORRESPONDIENTE ESTATUTO.

SEGUNDO.- EL MONTO DEL CAPITAL DE LA SOCIEDAD ES DE 19,934.21 EN DÓLARES AMERICANOS DIVIDIDO EN 1,993.42 ACCIONES NOMINATIVAS 
DE UN VALOR NOMINAL DE \$ 10.00 CADA UNA SUSCRITAS Y PAGADAS DE LA SIGUIENTE MANERA:

- CONSTANTINO ERNESTO ARCAYA VERNAL, SUSCRIBE 1,196 ACCIONES NOMINATIVAS Y PAGA \$ 11,960.6 MEDIANTE APORTES EN BIENES DINERARIOS.

- NATALIA ARCAYA DEL AGUILA, SUSCRIBE 797 ACCIONES NOMINATIVAS Y PAGA \$ 7,974 MEDIANTE APORTES EN BIENES DINERARIOS.

EL CAPITAL SOCIAL SE ENCUENTRA TOTALMENTE SUSCRITO Y PAGADO.

TERCERO.- LA SOCIEDAD SE REGIRÁ POR EL ESTATUTO SIGUIENTE Y EN TODO LO NO PREVISTO POR ESTE, SE ESTARÁ A LO DISPUESTO POR LA LEY GENERAL DE SOCIEDADES - LEY 26887 - QUE EN ADELANTE SE LE DENOMINARA LA “LEY”.

ESTATUTO

- ARTICULO 1.- DENOMINACION-DURACION-DOMICILIO: LA SOCIEDAD SE DENOMINA: "ECO CROPS SOCIEDAD ANONIMA CERRADA" PUDIENDO USAR LA DENOMINACIÓN ABREVIADA "ECO CROPS S.A.C.".

TIENE UNA DURACION INDETERMINADA, INICIA SUS OPERACIONES EN LA FECHA DE ESTE PACTO Y ADQUIERE PERSONALIDAD JURIDICA DESDE SU INSCRIPCION EN EL REGISTRO DE PERSONAS JURIDICAS DE LIMA.

SU DOMICILIO ES LA PROVINCIA DE LIMA, DEPARTAMENTO DE LIMA PUDIENDO ESTABLECER SUCURSALES U OFICINAS EN CUALQUIER LUGAR DEL PAIS O EN EL EXTRANJERO.

- ARTICULO 2.- OBJETO SOCIAL: LA SOCIEDAD TIENE POR OBJETO DEDICARSE A: LA PRODUCCION, EXPORTACION Y 
COMERCIALIZACION DE BARRAS ENERGETICAS A BASE DE QUINUA.

SE ENTIENDEN INCLUIDOS EN EL OBJETO SOCIAL LOS ACTOS RELACIONADOS CON EL MISMO QUE COADYUVEN A LA REALIZACION DE SUS FINES. PARA CUMPLIR DICHO OBJETO PODRA REALIZAR TODOS AQUELLOS ACTOS Y CONTRATOS QUE SEAN LICITOS, SIN RESTRICCION ALGUNA.

- ARtículo 3.- CAPITAL SOCiAL: EL MONTO DEL CAPITAL DE LA SOCIEDAD ES DE 19,934.21 $\quad(19,934.21 \quad / 100 \quad$ EN DÓLARES AMERICANOS) REPRESENTADO POR 1,993 ACCIONES NOMINATIVAS DE UN VALOR NOMINAL DE \$ 10.00 CADA UNA.

EL CAPITAL SOCIAL SE ENCUENTRA TOTALMENTE SUSCRITO Y PAGADO.

- ARTICULO 4.- TRANSFERENCIA Y ADQUISICION DE ACCIONES: LOS OTORGANTES ACUERDAN SUPRIMIR EL DERECHO DE PREFERENCIA PARA LA ADQUISICION DE ACCIONES, CONFORME A LO PREVISTO EN EL ULTIMO PARRAFO DEL ARTICULO $237^{\circ}$ DE LA "LEY".

- ARTICULO 5.- ORGANOS DE LA SOCIEDAD: LA SOCIEDAD QUE SE CONSTITUYE TIENE LOS SIGUIENTES ORGANOS:
A) LA JUNTA GENERAL DE ACCIONISTAS;
B) EL DIRECTORIO Y
C) LA GERENCIA.

- ARTICULO 6.- JUNTA GENERAL DE ACCIONISTAS: LA JUNTA GENERAL DE ACCIONISTAS ES EL ORGANO SUPREMO DE LA SOCIEDAD. LOS ACCIONISTAS CONSTITUIDOS EN JUNTA GENERAL DEBIDAMENTE CONVOCADA, Y CON EL QUORUM 
CORRESPONDIENTE, DECIDEN POR LA MAYORIA QUE ESTABLECE LA "LEY" LOS ASUNTOS PROPIOS DE SU COMPETENCIA. TODOS LOS ACCIONISTAS INCLUSO LOS DISIDENTES Y LOS QUE NO HUBIERAN PARTICIPADO EN LA REUNION, ESTAN SOMETIDOS A LOS ACUERDOS ADOPTADOS POR LA JUNTA GENERAL.

LA CONVOCATORIA A JUNTA DE ACCIONISTAS SE SUJETA A LO DISPUESTO EN EL ART. 245 DE LA "LEY". EL ACCIONISTA PODRA HACERSE REPRESENTAR EN LAS REUNIONES DE JUNTA GENERAL POR MEDIO DE OTRO ACCIONISTA, SU CONYUGE, O ASCENDIENTE O DESCENDIENTE EN PRIMER GRADO, PUDIENDO EXTENDERSE LA REPRESENTACION A OTRAS PERSONAS.

- ARTICULO7.- JUNTAS NO PRESENCIALES: LA CELEBRACION DE JUNTAS NO PRESENCIALES SE SUJETA A LO DISPUESTO POR EL ARTICULO 246 DE LA "LEY".

- ARTICULO 8.- EL DiRECTORIO: LA SOCIEDAD TENDRÁ UN DIRECTORIO INTEGRADO POR CONSTANTINO ERNESTO ARCAYA VERNAL Y NATALIA ARCAYA DEL AGUILA. MIEMBROS QUE PUEDEN O NO, SER ACCIONISTAS, CUYO PERÍODO DE DURACIÓN SERÁ DE TRES (3) AÑOS, PUDIENDO SUS MIEMBROS SER REELEGIDOS.

EL CARGO DE DIRECTOR SÓLO RECAE EN PERSONAS NATURALES. LOS DIRECTORES PUEDEN SER REMOVIDOS EN CUALQUIER MOMENTO POR LA JUNTA GENERAL. EL CARGO DE DIRECTOR ES RETRIBUIDO. LOS DIRECTORES SERÁN ELEGIDOS CON REPRESENTACIÓN DE LA MINORÍA, DE ACUERDO A LA LEY GENERAL DE SOCIEDADES. 
- ARTículo 9.- VACANCIA: VACA EL CARGO DE DIRECTOR POR FALLECIMIENTO, RENUNCIA, REMOCIÓN O POR INCURRIR EL DIRECTOR EN ALGUNA DE LAS CAUSALES DE IMPEDIMENTO SEÑALADAS POR LA LEY. EN CASO DE VACANCIA, EL MISMO DIRECTORIO PODRÁ ELEGIR A LOS REEMPLAZANTES PARA COMPLETAR SU NÚMERO POR EL PERÍODO QUE AÚN RESTA AL DIRECTORIO. EN CASO DE QUE SE PRODUZCA VACANCIA DE DIRECTORES EN NÚMERO TAL QUE NO PUEDA REUNIRSE VÁLIDAMENTE EL DIRECTORIO, LOS DIRECTORES HÁBILES ASUMIRÁN PROVISIONALMENTE LA ADMINISTRACIÓN Y CONVOCARÁN DE INMEDIATO A LA JUNTA DE ACCIONISTAS QUE CORRESPONDA PARA QUE ELIJAN NUEVO DIRECTORIO. DE NO HACERSE ESTA CONVOCATORIA O DE HABER VACADO EL CARGO DE TODOS LOS DIRECTORES, CORRESPONDERÁ AL GERENTE REALIZAR DE INMEDIATO DICHA CONVOCATORIA. SI LAS REFERIDAS CONVOCATORIAS NO SE PRODUJESEN DENTRO DE LOS DIEZ DIAS SIGUIENTES, CUALQUIER ACCIONISTA PUEDE SOLICITAR AL JUEZ QUE LA ORDENE, POR EL PROCESO SUMARISIMO.

- ARTículo 10.- CONVOCATORIA, QUÓRUM Y ACUERDOS: EL DIRECTORIO SERÁ CONVOCADO POR EL PRESIDENTE, O QUIEN HAGA SUS VECES, CONFORME A LO ESTABLECIDO EN EL ARTÍCULO $167^{\circ}$ DE LA LEY GENERAL DE SOCIEDADES. EL QUÓRUM PARA LA REUNIONES DEL DIRECTORIO SERÁ DE LA MITAD MÁS UNO DE SUS MIEMBROS SI EL NÚMERO DE DIRECTORES ES IMPAR, EL QUÓRUM ES EL NÚMERO ENTERO INMEDIATO SUPERIOR AL DE LA MITAD DE AQUÉL. CADA DIRECTOR TIENE DERECHO A UN VOTO. LOS ACUERDOS DE DIRECTORIO SE ADOPTAN POR MAYORÍA ABSOLUTA DE VOTOS DE LOS DIRECTORES PARTICIPANTES; EN CASO DE EMPATE, DECIDE QUIEN PRESIDE LA SESIÓN. 
- ARTÍCULO 11.- GESTIÓN Y REPRESENTACIÓN: EL DIRECTORIO TIENE LAS FACULTADES DE GESTIÓN Y DE REPRESENTACIÓN LEGAL NECESARIAS PARA LA ADMINISTRACIÓN DE LA SOCIEDAD, DENTRO DE SU OBJETO, CON EXCEPCIÓN DE LOS ASUNTOS QUE LA LEY O EL ESTATUTO ATRIBUYAN A LA JUNTA GENERAL.

- ARTÍCUlO 12.- DELEGACIÓN: EL DIRECTORIO PUEDE DELEGAR SUS FACULTADES CONFORME A LO ESTABLECIDO EN EL ARTÍCULO $174^{\circ}$ DE LA LEY GENERAL SOCIEDADES.

- ARTÍCULO 13.- RESPONSABILIDAD: LA RESPONSABILIDAD DE LOS DIRECTORES SE RIGE POR LO ESTABLECIDO EN LOS ARTÍCULO $177^{\circ}$ Y SIGUIENTES DE LA LEY GENERAL SOCIEDADES.

- ARTÍCULO 14.- GERENTE GENERAL: LA SOCIEDAD TENDRÁ UN GERENTE GENERAL. LA DURACIÓN DEL CARGO ES POR TIEMPO INDEFINIDO. EL GERENTE PUEDE SER REMOVIDO EN CUALQUIER MOMENTO POR EL DIRECTORIO O POR LA JUNTA GENERAL, CUALQUIERA QUE SEA EL ÓRGANO DEL QUE HAYA EMANADO SU NOMBRAMIENTO.

- ARTíCUlO 15.- ATRIBUCIONES: EL GERENTE GENERAL ESTA FACULTADO PARA LA EJECUCION DE TODO ACTO Y/O CONTRATO CORRESPONDIENTES AL OBJETO DE LA SOCIEDAD, PUDIENDO ASIMISMO REALIZAR LOS SIGUIENTES ACTOS:

A) DIRIGIR LAS OPERACIONES COMERCIALES Y ADMINISTRATIVAS.

B) ASISTIR CON VOZ PERO SIN VOTO A LAS SESIONES DEL DIRECTORIO, SALVO QUE ESTE ACUERDE SESIONAR DE MANERA RESERVADA. 
C) ASISTIR CON VOZ PERO SIN VOTO A LAS SESIONES DE JUNTA GENERAL, SALVO QUE ESTA DECIDA LO CONTRARIO.

D) REPRESENTAR A LA SOCIEDAD ANTE TODA CLASE DE AUTORIDADES. EN LO JUDICIAL GOZARA DE LAS FACULTADES SENALADAS EN LOS ARTICULOS 74, 75, 77 Y 436 DEL CODIGO PROCESAL CIVIL, ASI COMO LA FACULTAD DE REPRESENTACION PREVISTA EN EL ARTICULO 10 DE LA LEY 26636 Y DEMAS NORMAS CONEXAS Y COMPLEMENTARIAS; TENIENDO EN TODOS LOS CASOS FACULTAD DE DELEGACION O SUSTITUCION. ADEMAS, PODRA CELEBRAR CONCILIACION EXTRAJUDICIAL, PUDIENDO SUSCRIBIR EL ACTA CONCILIATORIA, GOZANDO DE LAS FACULTADES SENALADAS EN LAS DISPOSICIONES LEGALES QUE LO REGULAN. ADEMAS PODRA CONSTITUIR Y REPRESENTAR A LAS ASOCIACIONES QUE CREA CONVENIENTE Y DEMAS NORMAS CONEXAS Y COMPLEMENTARIAS.

E) ABRIR, TRANSFERIR, CERRAR Y ENCARGARSE DEL MOVIMIENTO DE TODO TIPO DE CUENTA BANCARIA; GIRAR, COBRAR, RENOVAR, ENDOSAR, DESCONTAR Y PROTESTAR, ACEPTAR Y REACEPTAR CHEQUES, LETRAS DE CAMBIO, PAGARES, CONOCIMIENTO DE EMBARQUE, CARTA DE PORTE, POLIZAS, CARTAS FIANZAS Y CUALQUIER CLASE DE TITULOS VALORES, DOCUMENTOS MERCANTILES Y CIVILES; OTORGAR RECIBOS CANCELACIONES, SOBREGIRARSE EN CUENTA CORRIENTE CON GARANTIA O SIN ELLA, SOLICITAR TODA CLASE DE PRESTAMOS CON GARANTIA HIPOTECARIA.

F) ADQUIRIR Y TRANSFERIR BAJO CUALQUIER TITULO; COMPRAR, VENDER, ARRENDAR, DONAR, DAR EN COMODATO, ADJUDICAR $Y$ GRAVAR LOS BIENES DE LA SOCIEDAD SEAN MUEBLES O INMUEBLES, SUSCRIBIENDO LOS RESPECTIVOS DOCUMENTOS YA SEAN PRIVADOS O PUBLICOS. EN GENERAL PODRA CONSTITUIR GARANTIA HIPOTECARIA, MOBILIARIA Y DE CUALQUIER FORMA. 
PODRA CELEBRAR TODA CLASE DE CONTRATOS NOMINADOS E INNOMINADOS, INCLUSIVE LOS DE LEASING O ARRENDAMIENTO FINANCIERO, LEASE BACK, FACTORY Y/O UNDERWRITING, CONSORCIO, ASOCIACION EN PARTICIPACION Y CUALQUIER OTRO CONTRATO DE COLABORACION EMPRESARIAL, VINCULADOS CON EL OBJETO SOCIAL. ADEMAS PODRA SOMETER LAS CONTROVERSIAS A ARBITRAJE Y SUSCRIBIR LOS RESPECTIVOS CONVENIOS ARBITRALES.

G) SOLICITAR, ADQUIRIR, TRANSFERIR REGISTROS DE PATENTE, MARCAS, NOMBRES COMERCIALES.

H) CONFORME A LEY, SUSCRIBIENDO CUALQUIER CLASE DE DOCUMENTOS VINCULADOS A LA PROPIEDAD INDUSTRIAL O INTELECTUAL.

I) PARTICIPAR EN LICITACIONES, CONCURSOS PUBLICOS Y/O ADJUDICACIONES, SUSCRIBIENDO LOS RESPECTIVOS DOCUMENTOS, QUE CONLLEVE A LA REALIZACION DEL OBJETO SOCIAL.

J) EL GERENTE GENERAL PODRA REALIZAR TODOS LOS ACTOS NECESARIOS PARA LA ADMINISTRACION DE LA SOCIEDAD, SALVO LAS FACULTADES RESERVADAS A LA JUNTA GENERAL DE ACCIONISTAS.

- ARTÍCULO 16.- RESPONSABILIDAD: EL GERENTE RESPONDE ANTE LA SOCIEDAD, LOS ACCIONISTAS Y TERCEROS, CONFORME A LO QUE SE ESTABLECE EN EL ARTÍCULO 190" DE LA LEY GENERAL DE SOCIEDADES.

EL GERENTE ES RESPONSABLE, SOLIDARIAMENTE CON LOS MIEMBROS DEL DIRECTORIO CUANDO PARTICIPE EN ACTOS QUE DEN LUGAR A RESPONSABILIDAD DE ÉSTOS O CUANDO, 
CONOCIENDO LA EXISTENCIA DE ESOS ACTOS, NO INFORME SOBRE ELLOS AL DIRECTORIO O A LA JUNTA GENERAL.

- ARTICULO 17.- MODIFICACION DEL ESTATUTO, AUMENTO Y REDUCCION DEL CAPITAL: LA MODIFICACION DEL PACTO SOCIAL, SE RIGE POR LOS ARTICULOS 198 Y 199 DE LA "LEY", ASI COMO EL AUMENTO Y REDUCCION DEL CAPITAL SOCIAL, SE SUJETA A LO DISPUESTO POR LOS ARTICULOS 201 AL 206 Y 215 AL 220, RESPECTIVAMENTE, DE LA "LEY".

- ARTICULO 18.- ESTADOS FINANCIEROS Y APLICACION DE UTILIDADES: SE RIGE POR LO DISPUESTO EN LOS ARTICULOS 40, 221 AL 233 DE LA "LEY".

- ARTICULO 19 - DISOLUCION, LIQUIDACION Y EXTINCION: EN CUANTO A LA DISOLUCION, LIQUIDACION Y EXTINCION DE LA SOCIEDAD, SE SUJETA A LO DISPUESTO POR LOS ARTICULOS 407, 409, 410, 412, 413 A 422 DE LA "LEY".

CUARTO.- EL PRIMER DIRECTORIO DE LA SOCIEDAD ESTARÁ INTEGRADO POR:

- CONSTANTINO ERNESTO ARCAYA VERNAL

- NATALIA ARCAYA DEL AGUILA

QUINTO.- QUEDA DESIGNADO COMO GERENTE GENERAL: NATALIA ARCAYA DEL AGUILA, COM DOMICILIO EN: JR. ENRIQUE LEON GARCIA 473 URBANIZACION CHAMA, SANTIAGO DE SURCO.

CLAUSULA ADICIONAL I.- SE DESIGNA COMO SUB-GERENTE DE LA SOCIEDAD A CONSTANTINO ERNESTO ARCAYA VERNAL CON DOMCILIO EN JR. ENRIQUE LEON GARCIA 473 URBANIZACION CHAMA, SANTIAGO DE SURCO, QUIEN TENDRA LAS SIGUIENTES FACULTADES: 
- REEMPLAZAR AL GERENTE EN CASO DE AUSENCIA.

- intervenir en forma individual o conjunta con el GERENTE GENERAL, EN LOS CASOS PREVISTOS EN LOS INCISOS E, F, G Y H DEL ARTÍCULO 15 DEL ESTATUTO.

- AGRegUe USTED, SEÑOR NOTARIO, LO QUE FUERE DE LEY Y SÍRVASE CURSAR PARTES CORRESPONDIENTES AL REGISTRO DE PERSONAS JURÍDICAS DE LIMA PARA SU RESPECTIVA INSCRIPCIÓN.

LIMA, 02 DE FEBRERO DEL 2015 


\begin{abstract}
ANEXO 8
Diario Gestión - 23/02/2015.

CCL: Exportación de quinua creció seis veces más en los últimos dos años

Lunes, 23 de febrero del 2015

ECONOMÍA
\end{abstract}

09:51

Durante el 2014 más de 80 empresas peruanas exportaron por primera vez este producto en respuesta a la demanda mundial, dijo el gremio empresarial.

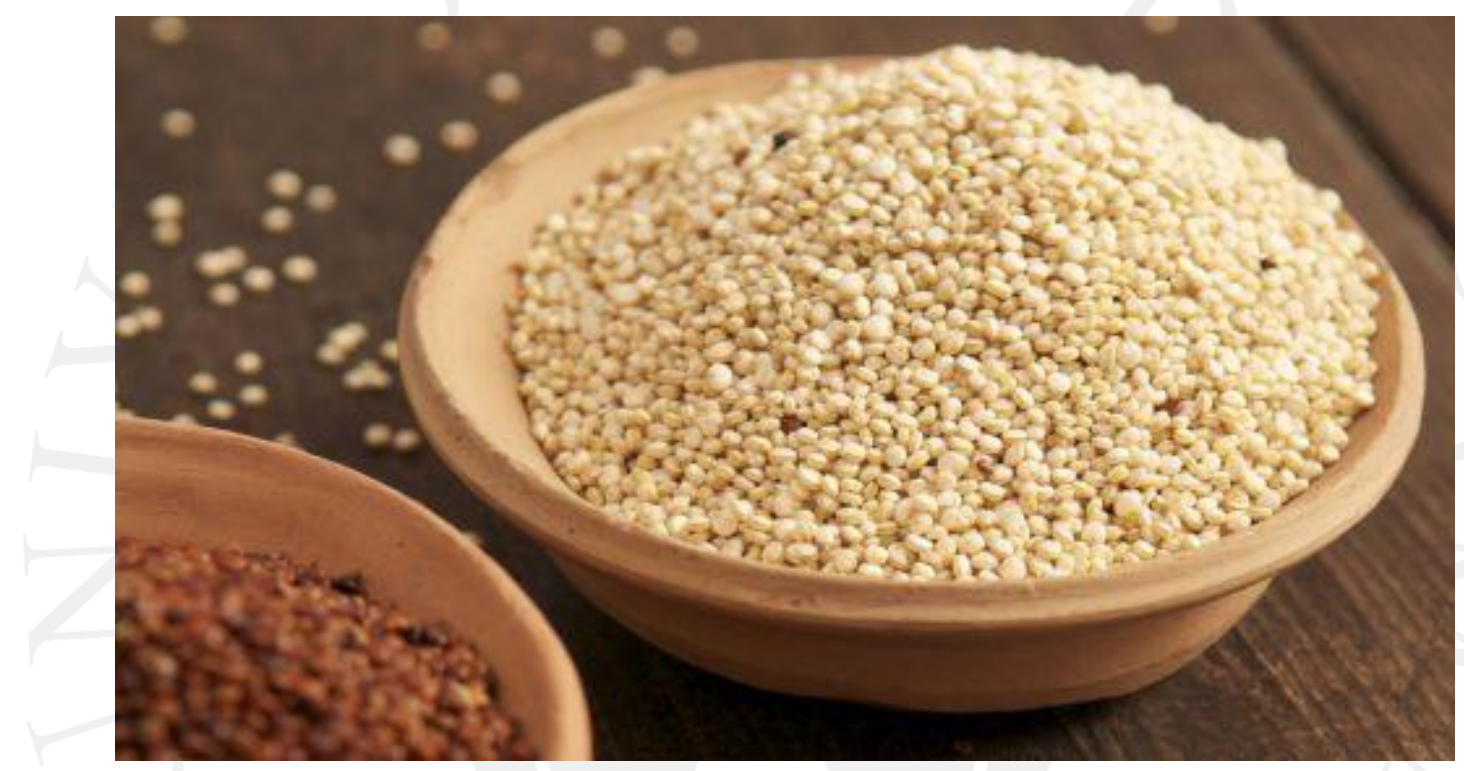

En el 2014 la quinua ocupó el cuarto puesto de las exportaciones agropecuarias.

Las exportaciones de la quinua peruana tuvieron un crecimiento exponencial de seis veces su valor en los dos últimos años, así lo afirmó la Cámara de Comercio de Lima (CCL ).

Según el Centro de Comercio Exterior (CCEX) de la CCL, en el 2012 las exportaciones de quinua alcanzaron valores por US\$ 31 millones, mientras que en el 2013 y 2014 las exportaciones sumaron US\$ 79 y 196 millones, respectivamente. Esto representa un crecimiento de $148 \%$.

"En los últimos años, este producto ha mostrado un aumento notable en el volumen de sus exportaciones, su producción y un significativo aumento de precio", afirmó Carlos García, gerente de CCEX.

Precisamente junto con el incremento de la demanda y la oferta de quinua, el interés por el producto ha generado que el precio del grano andino aumente en promedio un $50 \%$ en los últimos dos años. 
"En el 2012 el precio por kilogramo era en promedio de US\$ 3.7 por kilogramo, pasando a US\$ 4.3 y a US\$ 5.6 en el 2013 y 2014 respectivamente. Durante el último año, el precio ha alcanzado picos de hasta US\$ 7 por kilogramo", destacó.

Por este resultado, en el 2014 la quinua ocupó el cuarto puesto de las exportaciones agropecuarias, antecedido por otros productos estrellas como las uvas frescas, los espárragos y las paltas, desplazando a productos como el cacao, el mango y la leche evaporada.

De otro lado, García precisó que Estados Unidos es de lejos el principal mercado de las exportaciones de quinua, sin embargo aunque las exportaciones a este mercado vienen creciendo exponencialmente; su participación exportable respecto al total de exportaciones viene cayendo en forma gradual año tras año, pasando de $68 \%$ en el 2012 a $55 \%$ y $51 \%$ en el 2013 y 2014 respectivamente.

"Esto se explica en parte por la cantidad de nuevos mercados a los que año a año ingresamos con este producto. En 2013 se empezó a exportar a 8 nuevos mercados entre los que destacan Polonia, Taiwán, Singapur, Tailandia y China mientras en el 2014 se exportó a 18 nuevos destinos siendo los más importante Malasia, Corea del Sur, Arabia Saudita, Rumania y Portugal”, afirmó.

Gracias a la diversificación en los mercados, durante el año pasado más de 80 empresas exportaron por primera vez este producto respondiendo así a la demanda mundial. Sin embargo, precisó que más del $50 \%$ de envíos se concentra en seis empresas: Exportadora Agrícola Orgánica, Vínculos Agrícolas, ALISUR, Grupo Orgánico Nacional, Wiraccocha del Perú y Aplex Trading.

La principal variedad de quinua exportada es la quinua blanca representando cerca del $85 \%$ en valor de las exportaciones, le sigue la quinua roja (10\%). Asimismo, cerca del $70 \%$ del valor total exportado representa quinua convencional y el otro $30 \%$ quinua, siendo esta última en promedio un $10 \%$ mejor pagada que el producto convencional.

"Desde hace dos años aproximadamente se viene produciendo quinua convencional procedente de la costa dado que las áreas de cultivo de la sierra son insuficientes para abastecer la demanda internacional; sin embargo, es una tarea pendiente regular el uso de plaguicidas", anotó 


\section{ANEXO 9}

Noticia Página Web Quinua.pe

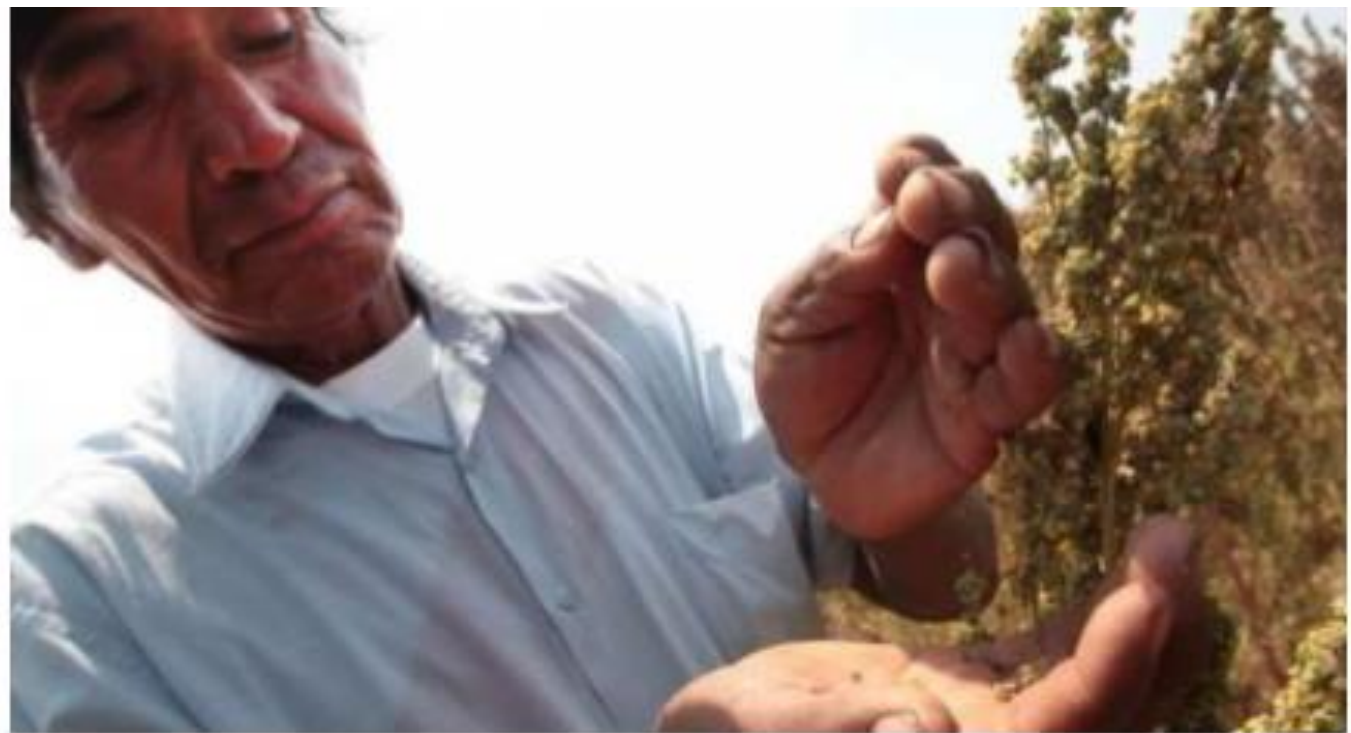

\section{Perú con el 52\% es el primer productor mundial de quinua}

26 de febrero.- El director general de Negocios Agrarios del Ministerio de Agricultura, Marco Vinelli, manifestó que el Perú es el primer productor mundial de quinua y este 2015 se consagrará al producir 140 mil toneladas, incrementando su producción en 28 mil toneladas más.

"En los últimos años hemos duplicado la exportación de quinua, el año pasado hemos cerrado con 196 millones de dólares en exportación, cuando el año 2013 habiamos hecho cerca de 80 millones de dólares", dijo Vinelli en declaraciones a la prensa,

Explicó que en términos de producción se superó las 55 mil toneladas de quinua del 2013 a más de 112 mil toneladas en el 2014. Asimismo, el representante del Ministerio de Agricultura y Riego, dijo que para el 2015 se espera tener 140 mil toneladas en producción a escala nacional.

"Puno es el principal productor de quinua del Perú con el 35\% de la producción nacional, los cuales junto con las otras cosechas cubren las demandas de los Estados Unidos y Europa y ahora se logró abrir mercado en la India", manifestó.

Los Andes 